\title{
Investigating educative mentoring for provisionally certificated teachers in the New Zealand primary school
}

\author{
D. KAYE STANNARD
}

A thesis submitted in partial fulfilment of the requirements for the degree of Master of Education, Victoria University of Wellington 



\begin{abstract}
The Guidelines for Induction and Mentoring and Mentor Teachers were published in 2011 by the New Zealand Teachers Council. The Guidelines signalled a shift from what had been an induction programme based on advice and guidance to one that involved educative mentoring. These guidelines were developed to support the provision of nationally consistent, high quality, and comprehensive support for provisionally certificated teachers (PCTs).

This qualitative investigation used an interpretative case study approach to describe what educative mentoring looked like in three New Zealand primary schools. Data were gathered using an online survey, interviews, recorded meeting and analysis of documents.

The findings were that mentors and provisionally registered teachers had differing levels of understanding of educative mentoring. While mentors espoused using educative mentoring components (Education Council of Aotearoa New Zealand, 2015a, pp. 25-26) this did not appear to be happening in practice. This suggests the need for mentor training if educative mentoring is to become embedded. Mentors need training to understand what educative mentoring really means. In particular the elements of deconstruction (describing, analysing, and discussing evidence) and co-construction (setting new personal goals) were missing to some degree in each relationship investigated. The process of induction and mentoring is to develop practice and ultimately for the provisionally registered teacher to attain the Practising Teacher Criteria. However this study revealed that the developmental process of practice appears to be more focused on meeting the Practising Teacher Criteria than developing understanding through the setting of personal goals.
\end{abstract}




\section{ACKNOWLEDGEMENTS}

I am most appreciative for the support and encouragement I have received during this research from:

My supervisor, Brenda Service who generously gave time, thoughtfully deconstructed and co-constructed the process, and asked if I was okay about where we were up to. She always asked the right open questions.

Deborah Wansborough from the Education Council who responded to emails and freely gave her time to talk through mentoring processes.

My study buddies, Amanda and Sela who started with the same challenging masters paper a few years ago and are still having the conversations.

My friends who spend a lot of time sitting at computers and having supportive conversations, Silia, Tien, and Hue.

Janine, Janis, Janet and Christine who always wanted to know how it was going and read some early chapters.

Maggie Smith and Dr lan Smith who gave up some of their summer to proof read.

My husband Mike and family Emma, Petra, and especially Hannah and Tom, who were studying at the same time and understood the challenges.

I wholeheartedly wish to thank the mentors and PCTs who took part in the study, so openly shared their thoughts, teaching and learning experiences. 


\section{TABLE OF CONTENTS}

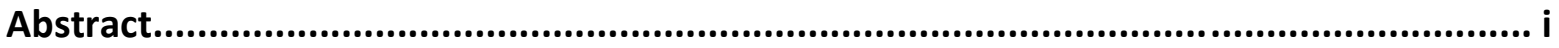

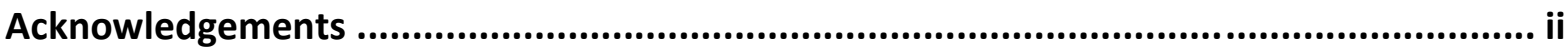

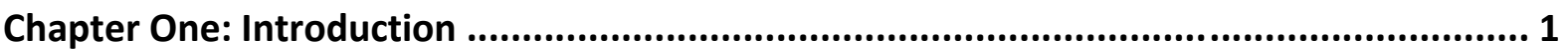

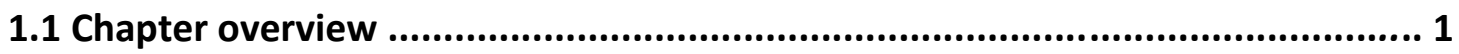

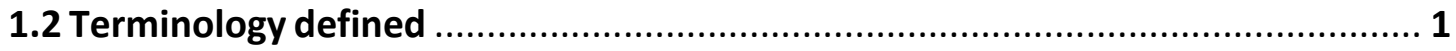

1.2.1 Provisionally Certificated Teachers (PCT) ............................................

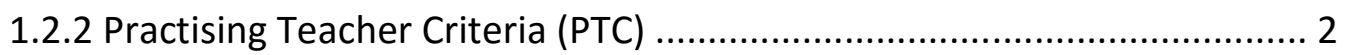

1.2.3 Education Council (EC) New Zealand ............................................... 2

1.2.4 Guidelines for Induction and Mentoring and Mentor Teachers ............. 3

1.3 New Zealand primary school context ........................................................... 3

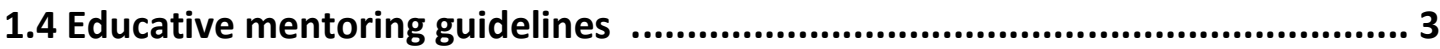

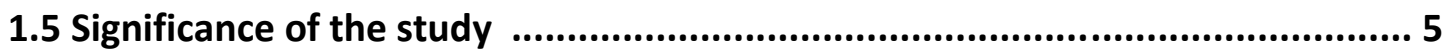

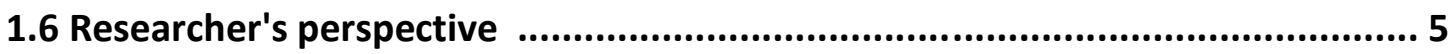

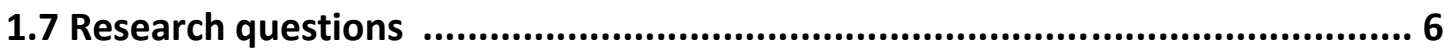

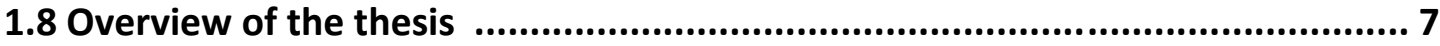

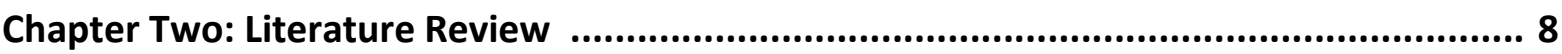

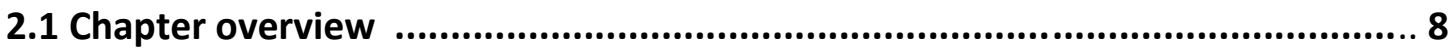

2.2 The importance of induction for beginning teachers ................................... 9

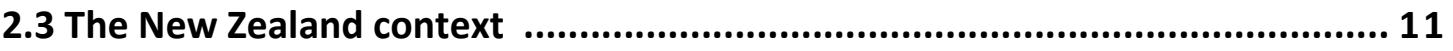

2.4 The previous induction programme ....................................................... 11

2.5 The change from tutor to mentor ......................................................... 12

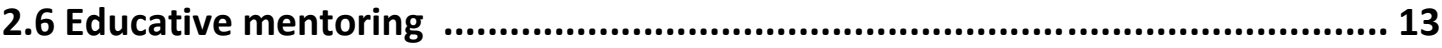

2.7 The implementation of educative mentoring .............................................. 15

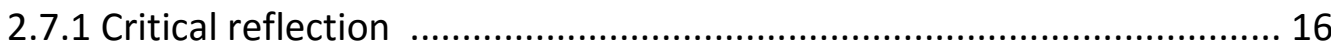

2.7.2 Deconstruction and reflection ......................................................... 17 
2.7.3 Co-construction and goal setting ....................................................... 18

2.8 Rationale for educative mentoring ............................................................ 18

2.9 Comparing the two induction programmes............................................... 19

2.10 Creating conditions for deliberate educative mentoring ............................ 20

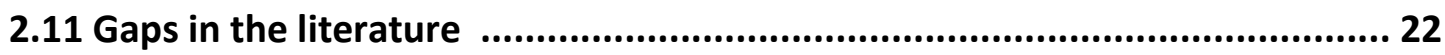

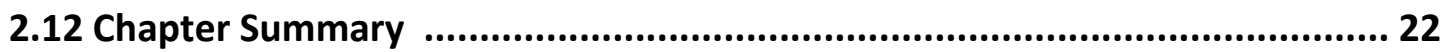

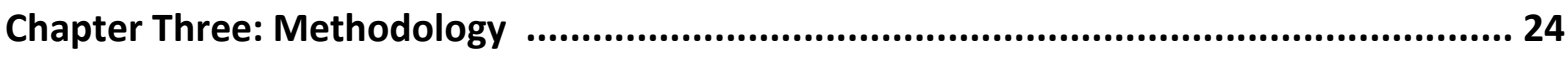

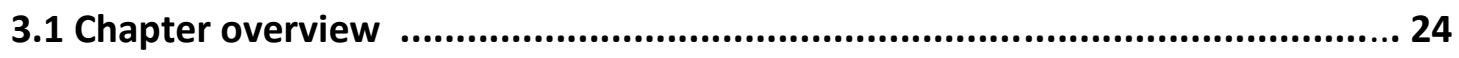

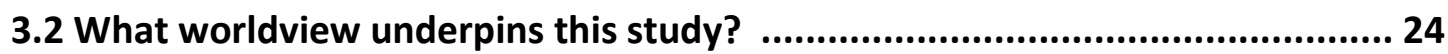

3.3 What questions fit the purpose for this study? ............................................... 25

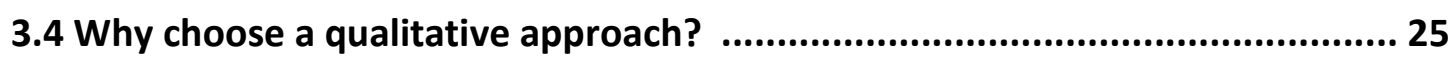

3.5 Why use an interpretive case study? ........................................................... 26

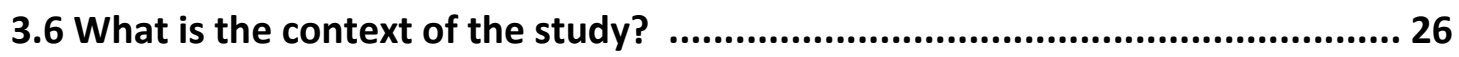

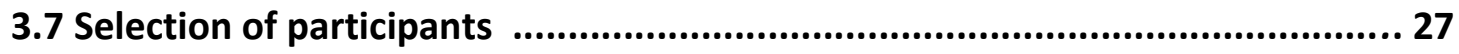

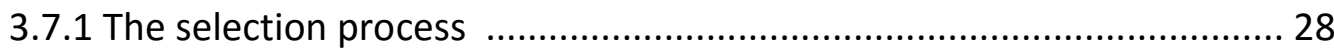

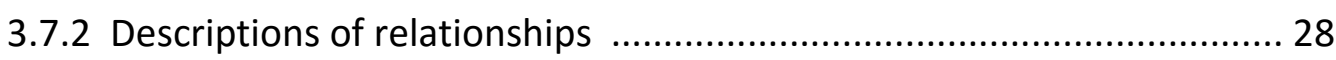

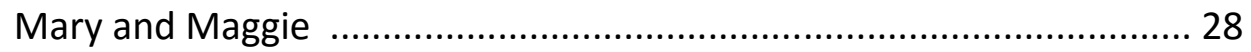

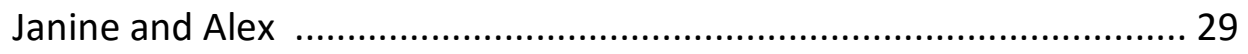

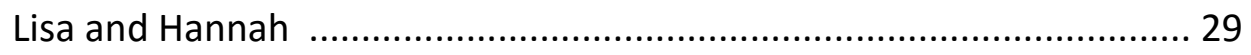

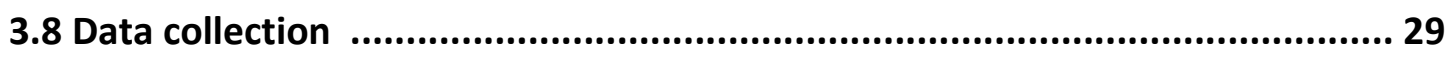

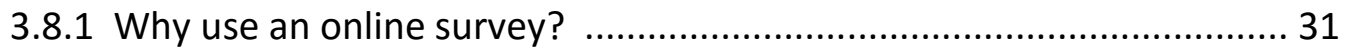

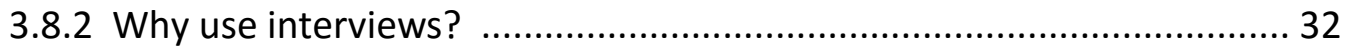

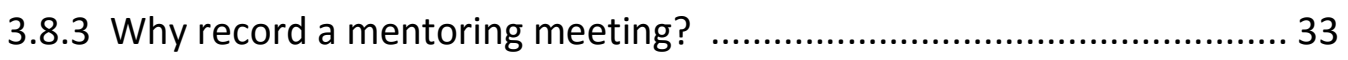

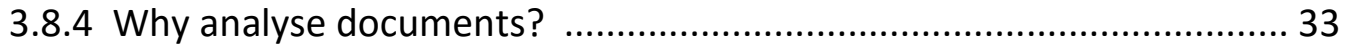

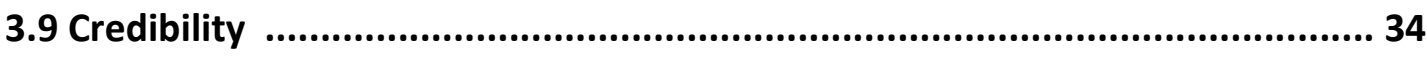

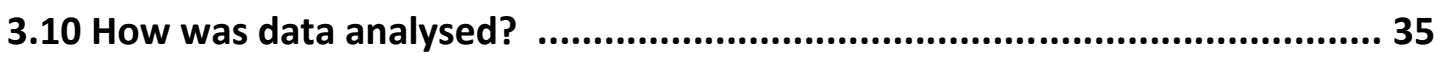

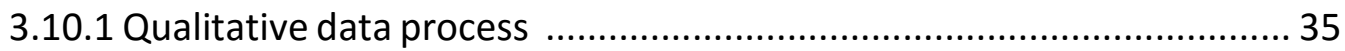




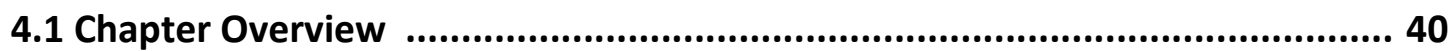

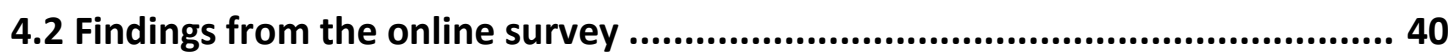

4.2.1 Demographic information ............................................................ 41

4.2.2 Agreement to educative statements ............................................. 42

4.2.3 Open ended questions .............................................................. 43

4.3 Relationship One-Mary (mentor) and Maggie (PCT) - Kiwiland School ........... 47

4.3.1 Background to the mentoring relationship .................................... 47

4.3.2 Mentor's espoused understanding of educative mentoring and perception of the role

4.3.3 PCT's espoused understanding of educative mentoring and perception of the role 50

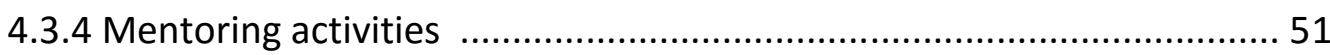

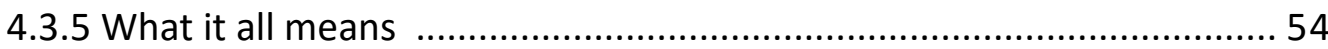

4.4 Relationship Two-Janine (mentor) and Alex (PCT) - Pukeko School ................ 56

4.4.1 Background to the mentoring relationship ........................................... 56

4.4.2 Mentor's espoused understanding of educative mentoring and perception of the role

4.4.3 PCT's espoused understanding of educative mentoring and perception of the role 58

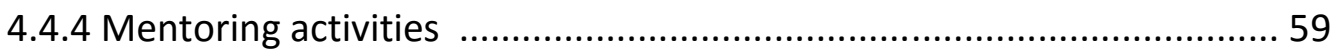

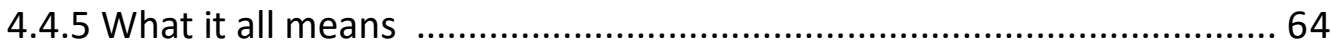

4.5 Relationship Three-Lisa (mentor) and Hannah (PCT) - Tui Primary School ..... 65

4.5.1 Background to the mentoring relationship ......................................66

4.5.2 Mentor's espoused understanding of educative mentoring and perception of the role

4.5.3 PCT's espoused understanding of educative mentoring and perception of the role 


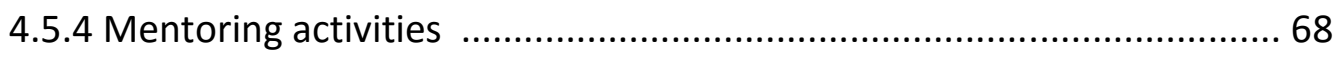

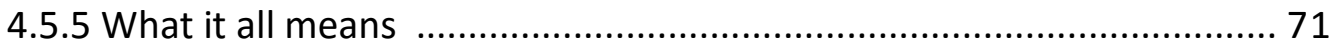

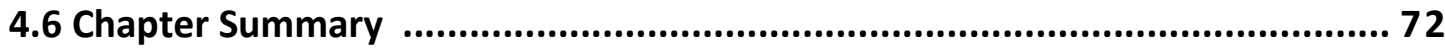

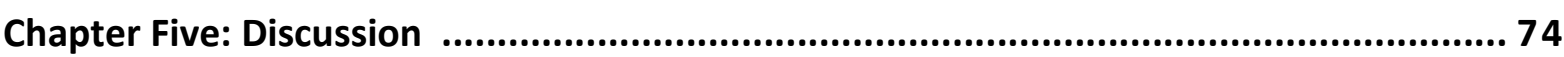

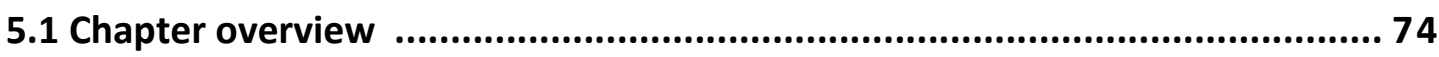

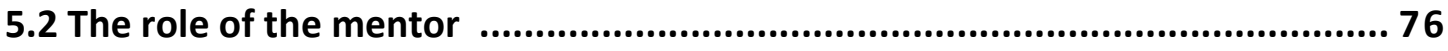

5.2.1 Understanding the concept of educative mentoring ......................... 76

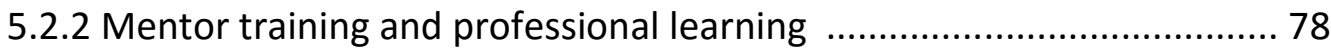

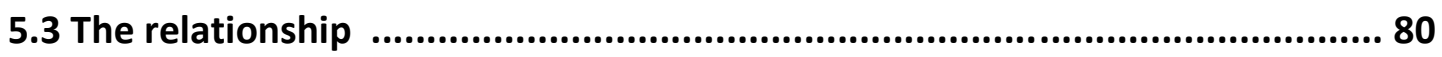

5.3.1 The Professional relationship ........................................................ 80

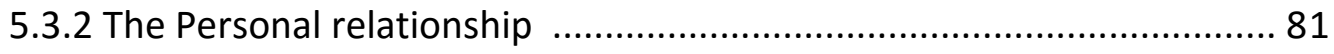

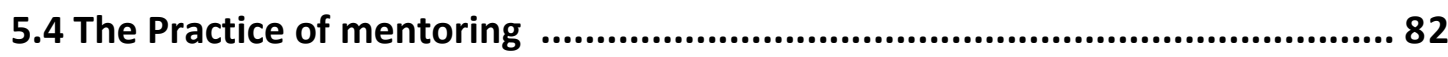

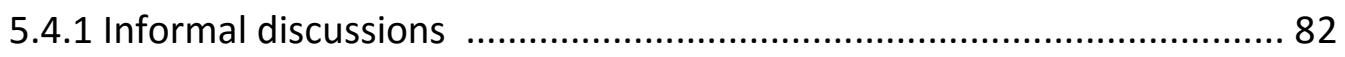

5.4.2 Formal meetings - the meeting in action ...................................... 83

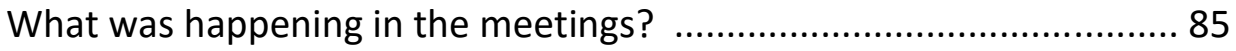

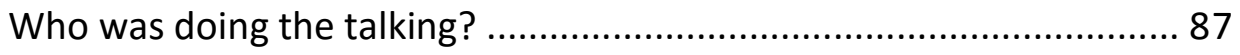

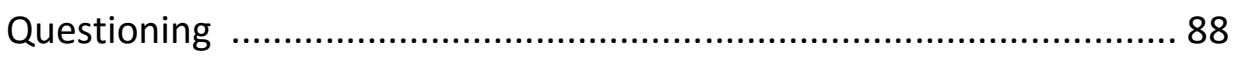

Deconstruction and reflection .......................................................... 90

Co-construction and goal-setting ................................................... 92

Elements that were missing ......................................................... 93

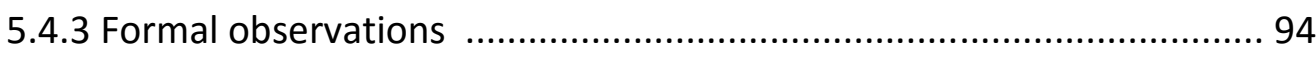

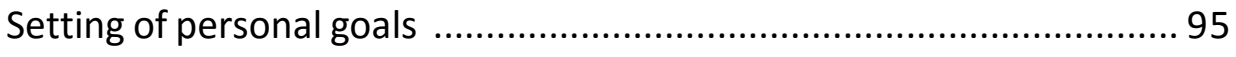

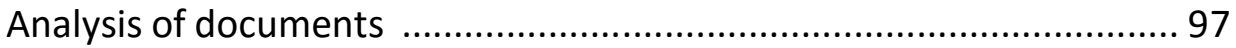

5.5 Chapter summary 


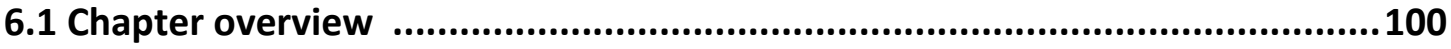

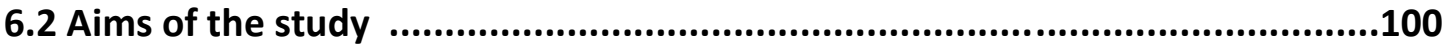

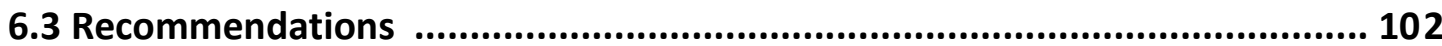

6.3.1 Clarification of the educative mentor role ........................................ 102

6.3.2 Understanding of educative elements ............................................ 102

6.3.3 Focus on development of the learner according to developmental needs instead of marking off the summative RTC ................................................ 104

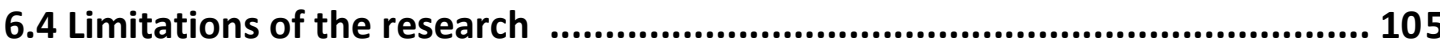

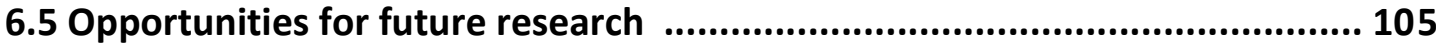

6.6 Chapter summary

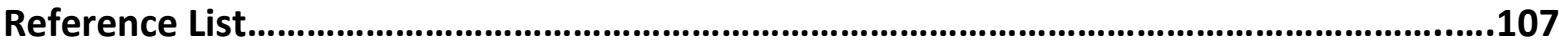

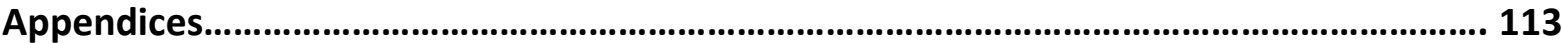

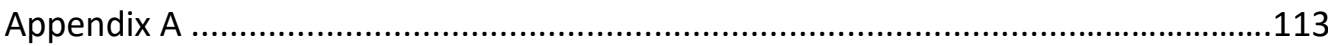

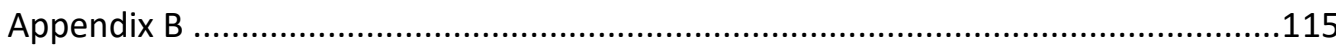

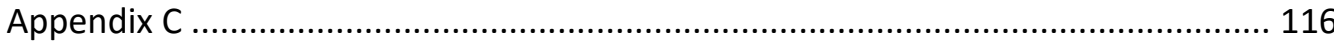

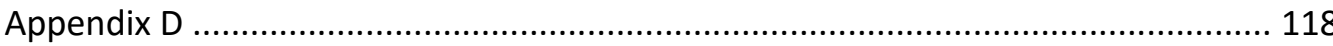

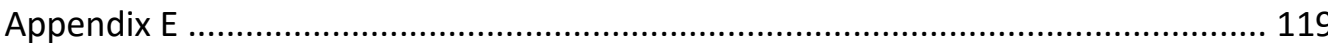

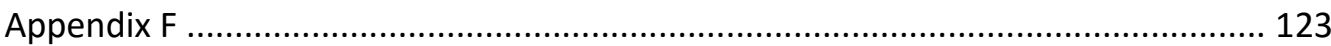

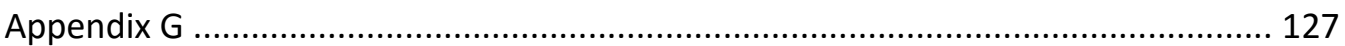

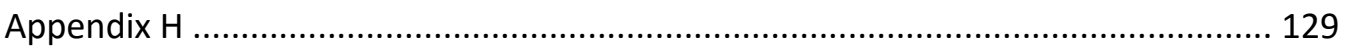

Tables

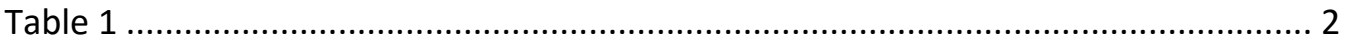

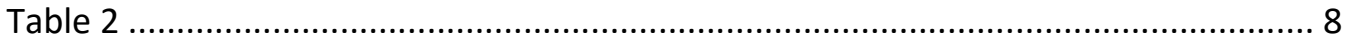

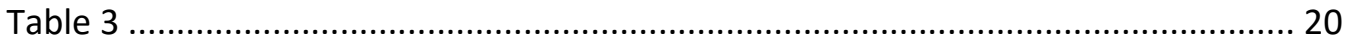

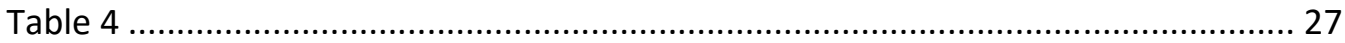

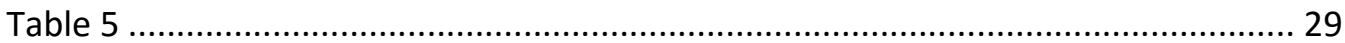

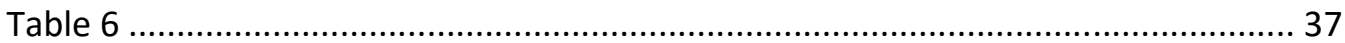

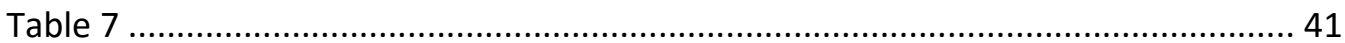




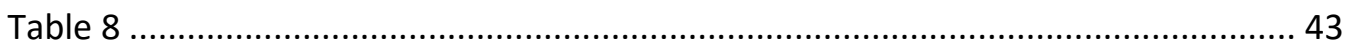

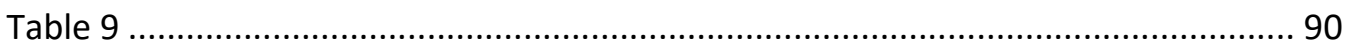

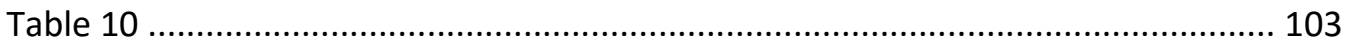

Figures

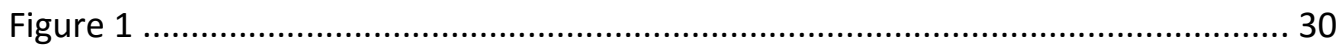

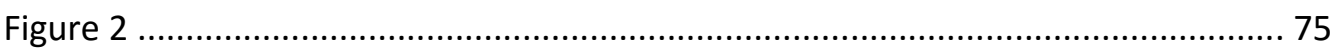

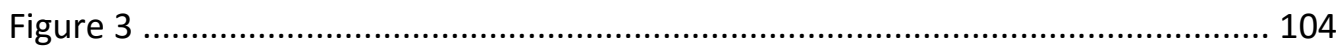




\section{CHAPTER ONE: INTRODUCTION}

\subsection{Chapter overview}

This thesis is a case study investigating what educative mentoring looked like in three New Zealand primary schools. It is an account of three mentoring relationships and the realities around enacting educative mentoring. Four years after a shift from an induction programme based on advice and guidance, to one grounded in educative mentoring, it is timely to investigate how successful this approach has been. Much thought and research has gone into selecting educative mentoring. It was seen as developing essential skills for new teachers in order to serve student learning (Achinstein \& Athanases, 2006; Bradbury, 2010; Feiman-Nemser, 2014; McDonald \& Flint, 2011; Thornton, 2013a). The purpose of this study was to investigate and understand how educative mentoring was employed in the New Zealand primary school. I recognized the challenge of moving from a being a tutor, to being a mentor and I wondered how teachers were managing this.

The aim of this introductory chapter is to provide the reader with an overview of the study. It begins by defining terminology and providing an explanation of the primary school context of the study. The educative mentoring guidelines that are central to this study are explained. Justification of the aspects focused on for the study, follows. The significance of the study and my motivation for embarking upon it are presented consecutively. The overarching research question and sub-questions are stated. The chapter concludes by outlining the organization of this thesis.

\subsection{Terminology defined}

This section defines the terms of Provisionally Certificated Teacher, Practising Teacher Criteria, Education Council of New Zealand and the Guidelines for Induction and Mentoring and Mentors that will be referred to throughout this study. Table 1 summarises a recent change in terminology for the first three terms used.

\subsubsection{Provisionally Certificated Teacher (PCT)}

Teachers apply for provisional certification when they have successfully completed an approved initial teacher education programme in New Zealand or been granted recognition of an overseas teaching qualification. They then undertake a structured 
programme of induction and mentoring, to enable them to demonstrate their competence in the Practicing Teacher Criteria when applying for full registration (Education Council of Aotearoa New Zealand, 2015a). Before July 2015, Provisionally Certificated Teachers (PCTs) were referred to as Provisionally Registered Teachers (PRTs). The attached appendices will continue to refer to Provisionally Registered Teachers (PRTs) as this study started in 2014. To avoid confusion teachers new to the profession will be referred to as Provisionally Certificated Teachers (PCTs).

\subsubsection{Practising Teacher Criteria (PTC)}

The Practising Teacher Criteria describe the twelve criteria for quality teaching that must be met by all fully registered teachers in Aotearoa New Zealand (Education Council of Aotearoa New Zealand, 2015b). These were first published in 2010 as the Registered Teacher Criteria.

\subsubsection{Education Council (EC) New Zealand}

The New Zealand Teachers Council (NZTC) was a Crown entity which was required to take account of government policy and set standards for teachers. Since July 2015 the New Zealand Teachers Council has been known as the Education Council (EC) Aotearoa New Zealand. The changes implemented by each council will be referred to during this study.

Table 1:

Change in terminology

\begin{tabular}{ll}
\hline Prior to July 2015 & From July 2015 \\
\hline Provisionally Registered Teacher & Provisionally Certificated Teacher \\
PRT & PCT \\
\hline Registered Teacher Criteria & Practising Teacher Criteria \\
RTC & PTC \\
\hline New Zealand Teachers Council & Education Council Aotearoa New Zealand \\
NZTC & EC
\end{tabular}




\subsubsection{Guidelines for Induction and Mentoring and Mentor Teachers}

In 2011 the NZTC first published the Guidelines for Induction and Mentoring and Mentor Teachers. This signalled the shift from an induction programme based on 'advice and guidance' to one of 'educative mentoring'. These guidelines were developed to support the provision of nationally consistent, high quality, and comprehensive support for PCTs in their first two years of practice and to enable them to become fully certificated teachers. For the purpose of this study the publication will be referred to as the Guidelines.

\subsection{New Zealand primary school context}

This study is set in the context of three New Zealand state funded primary schools. A primary school in New Zealand caters for Years 1 to 6 (sometimes including years seven and eight, and referred to as a full primary). Students at this level are typically aged between five and eleven years old (thirteen for the full primary). An important feature of primary schools in New Zealand is that students stay in one classroom with one teacher for most of the school day and have the continuity of an integrated curriculum delivery.

New Zealand schools are self-governing which means they are run by a board of trustees, the membership of which is representative of the school community and includes the principal and a teacher. The school principal is charged with the responsibility of managing the day-to-day operations of the school, the teaching and learning programmes and monitoring staff performance (Ministry of Education, 2013). The employment of PCTs is the principal's responsibility and, depending on the size of the school and support available, schools may employ one or more PCTs. Larger primary schools may employ more than five PCTs if they have sufficient mentors available.

Until 2011 teachers followed an induction programme of giving advice and guidance to teachers on entering and being inducted into the teaching profession. The current programme of educative mentoring involves a new approach in the induction process.

\subsection{Educative mentoring guidelines}

In 2011, the book, Guidelines for Induction and Mentoring and Mentor Teachers (Education Council of Aotearoa New Zealand, 2015a) was launched and since then New 
Zealand schools have been resourced for this induction and mentoring process. This publication has twenty-six pages and is written in both English and Maori with the purpose of shifting school policy and practices towards an 'educative mentoring' approach.

The Guidelines were designed to support professional leaders, mentor teachers, PCTs and the wider education sector. Central to the development of PCTs is for the school to provide a mentor for each PCT. A 'high-quality induction' programme is described as comprehensive, educative and evaluative. A comprehensive programme includes the elements of welcoming, professional development, evidence informed evaluations of professional practice and educative mentoring. The educative approach should be focused on enabling PCTs to learn and practice the skills and attitudes and attributes they need to become fully certificated teachers, not about progressing through a checklist of requirements. An induction and mentoring programme provides opportunity for formative and progressive evaluation for the PCT around professional learning ultimately leading to the final assessment of evidence towards meeting the PTC.

This educative focus is relationship-based and a process by which the mentor and PCT co-construct learning from an inquiry approach using evidence from practice. It is recognised and resourced by the school and the Ministry of Education. Educative mentoring has been chosen by the New Zealand Teachers Council as the preferred style of mentoring and provides "an experienced colleague with a dedicated time to guide, support, give feedback and facilitate evidence-informed, reflective learning conversations" (Education Council of Aotearoa New Zealand, 2015a, p. 11). The Guidelines state the following.

An 'educative mentor' is not merely a 'buddy' providing emotional support and handy 'just in time' tips to the PCT. Educative mentoring is a highly skilled and valued role in the profession, and mentors need appropriate professional development to learn and practice these skills (p.11).

This study was an opportunity to investigate whether mentors had been provided with the appropriate professional learning and support to develop educative mentoring skills. This signalled a change from the previous role of a tutor of giving 'advice and guidance', to mentoring where the focus is on the mentor working alongside the PCT to co-construct 
learning using evidence and an inquiry approach. These key ideas will be further discussed in chapter 2, the literature review.

\subsection{Significance of the study}

The purpose of this study was to investigate the educative mentoring practice advocated by Guidelines for Induction and Mentoring and Mentor Teachers (Education Council of Aotearoa New Zealand, 2015a) and to understand how these changes have been implemented by mentors in New Zealand primary schools. Uncovering how mentors and PCTs interact in a formal context and how practice has shifted from a tutor to a mentor, is of particular interest.

Over the last ten years, national and international research, has critically reviewed and examined induction and mentoring programmes (Hobson, Ashby, Malderez, \& Tomlinson, 2009; O'Brien \& Christie, 2005; Piggot-Irvine, Aitken, Ritchie, Ferguson, \& McGrath, 2009). However research has been focused on mentoring programme design and improvement, however more research to enrich our understanding of how educative mentoring is actually implemented is essential (Bradbury, 2010; Devos, 2010; Feiman-Nemser, 2003). This is a new field and there is limited research on the topic. National research is becoming more predominant as educative mentoring is implemented and becomes embedded in our schools.

This study contributes to the body of research around enriching our understanding of educative mentoring in the New Zealand context by providing additional data on what happens during formal interactions, for example PCT and mentor meetings or learning conversations. In addition, given that high quality mentoring should be recognised and resourced, this study reveals the extent to which this has happened in three primary schools. Resources need to be provided for the development of mentors to ensure that they are successful. This study will therefore assist the education sector, principals and management in determining what professional learning is needed to support mentors.

\subsection{Researcher's perspective}

I have been a teacher for over 25 years and have acted as both a tutor teacher and mentor teacher during that time. Latterly I have mentored two PCTs using the present 
Guidelines while embarking on my master's study. I recall being asked to be a tutor teacher for a new teacher more than 10 years ago. My approach at that time was of an experienced teacher advising and guiding a new teacher. Now I have moved into a different role as an educative mentor, working alongside and focusing on the teacher as a learner for the benefit of the student's learning. I see this new role as not teaching and telling the PCT but supporting them to enquire into practise, along with gathering new skills and knowledge myself.

My experience has raised the question in my mind that, although we have been inducting PCTs by guiding and supporting them for many years now we have this different approach called educative mentoring, what does this really look like and how have mentors adjusted to this role? In the last five years, working as a mentor I have become familiar with the Guidelines since they were first launched in 2011. I have also attended the one day course for mentors of PCTs offered along with the launch of the Guidelines. It was challenging to find there were quite a few skills that I did not have as a tutor but were required in order to be a mentor.

I am passionate about PCTs being well supported in an educative manner at the start of their careers to set them up with the skills and knowledge to be successful teachers. The task is no longer just telling what to do and giving advice to manage an immediate situation. Working alongside the PCT has meant new learning for me especially around the learning conversation. Being able to raise questions to engage the PCT in reflecting and thinking about practice by using evidence, identifying what went well and what didn't, and selecting a new goal are essential learning. The skills required when observing a teacher in action and giving critical feedback have also been challenging and required new learning to be embedded. Therefore, despite having done university papers on the topic of coaching and mentoring I still found the subject challenging, and I wondered how it was for other mentors who were involved in changing their role from tutor to mentor.

\subsection{Research Questions}

The purpose of this study is to investigate the educative mentoring process in three New Zealand primary schools and to explore what was working, what was not and, what was needed, in relation to the educative mentoring guidelines (Education Council of Aotearoa New Zealand, 2015a). The methodology was designed to answer the broad question: 
What does effective educative mentoring look like in the New Zealand primary school?

These sub-questions further guided the research:

* The word 'educative' is used in relation to the induction and mentoring guidelines, how is this term understood by mentors and PCTs?

* How might the educative mentoring process be improved?

What skills and knowledge do mentors still need to embed?

\subsection{Overview of the thesis}

This thesis comprises six chapters. Chapter 1 sets the scene for the study describing the issue under investigation, the significance of the research and what motivated me to undertake it. Chapter 2 is a literature review that I undertook before embarking on the study. In it I describe the importance of induction and mentoring programmes for PCTs, and the rationale for the shift from a programme of guidance and advice with a tutor to an educative mentoring approach with a mentor. Qualitative research is described in chapter 3 as the appropriate methodology for this study with the intention of interpreting and understanding the reported practices of educative mentoring. In chapter 4 the findings are shared from the initial online survey, one-to-one interviews, recording a formal PCT meeting and an analysis of data in the framework of the three mentor and PCT relationships. Chapter 5 presents a discussion to answer the research questions. A concluding chapter offers specific recommendations for mentors and PCTs, explores the limitations of the research and suggests areas for future research. 


\section{CHAPTER TWO: LITERATURE REVIEW}

\subsection{Chapter overview}

The purpose of this literature review was to explore what the change to educative mentoring involves. As described in chapter one, provisionally certificated teachers (PCTs) were supported in the past by an induction programme based around 'advice and guidance' with a tutor. Now educative mentoring with a mentor had been implemented as the preferred induction programme. Additional literature, explored as the study evolved will be discussed in chapter five.

Table 2 presents an overview of the questions that guided the literature review and the literature examined. First, the importance of induction and mentoring for beginning teachers is discussed. The New Zealand context is then described. Next, a description of the previous induction programme and the resulting change from tutor to mentor is examined. This is followed by an explanation of the implementation of educative mentoring and what is involved. The rationale for this change from guidance and support, to educative mentoring is discussed and a comparison of the two induction programmes given. The conditions necessary for deliberate educative mentoring to take place are explained. Finally, a justification for what this study brings to the literature is presented.

Table 2:

Questions to guide this Literature Review Questions

Literature examined

How have teachers been inducted into the teaching profession in New Zealand?

The importance of induction for beginning teachers

The New Zealand context
The previous induction programme

Change from tutor to mentor

The role of a mentor

The implementation of educative mentoring 


\title{
Why was educative mentoring chosen? Rationale for educative mentoring
}

\author{
What is needed for change to occur from \\ guidance and support to educative \\ mentoring? \\ Comparing the two induction \\ programmes for PCTs \\ Creating conditions for deliberate \\ educative mentoring
}

What can this study contribute to the

The gaps in the literature

literature?

\subsection{The importance of induction for beginning teachers}

Learning to teach is a developmental process (Feiman-Nemser, 2003; Schussler, Feiman-Nemser, Diez, \& Murrell, 2012) in which the early years of teaching play a pivotal part. Upon graduation from their initial teaching programmes PCTs are provisionally certificated. Two years of classroom experience enables the PCT to apply for full certification. PCTs in New Zealand are on their own in a classroom of students faced with the same responsibilities as experienced colleagues. Research suggests that the quality of their induction programme plays a significant role during this challenging stage of their careers (Cameron, Berger, Lovett, \& Baker, 2007; Feiman-Nemser, 2001).

Unlike other occupations and professions, teaching, historically has not had an induction programme (Darling-Hammond, 1998; Ingersoll \& Strong, 2011). However orientation programmes for new employees, collectively known as induction are common to many blue-collar and white-collar occupations. Induction programmes are offered to individuals of all ages to meet a variety of purposes across many professions (Brondyk \& Searby, 2013). For example schools' of medicine and nursing implement induction programmes to enhance individuals' socialisation into the profession. Many government agencies use mentoring to foster personal and professional growth. Mentoring in business and industry has become a common place practice as a strategy for recruiting, retaining and promoting potential talent (Brondyk \& Searby, 2013).

It is likely that there have always been informal relationships within schools that guided and supported new teachers into the teaching profession. However over the last twenty-five years more formalised induction programmes have increased in popularity as a 
way to support PCTs as they entered the teaching profession (Brondyk \& Searby, 2013; Ingersoll \& Strong, 2011). Prior to 2004 the support and guidance given to new teachers was not clearly defined and was interpreted by each individual school. The first New Zealand formal teaching induction process, 'Towards Full Registration: A support Kit for Schools' introduced in 2004, was described as a 'specific, school-based process designed to support teachers in a new school setting' (Ministry of Education \& New Zealand Teachers Council, 2004).

The rationale for teacher induction, is that although teaching is complex work, teacher preparation courses are insufficient in themselves to prepare new teachers for the classroom. A considerable part of the knowledge and skills required for successful teaching can only be acquired while on the job. (Feiman-Nemser, 2001; Ingersoll \& Strong, 2011). Mentoring has become a popular approach for teacher induction in many countries (Hobson et al., 2009; Ingersoll \& Strong, 2011; O'Brien \& Christie, 2005; Wang, Odell, \& Schwille, 2008). Mentoring can be defined as:

"The one-to-one support of a novice or less experienced practitioner (mentee), by a more experienced practitioner (mentor), designed primarily to assist the development of the mentee's expertise to facilitate their induction into the culture of the profession and into the specific context." (Hobson et al., 2009, p. 207).

There is abundant empirical support for induction and mentoring programmes for PCTs and the positive impact it has on teacher commitment and retention, teacher and classroom instructional practices and student achievement (Feiman-Nemser, 2003; FeimanNemser \& Carver, 2012; Hobson et al., 2009; Ingersoll \& Strong, 2011; Langdon, Lind, Shaw, \& Pilcher, 2010; McDonald \& Flint, 2011; Normore \& Loughry, 2006; Orland-Barak \& Hasin, 2010; Piggot-Irvine et al., 2009).

The adaptation in New Zealand from an induction programme of advice and support, to one of educative mentoring has meant a change in the model of induction. This involves changes in practices for experienced teachers who were formally tutors and are now designated as mentors to work alongside PCTs (Bradbury, 2010; Feiman-Nemser, 2003; Feiman-Nemser \& Carver, 2012). This study provided an opportunity to investigate how this change of practice has been implemented by mentors. 


\subsection{The New Zealand context}

This study focuses on the New Zealand primary school as explained in chapter 1. PCTs in New Zealand currently undertake a two-year induction process after completing their teacher training course. They are assigned an experienced teacher at their school who guides their progression towards achieving certification as a teacher, based on the Practising Teacher Criteria (PTC) which can be applied for at the end of the two years. Since 2011, mentors and PCTs have had release time, one day each week in the first year and half a day in the second year, to be used as each school determines. In addition, the Guidelines (Education Council of Aotearoa New Zealand, 2015a) advocate high quality induction as being comprehensive, educative and evaluative as outlined on page 4.

The educative programme is a key opportunity for the PCT to work alongside their mentor to co-construct learning using evidence from practice and an inquiry approach. During this process PCTs learn and practice skills, attitudes and attributes required to be a fully registered teacher, with full mentor support. Records are required to be kept of activities occurring as part of the induction process. Ultimately it is expected that mentors and PCTs would meet regularly, conduct classroom observations with constructive feedback, and engage in a developmental process of inquiring into current practice and gathering evidence of progress towards meeting the PTC.

In summary the present induction programme is one of educative mentoring using the Guidelines (Education Council of Aotearoa New Zealand, 2015a) in conjunction with meeting the PTC (Education Council of Aotearoa New Zealand, 2015b) to fulfill the registration requirements.

\subsection{The previous induction programme}

An historical perspective indicates that more thirty years ago, the Education Department utilised inspectors in discussion with principals, to determine whether a beginning teacher became fully registered. It is thought that there was no formal expectation around induction for beginning teachers during this time beyond what would normally happen when inducting a new staff member (Wansborough, 2015). Booklets and flyers supported the expectations for this process and included some Ministry of Education support and direction. The Teacher Registration Board was disestablished in 2001/2 but promoted 
'support and guidance' programmes for beginning teachers. The NZTC, established in 2002, developed and published the Support Kit for Schools in 2004.

The previous induction programme was called 'Towards Full Registration: A Support Kit for Schools' (Ministry of Education \& New Zealand Teachers Council, 2004). It was divided into four sections with relevant information for PCTs, those responsible for PCTs, principals and Boards of Trustees (BOTs). The induction programme involved a co-ordinator who provided 'advice and guidance' (in conjunction with the principal) and oversaw the programme. In primary schools supervision was provided by a tutor teacher. This was the first time this term 'tutor teacher' was used. A tutor can be described as a person charged with the instruction and guidance of another (Merriman \& Webster, 2015).

The induction programme using the Support Kit for Schools introduced PCTs to a more formal programme with a tutor teacher and a time allowance of one day a week. This allocation of time out of the classroom was to be shared between the PCT and tutor teacher for observations, reflecting, planning and record keeping in the first year. This was the first time a support role for new teachers with a tutor teacher, had been formalized and hence, introduced a form of accountability with time being given and records required. Although no staffing allowance was available in the second year for the PCT, schools would continue to provide support for the two years to enable PCTs to meet the criteria for full registration. The support kit listed the skills of asking open questions, using probing questions, providing specific feedback, and demonstrating teaching, as ways of developing the role of the tutor teacher. There were new skills surfacing, for example giving specific feedback was explained in the publication, but tutor teachers reading this new support kit had little opportunity to practice any of the skills listed. Tutors were aware of being more accountable for the role of tutoring than previously, for example having to keep written records.

While the words 'mentoring', 'mentor' and 'educative' were mentioned in this Support Kit for Schools they weren't fully explained, instead the focus was on advice and guidance. These expressions of mentoring used on occasion in this publication, perhaps signalled that change was to happen in the future. However the emphasis was on the role of being a tutor.

\subsection{The change from tutor to mentor}

In 2007 a research programme, Learning to Teach, was undertaken by the New Zealand Teachers Council (NZTC) and investigated the quality of the guidance and support 
available to PCTs. The three stages of the research included a literature review (Cameron, 2007), survey of PCTs (Cameron, Dingle, \& Brooking, 2007), and success case studies (Aitken, Ferguson, McGrath, Piggot-Irvine, \& Ritchie, 2008). As a result of the Learning to Teach research, the role of a tutor who gave advice and guidance, was replaced by a programme of 'induction and mentoring' with a mentor. This signalled the shift from 'advice and guidance', to a 'co-constructed relationship', contributing to a more equal partnership and a programme of professional learning (Education Council of Aotearoa New Zealand, 2015a, p. 1).

The shift to mentor introduced a more rigorous induction programme of not only assistance but also assessment using an educative mentor model which included a cycle of inquiry which included evaluation and feedback. The shift from tutor to mentor potentially created a tension between the role of assessing and measuring PCTs performance on one hand, and wanting to build a lasting professional relationship that was trusting and caring, on the other hand (Langdon et al., 2010; Yusko \& Feiman-Nemser, 2008). However Yusko and Feiman-Nemser (2008) concluded that mentoring could be most educative when mentors engaged in assistance and assessment, and this did not necessarily prevent mentors from forming trustworthy relationships although sometimes making it more challenging. Carefully chosen mentors who were also highly regarded teachers with professional expertise were seen as allowing assistance and assessment to co-exist (Yusko \& Feiman-Nemser, 2008).

The Learning to Teach research (2006-2008) resulted in the development of the Guidelines for Mentoring and Mentor Teachers with a change from tutor to mentor. This was a shift from 'advice' to a 'co-constructive relationship and programme of professional learning' (Education Council of Aotearoa New Zealand, 2015a, p. 2). A mentor must 'dig' into practice by deconstructing and co-constructing, reflecting, and providing critical feedback on practice, alongside their PCT. The advice and guidance programme had a similar framework of content with meetings and observations as the educative mentoring programme. However it was the type of conversations that took place during meetings and as feedback from observations that were critical to learning in the educative mentoring approach.

\subsection{Educative mentoring}

Educative mentoring is a concept developed by Feimen-Nemser (1998) which emphasises PCTs learning from their own practice with the support of a mentor teacher. The core principles include "cultivating a disposition of inquiry, focusing attention on student 
thinking and understanding, and fostering disciplined talk about problems and practice" (Feiman-Nemser, 2001, p. 28). Bradbury (2010) describes the key components in the mentoring relationship as learning together and co-thinking, indicating two learners working and learning together. It is in the classroom, where both teaching and learning takes place, that the mentor and PCT develop a relationship and work together to improve teaching practice and learning outcomes for students.

In addition to the above definitions the key components of educative mentoring as described by the Guidelines (Education Council of Aotearoa New Zealand, 2015a, p. 11) are the dedicated time for the mentor to:

- $\quad$ Guide the PCT;

- $\quad$ Support the PCT;

- Give feedback to PCT; and

- Facilitate evidence-informed reflective learning conversations.

The educative mentoring process is based on evidence and professional conversations, in which the mentor begins by focusing on immediate concerns that require skills of guidance and support. The educative approach involves mentors shifting their approaches from giving 'just in time handy hints' to asking PCTs to share thinking around 'why' they chose to do it in a particular way and to continue to enquire into their practice (Langdon, Flint, Kromer, Ryde, \& Karl, 2011).

Educative mentoring can be seen as a continual individual inquiry into practice. High quality, intensive induction and mentoring links practice to a view of good teaching which builds confidence by developing pedagogical expertise underpinned by the setting of personal goals and using achievement data (Education Council of Aotearoa New Zealand, 2015a, p. 28). Evidence-informed reflective learning conversations are based on student progress in the form of students' work and achievement data. The major aim of the educative process is to assist in identifying the gaps, for example, "How am I going? Where am I going?" and to provide remediation in the form of alternative or other steps, "Where to next?" (Hattie \& Timperley, 2007).

Learning to teach is developmental and involves deeper exploration of practice and evidence of learning and what lies behind the surface issues by asking the 'why' questions 
(Feiman-Nemser, 2003; Feiman-Nemser \& Carver, 2012). The PCT is asked to examine and reflect on their own practice and explore deeper issues which involves them in serious professional conversations. Mezirow (1991) says that making change to practice is very difficult but the powerful question is 'why', why did you choose to do it in a particular way. Unless people are asked 'why' they won't think deeply and dig into practice. In this way educative mentoring has the potential to be 'transformational'. Transformation as a learning outcome suggests that the individual is radically changed as a consequence of learning and development (Brookbank \& McGill, 2006; Mezirow, 1991).

Professional conversations help PCTs develop alternative perspectives that lead to solutions (Feiman-Nemser, 2001). Teacher inquiry into practice is an ongoing knowledgebuilding cycle in the learning process, which benefits the learner and aims to promote student outcomes (Timperley, Wilson, Barrar, \& Fung, 2007).

\subsection{The implementation of educative mentoring}

The Guidelines for Induction and Mentoring and Mentor Teachers were drafted in 2008 and piloted across the education sector (including early childhood education, primary, secondary and Maori medium settings). They identified ways to support a shift towards educative mentoring practices. In 2010 a two day conference was held to discuss the pilot programme and provide professional learning on educative mentoring. This was the first public airing of educative mentoring in New Zealand. A national programme of workshops was announced, and offered to introduce professional leaders and mentors to the Guidelines (Education Council of Aotearoa New Zealand, 2015a) publication. After this a one day workshop explored how the Guidelines could be implemented and offered the opportunity to practice educative mentoring skills.

In educative mentoring the learning for mentors and PCTs occurs through meaningful social communication, interaction and practice (McDonald \& Flint, 2011). Conversations are critical to the process. Langdon (2011) stated that engaging PCTs in serious professional conversations is at the foundation of linking practice to a view of good teaching. Conversations are an occasion for learning and are a constant in our personal and professional lives (Haigh, 2006). Research emphasizes the importance of dialogue and conversations between professionals in enriching, supporting and challenging each other's learning (Cordingley, 2005). The use of questions to challenge PCTs to talk about what they do, and why they do it is important. Mentors are expected to engage in learning conversations based 
on collected evidence and give feedback, with the aim of supporting the PCT to identify the gaps, and set new goals and learning steps (Hattie \& Timperley, 2007). This evidence may include a written script from a classroom observation, lesson plans, student work or informal observations of the PCT working in the classroom. During this learning conversation the skills of critical feedback, deconstruction and reflection, co-construction and goal setting, are used. The next sections will examine what is involved for each.

\subsubsection{Critical Feedback}

Critical reflection-with-another is the intentional dialogue that occurs in a mentoring situation (Brookbank \& McGill, 2006). The dialogue is characterized by 'engaging the person at the edge of their knowledge' and has a purpose which is clear to both mentor and PCT (Brookbank \& McGill, 2006, p. 57). This involves the mentor challenging the PCT's practice by asking questions, especially the 'why' questions for the purpose of inquiring into practice with a view to transformative learning. Naturally occurring dialogue and casual conversation may reflect power differences which can inhibit learning. A mentor whose dialogue takes the form of a monologue about how things should be done, often with the PCT obliged to agree is unlikely to promote reflective learning for improvement (Brookbank \& McGill, 2006). Critical reflection must be managed by the mentor and includes the skills of deconstruction and coconstruction. Both reflection and feedback during a learning conversation need to be critical, that is that they must be analytical and significant.

Feedback is the information provided by the mentor regarding aspects of the PCT's performance and understanding, and typically occurs after instruction or observation. Critical feedback seeks to provide knowledge and skills or develop particular attitudes (Hattie \& Timperley, 2007). Contrasting outcomes suggest that while observation and feedback may help teachers to implement or refine new practices it does not guarantee it (Timperley et al., 2007). Praise is rarely effective as it doesn't address "Where to next?" and is unlikely to enhance learning. Effective instruction and feedback can be powerful in enhancing learning and requires much skill by mentors relating to timing, how it is given and how it is received (Hattie \& Timperley, 2007). 


\subsubsection{Deconstruction and reflection}

Deconstruction allows the PCT to describe what happened, to discuss the evidence and to examine understandings and outcomes (Education Council of Aotearoa New Zealand, $2015 a$, p. 25). It invites the asking of open ended questions by the mentor which requires cognitive engagement by the PCT (Cordingley, 2005; Timperley et al., 2007). For example, after observing a writing lesson, the mentor might deconstruct the experience by asking such questions as, "Tell me what went well? Why did it work well? What might you change next time? Why would this work better?" (Hattie \& Timperley, 2007). The PCT is being asked to critically reflect on the practice and with the mentor guiding the reflection by deconstructing the experience and not just asking what happened, but why. The why question digs into the theory behind the practice. Practice won't become embedded unless teachers subscribe to the theory that underpins it (Timperley et al., 2007).

Mentors and PCTs approach the learning conversations as people who have rich theories about how students learn, how to teach them and what might comprise the content of the lesson and the desired outcome of the lesson (Cordingley, 2005; Feiman-Nemser \& Carver, 2012; Hanson, 2010). Timperley et al. (2007) present a model of learning and describe three processes involved in learning: consolidating and/or examining prior knowledge; adapting or adopting new knowledge; and resolving dissonance by accepting or rejecting the new position. For example, students working in groups are often used for learning. If we subscribe to the theory that learning is socially constructed through dialogue then we would use groups more often (Bandura, 2000). Some teachers may use groups occasionally because they are told it is a good thing to do, while others may have used them in a variety of settings and noticed the students more engaged in learning, and learning from one another, and therefore really believed it to be a good approach to facilitate learning. Linking practice to theory ensures that the practice is embedded because we really understand it and believe it. Experiences that promote trying something out and then coming back and talking about it stimulate learning (Feiman-Nemser, 2001). Conversations which allow for the articulation of ideas and ask the 'why' questions ensure a platform for learning to take place (Haigh, 2006).

Professional learning experiences seek to change and refine practice, as educative mentoring does. There is a need to interrupt established routines and help teachers to understand the theories of action underpinning them (Timperley et al., 2007, p. 9). Deeper 
learning typically requires repeated cycles of engagement with learning processes, practice and engagement. The use of conversations, to critically reflect and deconstruct practice, is therefore a crucial ingredient of educative mentoring.

\subsubsection{Co-construction and goal setting}

Together the mentor and PCT co-construct and set new goals as a result of a conversation, with a focus on the PCT's students' learning outcomes (Education Council of Aotearoa New Zealand, 2015a; Langdon, 2011). This involves a shared discussion about where to next for the PCT's learning and what goals would best achieve this outcome. Hattie and Timperley (2007) suggest the asking of questions as essential to identify the gaps for setting goals. Narrowing down the focus when there is so much to work on, allows the mentor and PCT to co-construct or discuss together a personal learning goal to work on until achieved. The setting of goals is reported to make the complex task of teaching manageable (Langdon, 2011). This co-construction of goals gives a clear focus to the mentor's feedback and provides evidence of teacher learning and development.

\subsection{Rationale for educative mentoring}

Three different approaches to mentoring, identified by Wang and Odell (2002), were evaluated by Timperley et al., (2007).

1. Humanistic perspective of mentoring (typified by emotional support) is likely to support and help retain beginning teachers but goals and processes appear to rarely be challenged.

2. Situated apprentice approach to mentoring sanctions mentors to assist PCTs to adjust to the new culture of teaching and existing norms, but ignores conflicts and deeply held beliefs and attitudes that may not match with the present experience. Mentors provide the necessary techniques and information and PCTs acquire what is provided in the set context, but no conflicts are addressed.

3. Critical constructivist approach sees important knowledge being constructed by the PCT and mentor through collaborative inquiry (Timperley et al., 2007). PCTs are encouraged to pose questions and face challenges related to their teaching practice. 
The concern was that little attention is given to developing specific teaching goals, knowledge and strategies.

It is reasonable to conclude that the Learning to Teach research considered all three approaches and found a better way forward (Cameron, Dingle, et al., 2007). If PCTs are mentored in ways that reinforce a divide between teaching and learning and are not seen as working together to shape beliefs and practices, then the greatest outcomes are unlikely to be achieved (Timperley et al., 2007).

The resulting approach of educative mentoring has emerged as it seeks to meet the immediate needs of teachers, focuses on long-term goals for growth, and encourages challenging questions related to PCTs teaching practice (Education Council of Aotearoa New Zealand, 2015a; Norman \& Feiman-Nemser, 2005). Educative mentoring is acknowledged as strongly contributing to PCTs professional development when engaged in effectively (Bradbury, 2010). Effective educative mentoring is seen as being 'transformative', contributing to the PCTs professional development, and not just being 'transmissive' and focused on the transmitting and receiving of knowledge and skills (Brookbank \& McGill, 2006). While there has been an increase in the amount of research around mentoring, there is still much to be learned in order to understand the concept of educative mentoring (Bradbury, 2010). This study provides an opportunity to investigate educative mentoring to find out where current understandings lie, and where to next.

\subsection{Comparing the two induction programmes}

Table 3 summarises the shifts in practice required for a tutor to become a mentor. Both induction programmes, the former advice and support programme and the current educative mentoring programme, offer emotional support to the PCT. Although surviving as a teacher is important, the focus has shifted to the learning needs of the students with a strong emphasis on cultivating inquiry in the classroom. Cultivating inquiry is the change from the tutor's role which could be considered as coaching and telling people what to do, to using evidence and asking "What went well here? What else could you have done differently?" Coaching focuses on specific and immediate issues or goals for enhancing the individual's performance at work (Garvey, Stokes, \& Megginson, 2009). Mentoring, in contrast, is 
associated with the broader and longer term issues - the individual career and holistic development (Rowley, 2006).

In summary, the tutor's role is one of advising and telling, whereas the mentor is asking inquiring questions that provoke thinking about and reflecting on practice. This challenges the PCT to reflect, deconstruct, co-construct alongside the mentor while receiving feedback and setting new goals for self and students.

Table 3:

Shifts in practice-from tutor to mentor

\begin{tabular}{|c|c|}
\hline Advice and support with a tutor & Educative mentoring with a mentor \\
\hline Emotional support & Emotional support \\
\hline Becoming part of the school culture & Becoming part of the school culture \\
\hline Focus on survival and self as a teacher & Focus on learning needs of students \\
\hline & Vision of good teaching \\
\hline $\begin{array}{l}\text { Frequent visits to observe teaching and } \\
\text { provide feedback. Keep records of } \\
\text { observed and discussed key areas. }\end{array}$ & $\begin{array}{l}\text { Mentor engages with } \mathrm{PCT} \text { as co-learner } \\
\text { with regular meetings, observations and } \\
\text { learning conversations. }\end{array}$ \\
\hline - Technical support & Cultivating inquiry \\
\hline - Coaching and telling & - Teachers critically reflecting on \\
\hline - Just in time handy tips & their own practice \\
\hline - Managing the immediate & $\begin{array}{l}\text { Deconstructing (reflection) and } \\
\text { co-constructing (goal setting) } \\
\text { practice }\end{array}$ \\
\hline & $\begin{array}{l}\text { Providing critical and evidence based } \\
\text { feedback }\end{array}$ \\
\hline
\end{tabular}

Adapted from Towards full registration: A support kit for schools (Ministry of Education \& New Zealand Teachers Council, 2004) and the Guidelines (Education Council of Aotearoa New Zealand, 2015a).

\subsection{Creating conditions for deliberate educative mentoring}

Mentors play a pivotal role in the retention and development of new teachers (Feiman-Nemser \& Carver, 2012). They are well-placed to interpret and enact the induction programme of educative mentoring in schools. It is really what mentors do within their mentoring relationship that is fundamental to effective and genuine educative mentoring. 
Feiman-Nemser and Carver (2012) advocate serious mentoring which I refer to as deliberate mentoring, as both 'supporting and stretching' new teachers, helping them with immediate problems and also moving their practice in the forward direction. The 'stretching' of PCTs includes a level of challenge that goes beyond emotional support. Mentors are able to ask challenging questions, the why questions, and give PCTs the opportunity to deconstruct and co-construct, to ensure that serious educative mentoring is occurring.

The purpose of educative mentoring is to go beyond emotional and technical support and for mentors to become the agents of change. Achinstein and Athanases (2006) point out that mentors can become the agents of change in the system by providing the opportunity for PCTs to reflect on their practices and the school's responsibility is to foster equal learning opportunities for all students. The skills required for this role go beyond those mastered by most classroom teachers and include observation analysis and specialized communication skills (Feiman-Nemser, 1998; McDonald \& Flint, 2011). As discussed above the mentor is required to observe the PCT and provide feedback against agreed criteria and to facilitate the PCT's reflection on that feedback. Effective learning conversations with the PCT challenge and support the use of evidence to develop the teaching strengths of PCTs (Education Council of Aotearoa New Zealand, 2015a, p. 17). Specialized communications skills are the opportunities the mentor provides for reflection, deconstruction and co-construction while inquiring into teaching and learning practice (Annan, Lai, \& Robinson, 2003; Timperley, 2001).

Feiman-Nemser (2003) states that serious mentoring requires the opportunity for mentors to see and analyse effective mentoring models to further develop skills of conversing and discussing in analytic and nonjudgmental ways. Mentors who are able to reflect on their actions and assess their own effectiveness as mentors, as well as PCT's progress, are engaging in professional learning and development (Feiman-Nemser, 2003). These reflective skills demonstrate mentor effectiveness and set up the conditions for serious and also deliberate educative mentoring to take place. It is this deliberate action or choice by the mentor to mentor in the 'educative' manner.

In summary deliberate educative mentoring requires new learning for mentors which like any new learning, requires on-going support and monitoring (Achinstein \& Athanases, 2006; Education Council of Aotearoa New Zealand, 2015a; Feiman-Nemser, 2003; Hobson et 
al., 2009; Thornton, 2013a). Research has shown that weak systems of mentor support contribute to uneven mentoring practices which result in new teachers and their students having missed learning opportunities (Feiman-Nemser \& Carver, 2012; Langdon, 2011).

\subsection{Gaps in the literature}

Devos (2010) stressed that more research is needed to 'enrich our understandings' of mentoring rather than "stick to a current narrow focus on aspects of mentoring programme design and improvement" (p. 1223). There is a dearth of research about what educative mentoring looks like in practice and there is much to be learned (Bradbury, 2010). As already discussed the launch of the Guidelines in 2011, a one day workshop was provided by NZTC to prepare mentors to mentor in an educative manner and change current induction practice. Do teachers understand what educative mentoring means after attending a one day workshop and reading the new Guidelines? The present study investigated mentoring practices in three New Zealand primary schools. It explored what was understood by the term educative mentoring and how this was being implemented. Examining what goes on in a meeting or mentoring conversation is expected to give a glimpse into the mentoring taking place. There is inadequate research providing close scrutiny of a formal interaction such as a meeting.

The NZTC sought feedback about the implementation of the Guidelines for mentoring after three years (Cameron et al., 2014) to inform future mentoring education and will be referred to in the discussion chapter. As part of the process they surveyed two cohorts of PCTs who gained full registration together with their mentors, and have conducted case studies in five primary schools. This present study aims to provide insights that complement the NZTC survey and case studies. Sharing these findings with the sector is likely to encourage and support mentors to examine their practice around educative mentoring. For these reasons increasing our understanding of educative mentoring and its impact on mentors mentoring and for PCTs teaching and learning, is paramount. 


\subsection{Chapter Summary}

Through this literature review I have explored what the previous induction programme, of 'advice and guidance' with a tutor looked like, and explained how the present induction programme of educative mentoring with a mentor, has resulted. The Guidelines for Induction and mentoring and Mentor Teachers (Education Council of Aotearoa New Zealand, 2015a) and Practising Teacher Criteria (Education Council of Aotearoa New Zealand, 2015b) together signalled a shift from tutor to mentor which has involved new learning and skills for mentors. This points to the challenge for mentors to firstly, understand what educative mentoring is and secondly, what is involved in the process. This study was based on the assumption that an induction and mentoring programme for PCTs is advantageous for the teaching profession. Literature on educative mentoring indicated that there has been a narrow focus around the design and improvement of educative mentoring and there is still much to be learned (Bradbury, 2010; Devos, 2010). This study provided an opportunity to describe how mentors and PCTs engage in the process of educative mentoring, and the specialized skills required for educative mentoring. 


\section{CHAPTER THREE: METHODOLOGY}

\subsection{Chapter overview}

This chapter sets the study within a constructivist system of beliefs and shows how the method of investigation fits the research question and a world view. It establishes the use of a qualitative case study approach. It describes the context for the study, the selection of participants, and the data collection process with the resulting data being analysed thematically. Finally the rigour of the process is addressed through a consideration of ethics. I found asking questions assisted me to shape this methodology and therefore questions are used as headings.

\subsection{What worldview underpins this study?}

This research is based on a social constructivist world view. Social constructivism is the belief that knowledge and meaning is constructed between participants within a particular social context, rather than discovered (Stake, 1995). This study is situated within a world view that suggests that the aim of the research is (1) not to discover but to construct a clearer reality; and (2) to develop and advance a more sophisticated reality of 'educative mentoring' (Stake, 1995, p. 101). To build a universal understanding requires each individual to have some degree of uniqueness but with much held in common. The reality we seek is of our own making but also builds on collective interaction. An individual's views are influenced by 'social interactions with others and their own personal histories' (Cresswell, Hanson, Clark Plano, \& Morales, 2007; Yin, 2009).

This definition fits with the goals of my research, which was to learn about the realities constructed by the participants and the implication of their perceptions of educative mentoring. My task as the researcher was to seek 'to understand reality from the point of view of the other' at one point in time, in a specific context (Cresswell et al., 2007).

By recognising that meaning is created and shared through social processes and interaction, I place the study within a constructivist (and particularly a social-constructivist) world-view (Patton, 2002). A social constructivist view provides the reader with relevant raw material. There is an emphasis on describing things especially events and people, and 
interpretations of the people most knowledgeable about the case, which in this situation are the mentors and PCTs.

\subsection{What questions fit the purpose for this study?}

A key question seeks to address:

What does effective educative mentoring look like in the New Zealand primary school?

The sub questions are:

* The word 'educative' is used in relation to the induction and mentoring guidelines; how is this term understood by mentors and PCTs?

* How might the educative mentoring process be improved?

What skills and knowledge do mentors still need to embed?

\subsection{Why choose a qualitative approach?}

- To understand how people make sense of their world; and

- To recognize that the researcher has an influence in constructing meaning.

The qualitative approach used in this study was selected as the most appropriate way to respond to the research question. The research question aimed to discover what a selection of mentors and PCTs believed to be effective in the practice of educative mentoring and aimed to reveal what was working and what was not working. Drawing meaning from another person's articulated beliefs and observable practices requires sensitivity from the researcher who is seeking the unanticipated as well as the expected (Stake, 1995). The researcher is attempting to make sense of this educative mentoring world. It is acknowledged that the researcher cannot be completely objective in situations of human interaction, but needs to apply professional insight and knowledge to what the participants say and do. In this study I had to interpret teachers' descriptions and actions with sensitivity. Stake (1995) sums this up by describing a good case study researcher as being patient, reflective and willing to see another's view. Out of this view the researcher constructs meaning. 


\subsection{Why use an interpretive case ${ }^{1}$ study?}

- To describe the reality;

- To understand why some situations work better than others;

- To interpret the most effective learning circumstances for PCTs;

- To employ multiple sources of evidence; and

- To allow for a chain of evidence and credibility.

Case study research provides a detailed account and analysis of one or more cases as it occurs in a real life context (Johnson \& Christensen, 2010; Yin, 2009). In this study, mentoring of PCTs is analysed in the real life context of the New Zealand primary school. The interpretive paradigm assumes that there are many different social realities of phenomena (Merriam, 2009b). The understanding of that phenomena is established through an individual's subjective interpretation of it (Cresswell et al., 2007; Merriam, 2009b). One of the main weaknesses of a case study is the inability to generalise from its findings (Johnson \& Christensen, 2010; Punch, 2000). However, case studies can result in rich, holistic and descriptive accounts of a phenomena, which helps the reader to understand the phenomena as a whole, resulting in new meaning for the reader, extending the readers experience or confirming what is known (Merriam, 2009b). Generalisation is not always necessary for valuable learning to occur.

\subsection{What is the context of the study?}

- Convenient location for selection of primary schools; and

- Purposeful sample of current mentors and PCTs.

I was seeking a purposeful and convenient sample of New Zealand primary schools where entry would be possible and where there was one or more PCTs being mentored. The schools needed to be of a convenient location. I initially contacted principals to ask whether there were PCTs in the school and to gauge interest. Three principals agreed to this study

\footnotetext{
1 "Case study is the study of a particularity and complexity of a single case, coming to understand its activity within important circumstances" (Stake, 1995, p. xi).
} 
taking place in their schools. These schools are referred to as Kiwiland School, Tui Primary School and Pukeko School. Descriptions of the schools are summarised in Table 4.

Table 4.

Details of primary schools

\begin{tabular}{lccc} 
& Kiwiland School & Pukeko School & Tui Primary School \\
\hline Location & City school & $\begin{array}{c}\text { Semi-rural suburb of a } \\
\text { city }\end{array}$ & $\begin{array}{c}\text { Urban suburb of a } \\
\text { city }\end{array}$ \\
\hline Decile rating & & 7 & 10 \\
\hline Roll & 10 & 160 & 407 \\
\hline $\begin{array}{l}\mathrm{n} \text { (mentor/PCT } \\
\text { relationships) }\end{array}$ & 750 & 1 & 3 \\
\hline
\end{tabular}

\subsection{Selection of participants}

The purpose of the selection was to seek participants who were engaged in an educative mentoring relationship. I was seeking those who were involved in an organized induction process that involved meeting regularly, and where there were elements of educative mentoring in their approach as described in the previous chapter. An online survey was used 1) to establish what the present mentoring process looked like in their context, 2) to ask mentors to identify as mentoring in the educative manner, and 3) to identify potential relationships for more intense study.

I was given contact emails for the eight mentors by the principals, contacted each mentor at the three schools and arranged a time to meet them with their PCTs to explain what was involved in the research. I presented the aims of the study with an information sheet and consent form (see appendices A, B, C \& D). All professed an interest in the study and volunteered to participate and signed their consent. They were sent a link to the online survey

\footnotetext{
${ }^{2}$ The socioeconomic level of the contributing population to a school is described in terms of a decile. Decile 1 represents the parents at the lowest income level and decile 10 the highest.
} 
and given two weeks to complete the survey (see appendices E \& F). From the online survey six mentors and seven PCTs completed the online survey and stated they were involved in educative mentoring. As a result of the online survey three mentor/PCT relationships were randomly chosen to proceed with the collection of data (see Table 5).

\subsubsection{The selection process}

- Recognized educative mentoring relationship in action;

- One mentoring relationship from each school; and

- A rich variety of perceived relationship interactions.

The selected participants provided differing examples of 'typical' mentoring which would allow the data to be viewed from different angles (O'Toole \& Becket, 2013). Comments from an open question in the survey resulted in, "The relationship I have with my mentor teacher is not particularly helpful..." warrants investigation, as does "Our relationship has strengthened over time ...this is valuable to me as I feel respected and understood..." These comments appear at different ends of the spectrum with one likely frustrated and the other valued and respected. This variety was likely to give a 'rich and thick' description for the reader about educative mentoring (Stake, 1995). Choosing one mentor/PCT relationship from each school gave three different contexts. Pukeko School had only one mentor/PCT relationship and was automatically part of the study. The other mentor/PCT relationships were a random choice, one from Kiwiland School and one from Tui Primary School (see Table 5) and descriptions below. The mentors and PCTs not selected were thanked for their input into the survey.

\subsubsection{Descriptions of relationships}

\section{Mary and Maggie}

Mary was an experienced tutor who was also the leader for a large team of teachers. She saw her role as mentor as one of professionalism and guidance. Maggie, the PCT, taught in a more senior class where she was the newest and youngest member of a large team. She felt very new to the school but was familiar with many of the staff, having completed a teaching experience as a student at this school the previous year. 


\section{Janine and Alex}

Janine was a first time mentor to a PCT but had been a tutor teacher of many students on teaching experience over the years which she thought was relevant. She was assistant principal and taught next door to the PCT, Alex, often exchanging pupils and visiting each other's classrooms during the day. Janine saw her role of mentor as a coaching role, being a main 'port of call' and getting her PCT to think for herself while listening, questioning, reviewing and reflecting constantly. Alex would complete her provisional certification at the end of next term and worked closely with Janine.

\section{Lisa and Hannah}

Lisa had been at Tui Primary School for many years, was a team leader, and had seen many changes in tutoring over that time. She saw her role of mentor as sharing her experience, giving direction and encouraging Hannah the PCT to think for herself. Hannah taught students who were a year older than her mentor's and had almost completed her first year of her provisional certificate of registration.

\section{Table 5.}

Details of participants

\begin{tabular}{cccc}
\hline $\begin{array}{c}\text { Mentors } \\
\text { (pseudonyms) }\end{array}$ & Years as mentor & $\begin{array}{c}\text { PCTs } \\
\text { (pseudonyms) }\end{array}$ & Year as PCT \\
\hline Mary (M1) & 6 & Maggie (PCT1) & 1st \\
\hline Janine (M2) & 2 & Alex (PCT2) & 2nd \\
\hline Lisa (M3) & 4 & Hannah (PCT3) & 1st \\
\hline
\end{tabular}

\subsection{Data collection}

Data are described by Merriam (2009b) as, "nothing more than ordinary bits and pieces of information found in the environment. They can be concrete and measurable, or invisible and difficult to measure" (p. 85). Johnson and Christensen (2010) suggest that multiple methods of data sources should be utilised for a case study as this provides for triangulation of data. Not only does this increase the validity of the research but it also allows 
for better understanding of the case, to better answer the research questions. The majority of the data consisted of direct quotes from the participants about their knowledge, experiences, opinions and feelings. The data consisted of:

1. Online survey;

2. Mentor and PCT interviews; 3.

Recording of a PCT meeting; and

4. Analysis of documents.

These documents included meeting minutes, class observation feedback, and PCT progress reports which mentors and PCTs were happy to share. The order of the data collection process is outlined in figure 1.

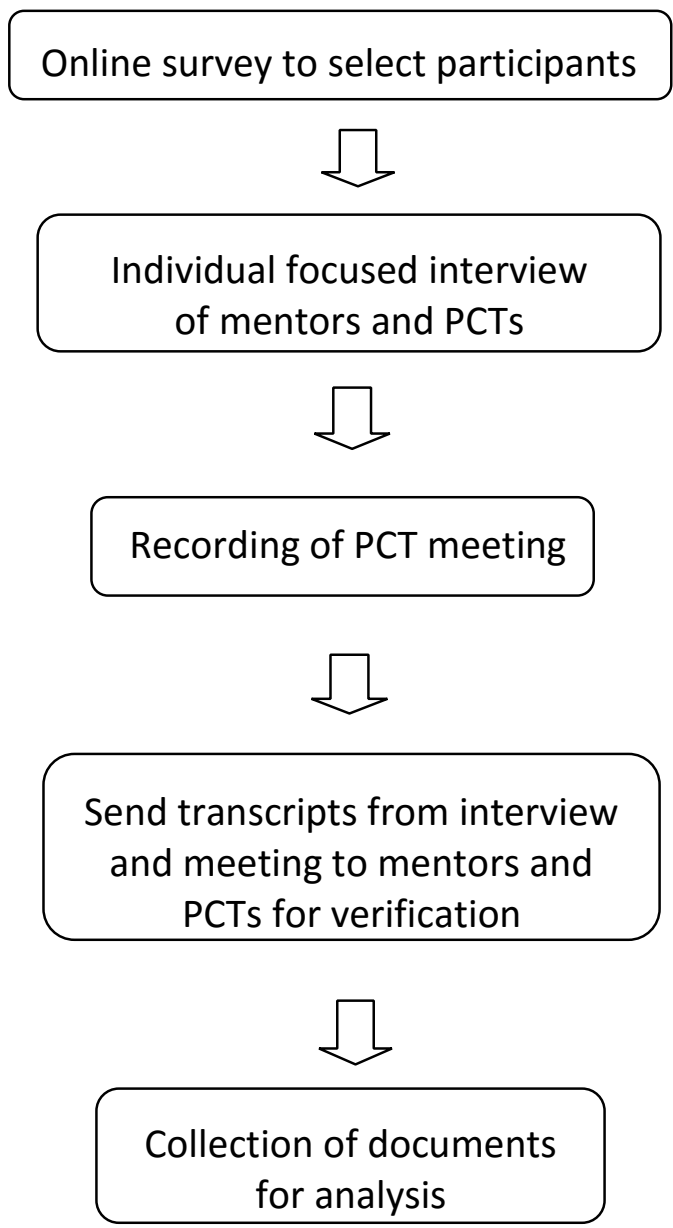

Figure 1. The data collection process 


\subsubsection{Why use an online survey?}

- To establish present mentoring practices;

- To give a sense of the issues in the schools; and

- To identify potential relationships for more intense study.

I used an online Qualtrics survey software to select the participants. There were eight mentor/PCT relationships across the three schools who were surveyed hoping there would be three relationships who would be willing to participate right through the study. Six mentors and seven PCTs responded to the online survey. I invited one mentor and PCT relationship from each school to continue. Fortunately they agreed but I had others to fall back on if needed. Three mentors and three PCTs were a manageable number to interview and carry out the study.

The survey was broken into three parts (see appendix E \& F). The first part asked mentors and PCTs for demographic information about their teaching and mentoring experiences and the frequency of their mentoring interactions. The second section asked mentors and PCTs to indicate the extent to which their interactions met the guidelines for educative mentoring (Education Council of Aotearoa New Zealand, 2015a, pp. 25-26). A five point Likert scale (strongly agree to strongly disagree) was used for these questions. Thirdly, open ended questions asked mentors to comment on their training for the role, the ways mentoring had changed for them (if at all), the RTC, the Guidelines, and their schools' induction and mentoring programmes. PCTs were asked to comment on their relationship with their mentor, the RTC, the Guidelines and how the programme might be improved in their school. The final question asked mentors to identify that they were mentoring in an educative manner. This question was a signal that I was talking about educative mentoring and if participants were uncomfortable about this they may choose not to continue. All mentors identified as using educative mentoring. These questions are further discussed in the findings chapter. The survey was piloted with two mentors and two PCTs outside this study.

The advantage of a survey is that it is low cost and easy to administer (Johnson \& Christensen, 2010). By sending it out online there was no travel involved and it was an opportunity for participants to record data and thoughts honestly and freely because they were not face to face with an individual. On the other hand disadvantages of a survey are that 
you cannot read the body language of participants, there is no rapport established and participants could respond to questions with anything just to complete the task (Johnson \& Christensen, 2010). This online survey gave me a sense of the issues and what was occurring in the schools and helped to structure questions for the interviews. Three mentor/PCT relationships were chosen, one from each school as a result of the online survey.

\subsubsection{Why use interviews?}

- Participants can use own words to describe their reality;

- Targeted and insightful approach; and

- Interviews allow flexibility and consistency across participants.

Each of the participants were interviewed for approximately forty minutes. I discovered that classroom teachers were busy people so interviews were fitted in before school, lunchtimes and after school. Yin (2009) describes interviews as having the strengths of being targeted and insightful. They focus directly on the case study and provide causal inferences and explanations. In this study the interview questions were focused on educative mentoring (see appendices $G \& H$ ), most questions were open-ended and the interview assumed a conversational manner. The interviews followed a set of carefully worded questions allowing the interviewee to provide fresh commentary about their experiences (Yin, 2009). These questions were used as a guide and were open to exploring avenues in other directions. An audio recording was made of each interview.

As a researcher I needed to be aware that interview data may be limited by the possibility of distorted responses due to my personal bias, anxiety, or simple lack of awareness, since interviews can be greatly affected by the emotional state of the interviewee or interviewer at the time of the interview (Patton, 2002). It was important for the interviewer to remain neutral with regard to the content of what was being said, but careful that the interviewee was willing to share the content (Merriam, 2009a). The interviewer also needed to be aware that data can be subject to recall error depending on the how the interviewee and interviewer react to each other (Patton, 2002). The recording of the interview, transcribing it and sending it to be checked by the interviewee for verification was helpful to eliminate bias. Interviews allow the interviewer to read body language of the interviewee, 
and ensure they are relaxed and comfortable before starting the interview is important. I purposely asked a warm up question to build rapport before commencing an interview (see appendices $\mathrm{G} \& \mathrm{H}$ ).

The purpose of the interviews was to investigate the mentoring process more deeply. I wanted to discover what mentors and PCTs saw as working well and what was not, and what the issues were for them.

\subsubsection{Why record a mentoring meeting?}

- To give the researcher a feel for the dynamics of the relationship;

- To triangulate with participants' expressed beliefs;

- To give insight into interpersonal behaviours; and

- To give an opportunity to examine what was happening in a formal meeting.

Data were next collected from the mentoring relationship through recording a PCT formal meeting. I was not present for the meeting as it is possible that an observer may affect the situation being observed in unknown ways (Patton, 2002). The mentor and PCT were asked to conduct the meeting as they usually did and I returned at a specified time. Observational data and recorded data is often constrained by the limited sample of the activity being recorded, in this case a meeting. Researchers need other data sources to find out the extent to which the activity is typical or atypical (Patton, 2002). Therefore interviews and documents were used to triangulate data.

The purpose of the recording was to listen to how the mentor and PCT interacted during a formal meeting. It was an opportunity to listen to all potentially relevant phenomena and gather extensive notes without specifying exactly what was to be detected (Johnson \& Christensen, 2010). This qualitative recording was transcribed and sent to both the mentor and PCT to check for accuracy.

\subsubsection{Why analyse documents?}

- To inform and enrich the data;

- To provide triangulation and credibility; and 
- An opportunity for participants to share documents.

The documents analysed consisted of meeting minutes, class observation feedback and PCT progress reports which were freely shared by the mentors and PCTs. The purpose for examining these documents was to further develop the context in which the mentors and PCTs worked and to contribute to a deeper understanding of what educative mentoring looked like in the New Zealand primary school.

Documents have limitations because they may be incomplete or inaccurate (Patton, 2002). Files and notes are known to be variable in quality and completeness, with much detail in some cases and virtually nothing in others (Yin, 2009). Document analysis, however offers a behind-the-scenes look at the programme that may not be in evidence during the interview or recording of the formal meeting.

\subsection{Credibility}

In the following section I describe my sources of evidence for credibility using Eisner's (1998) suggested categories: structural collaboration, consensual validation and referential adequacy.

Firstly, structural collaboration is used in educational circles for what is referred to as triangulation in other qualitative approaches (Johnson \& Christensen, 2010; Merriam, 2009b). It refers to using different sources of data to build a logical pathway for interpretation and evaluation of the research. In this study, data were collected via an online survey, interviews, recording of a meeting and analysis of documents. This "mustering of evidence" provided sufficient data to support my analysis and interpretation of the identified themes (Eisner, 1998, p. 111).

Next, consensual validity "is agreement among competent others that the description, interpretation, evaluation and thematics of the educational situation are right" (Eisner, 1998, p. 112). In the present study participants were sent transcripts of the interview and meeting of which they were part and were invited to check them for accuracy. The majority came back saying, 'it all looked good' and in two cases I had interpreted the initials ICAS and IKAN (in relation to numeracy) incorrectly. They were corrected along with other initials (VLN and 
NAPP). Figure 1 (page 30) clearly demonstrates how this checking was incorporated into the data collection. In the written report real names of participants and schools were not included.

Lastly the aspect of credibility or validity gauges the degree to which this study highlights aspects of teacher learning and is referred to as referential adequacy (Eisner, 1998). In this study, the reader is provided with the context, a description of the teacher relationships, interviews, meetings, and analysis of documents to give a picture of the impact of educative mentoring in relation to the Guidelines for induction and mentoring and mentor teachers (Education Council of Aotearoa New Zealand, 2015a). The qualitative approach to this data is discussed in the next section.

\subsection{How was data analysed?}

All data were analysed using a qualitative approach. This can be defined as classifying observations and dialogue into files or categories that are usually predetermined (Stake, 1995). The analysis of the data may be defined as a continuous flow of activity consisting of data reduction, data display and drawing conclusions (Miles \& Huberman, 1994). This was the process I used throughout the study. The simultaneous data collection was reduced to a manageable form, displayed tables enabling conclusions to be drawn more readily. Data analysis occurred from an online survey, conducting interviews, recording meetings and examining documents and I was aware of the importance of this continuous activity being part of my research (Merriam, 2009b, p. 170).

\subsubsection{Qualitative data process}

Saldana $(2009$, p. 3) defines a code in qualitative inquiry as, "most often a word or short phrase that symbolically assigns a summative, salient, essence capturing attribute for a portion of the data." While identifying codes within the data I used the five step method of familiarizing myself with the data, then generating these initial codes, searching for themes, reviewing themes and defining and naming the themes, before writing conclusions, as a logical and helpful progression (Braun \& Clarke, 2006, p. 87). I reflected by taking field notes while collecting data and during the transcribing process and also highlighted sections of initial significance which allowed for delving deeper into the interview and reflecting on thoughts and text. 
The first phase was becoming familiar with the data, carefully reading it and rereading it to totally immerse myself in the transcripts and field notes. The analysis process of discussion with my supervisor further provided an opportunity to articulate my internal thinking processes and also presented the opportunity to clarify emerging ideas and possibly make insights about the data.

The second phase was to generate initial codes by highlighting relevant sections of data for the three mentors and PCTs transcribed interviews and meetings and reducing these sentences to a code consisting of a word or short phrase. An example of this process can be seen in Table 6 on page 37. These were summarized in separate tables for both mentors' and PCTs' interviews, recorded meetings and documents. I ensured that I read the data several times attempting to use fresh eyes each time. I gradually built up a collection of codes which included initial codes and new ones as they emerged. Documents were treated the same way.

The third phase involved 'touching the data' (Saldana, 2009, p. 22) where hard-copy print outs of coded data were generated and highlighters were used to explore the data in additional ways. From this hands-on approach to the data, themes started to emerge. A theme is an outcome of coding, categorization, and analytical reflection (Saldana, 2009). This was an opportunity to think critically about what and why. Most importantly it was an opportunity to challenge my assumptions and recognize how much of my own thoughts, decisions and actions, might shape what I was seeing and how this might influence my study (Saldana, 2009). What do I see going on here? What did I learn from these notes?

The fourth phase was reviewing the themes and a final opportunity for analysis. The themes started to emerge as can be seen in Table 6. The themes emerging were the role of the mentor, the relationship between the mentor and PCT, and the practice of mentoring. These themes connect educative mentoring together. The practice of educative mentoring is not going to happen without the mentor firstly understanding what the role of the mentor is, then establishing the mentor/PCT relationship and finally when these are in place the practice of mentoring can follow in a deliberate manner.

Table 6 gives an example from the interviews, meeting and an observation document of the raw data, codes and emerging themes. The final phase is selecting extracts and relating the analysis back to the research question and literature. 
Table 6.

Example of coding

\begin{tabular}{|c|c|c|}
\hline Raw Data & Codes & Emerging themes \\
\hline $\begin{array}{l}\text { PCT interview } \\
\text { I know where those boundaries are, so we } \\
\text { are friends but I also know that she is my } \\
\text { mentor and she's also my boss, she's the } \\
\text { person I report to so there is that respect. }\end{array}$ & $\begin{array}{l}\text { Friend, boss, respectful, } \\
\text { positive approach }\end{array}$ & $\begin{array}{l}\text { Role of mentor } \\
\text { Relationship }\end{array}$ \\
\hline $\begin{array}{l}\text { Mentor interview } \\
\text { Teaching experience, good strong classroom }\end{array}$ & & \\
\hline $\begin{array}{l}\text { practice and a passion. Really have to have a } \\
\text { passion for this job otherwise don't be in it. }\end{array}$ & $\begin{array}{l}\text { Teaching experience, strong } \\
\text { classroom practice, passion }\end{array}$ & Role of mentor \\
\hline \multicolumn{3}{|l|}{ Recorded meeting } \\
\hline $\begin{array}{l}\text { I think you are amazing, well done! (Mentor). } \\
\text { Yes, I should do that. That's a good idea. }\end{array}$ & & \\
\hline $\begin{array}{l}\text { (PCT). That was a good call. Excellent, it } \\
\text { sounds like things are going really, really well } \\
\text { (Mentor) }\end{array}$ & $\begin{array}{l}\text { Sharing of ideas. Very Positive } \\
\text { comments. Can do no wrong. }\end{array}$ & $\begin{array}{l}\text { Relationship } \\
\text { Mentoring practice }\end{array}$ \\
\hline Observation document & RTC goals. Personal goals? & \\
\hline $\begin{array}{l}\text { Related to RTC. Team teaching occasion. } \\
\text { Mentor asking questions of class happenings. } \\
\text { Mentor model DATs-prompting, questioning } \\
\text { directive, praise, building confidence. }\end{array}$ & $\begin{array}{l}\text { Mentor participation in } \\
\text { observation. }\end{array}$ & $\begin{array}{l}\text { Mentoring practice } \\
\text { Role of mentor }\end{array}$ \\
\hline
\end{tabular}

\subsection{Ethics}

As the researcher I am aware that I am left to rely on my own instincts and abilities throughout much of the research (Merriam, 2009b). Deciding what is important and what should be attended to, is up to me. Therefore the risk of excluding data contradictory to my views must be considered. DeWalt and DeWalt (2002) contend that researchers must be aware of ethical issues at every stage of the research, for example when considering the questions, selecting the context, deciding on methods through to completion. Stake (1995) considers most educational data gathering as, "at least a small invasion of personal privacy" 
(p. 57). I was aware that interviewing and recording mentors and PCTs needed to be as relaxed and as comfortable as possible for them to feel they could be honest and that the "small invasion" was for a worthwhile purpose.

Participants had a right to be involved or not, and to be able to make that decision they needed to be fully informed about the project. I needed to ensure that the principals, mentors and PCTs all understood the aims of the research and they had a choice whether they wished to be involved or not. When seeking entry to each school I met initially with two principals at two schools and one deputy principal at the largest school. At the meeting I described the purpose of the research and its design. I then met with the mentors and PCTs and it was made clear to participants that they were free to withdraw from the study before the data analysis stage. As this was a small study, it was important that the participants knew that they would not be referred to by name and that all data would be anonymous and confidential. It was important to maintain confidentiality throughout the process in order to preserve the relationship between the two, and enable the participants to be honest. One of the main limitations around collecting data about the effectiveness of the mentoring process was that people like to portray themselves in a positive light and mentors may not be truthful when answering survey questions (Hobson et al., 2009). This was potentially delicate but I made sure I was asking about the process not the person, so they would not feel personally criticised. Since confidentiality was maintained they may have been encouraged to be more honest.

I ensured that the ethics of this study followed the Human Ethics Policy (Hattie \& Timperley, 2007). Approval for this research was granted by Victoria University of Wellington Faculty of Education Ethics Committee.

\subsection{Chapter Summary}

This chapter has outlined and explained the methods used in this study. Its purpose was to provide an overview of the research to enable the reader to understand the steps taken and to gain a sense of the context in which it was carried out. Educative mentoring takes place in a socially constructed context. The interpretive case study approach used to investigate mentors and PCT's beliefs and practices within the educative mentoring process 
enabled the research question to be explored in a manner that best fits the sociocultural perspective. 


\section{CHAPTER FOUR: FINDINGS}

\subsection{Chapter Overview}

The purpose of this chapter is to present the reader with a picture of the mentoring relationships from the data collected across the three mentor/PCT relationships. Through a description of what is happening the reader can gain an understanding of the mentoring in each relationship, how educative mentoring has been understood and implemented, and the degree to which educative components have emerged.

The first part of this chapter discusses the findings of the online survey. Each mentoring relationship is then described; firstly by explaining the context in which it took place, the school and background to the relationship; secondly by relating the mentor and PCTs expressed understanding of educative mentoring and their perception of the role; and thirdly by commenting on the evidence presented in the meetings and an analysis of the documents. What it all means in relation to how educative mentoring is enacted in each relationship is then discussed with a summary of the educative elements present.

\subsection{Findings from the online survey}

The purpose of the survey was:

- To build a picture of present mentoring practices;

- To identify potential participants; and

- To ask mentors to self-identify as mentoring in an educative manner.

The online survey provided background information and began to build a picture of mentoring practices with which to begin the interviews. It was anonymous and allowed the participants to be open and honest. I received a range of responses and a general sense of the issues. The final question gave the mentors the opportunity to self-identify as mentoring in the educative manner. Eight mentors and eight PCTs were invited to complete the survey.

Six mentors and seven PCTs responded to the survey.

The survey was broken into three parts (see appendix E \& F). It collected data from demographic information, agreement to educative statements and open ended questions as described below. 


\subsubsection{Demographic information}

The first part of the survey asked the mentors and PCTs for some demographic information, the range of which is summarized in Table 7. For example, mentors and PCTs gave details of their teaching experience. The majority of the mentors had been teaching for more than 10 years with one having taught for three to five years. Three of the mentors were new to mentoring having been mentors for less than 2 years with the others ranging from more than two years to more than ten years. Five of the PCTs were in their first year of being provisionally certificated and two were in their second year. Informal interactions with mentors were reported by PCTs as varying from weekly, a few times a week, daily and also to a few times a day, whereas mentors reported this to be daily or a few times a week. Formal interactions of (meetings and observations) were mostly weekly but one mentoring relationship met fortnightly and one PCT reported meeting monthly. These interactions were reported as being thirty minutes to an hour long and one being more than an hour.

\section{Table 7.}

Summary of Survey demographics

\begin{tabular}{|c|c|c|c|c|c|}
\hline \multicolumn{3}{|c|}{ Mentor Information } & \multicolumn{3}{|c|}{ PCT Information } \\
\hline \multirow[t]{2}{*}{ Years as teacher } & 3-5 years & 1 & Year as PCT & $1^{\text {st }}$ year & 5 \\
\hline & $10+$ years & 5 & & $2^{\text {nd }}$ year & 2 \\
\hline \multirow[t]{4}{*}{ Years as mentor } & $<2$ years & 3 & & & \\
\hline & $2-5$ years & 1 & & & \\
\hline & $5-10$ years & 1 & & & \\
\hline & $10+$ years & 1 & & & \\
\hline \multirow[t]{4}{*}{ Informal interactions } & Weekly & & & & 1 \\
\hline & Few times a week & 4 & & & 1 \\
\hline & Daily & 2 & & & 3 \\
\hline & Few times a day & & & & 2 \\
\hline
\end{tabular}




\begin{tabular}{llll}
\hline Formal interactions & Once a month & & 1 \\
& Fortnightly & 1 & 1 \\
& Once a week & 5 & 5 \\
\hline $\begin{array}{l}\text { Time frame for formal } \\
\text { interactions }\end{array}$ & $\begin{array}{l}\text { Half hour an } \\
\text { hour more than } \\
\text { hour }\end{array}$ & 3 & 4 \\
& 3 & 2 \\
\hline
\end{tabular}

\subsubsection{Agreement to educative statements}

The second part of the survey asked mentors and PCTs to indicate the extent to which their interactions met the guidelines for educative mentoring. The one to five scale asked mentors and PCTs to strongly disagree, disagree, neither agree nor disagree, agree or strongly agree with fifteen statements. The statements presented in the survey were based on the educative mentoring guidelines (Education Council of Aotearoa New Zealand, 2015a, pp. 25-26). Table 8 summarizes some of the statements and the rest can be seen in appendices E \& F. These results indicated that generally mentors 'strongly agreed', 'agreed', or 'neither agreed nor disagreed' with the statements. They espoused meeting the guidelines for educative mentoring and were using the components of setting goals, listening, using effective questioning, encouraging reflection, and inquiring into practice etc. On the other hand PCT results indicated less agreement with the statements. For example, four out of seven of PCTs 'neither agree nor disagree' and 'disagree', that 'during meetings my mentor spends more time listening than talking'. Two out of seven PCTs also indicated 'neither agree nor disagree' or 'disagree' that their mentor used effective questioning and also, that time is given for reflection on practice. There was therefore some difference in the mentor and PCTs perceptions of the extent to which the educative components were happening. 


\section{Table 8.}

Summary of educative component statements

\begin{tabular}{ll}
\hline \multicolumn{1}{c}{ Mentor statements } & \multicolumn{1}{c}{ PCT statements } \\
\hline My PCT sets their own goals & I set my own goals \\
\hline My PCTs goals are co-constructed with me. & $\begin{array}{l}\text { Goals are co-constructed with my mentor } \\
\text { teacher. }\end{array}$ \\
\hline $\begin{array}{ll}\text { During meetings I spend more time listening to } \\
\text { my PCT than talking. }\end{array}$ & $\begin{array}{l}\text { During meetings my mentor spends more time } \\
\text { listening than talking. }\end{array}$ \\
\hline $\begin{array}{l}\text { I use effective questioning to promote deeper } \\
\text { thinking to challenge my PCTs pedagogical } \\
\text { beliefs. }\end{array}$ & $\begin{array}{l}\text { My mentor uses effective questioning to } \\
\text { promote deeper thinking to challenge my } \\
\text { pedagogical beliefs. }\end{array}$ \\
\hline $\begin{array}{l}\text { Inquiry into learning and teaching is standard } \\
\text { practice. }\end{array}$ & $\begin{array}{l}\text { Inquiry into learning and teaching is standard } \\
\text { practice. }\end{array}$ \\
\hline $\begin{array}{l}\text { We engage in meaningful learning } \\
\text { conversations. }\end{array}$ & $\begin{array}{l}\text { I am aware that our learning conversations are } \\
\text { meaningful. }\end{array}$ \\
\hline
\end{tabular}

\subsubsection{Open ended questions}

The third part of the survey asked mentors five open ended questions and PCTs four open ended questions. These questions are discussed below.

\section{What formal and informal training have you had for the PCT mentor role?}

All mentors had received some sort of training within the school or from outside agencies in the past or more recently. There was a range of responses and three mentors had attended courses in the past and one had no formal training for the mentor role. Two schools had met during the year to discuss the expectations for mentors.

Mentor: I attended a course at the beginning of the year. 
Mentor: I have had no formal training as a mentor teacher, aside from reading the 2011 publication referred to.

Mentor: There have been a few meetings at school in which expectations and duties for mentors have been discussed. Our school has come up with a new PCT packet for us to refer to.

\section{In what ways (if any) has the way you mentor changed over time?}

Mentors made suggestions about how their mentoring had changed over time and three out of six mentioned it being more formalized and evidence based. One spoke of coming to terms with the role the second time she mentored, and having a learning phase. Another mentor was complimentary of PCTs and also empathetic.

Mentor: I now keep a documented record of weekly meetings.

Mentor: This is the second time I have been a mentor and feel that the first time I was learning...so hopefully more equipped to fulfil the role this time.

\section{In what ways has the relationship with your mentor changed over time?}

Four out of seven PCTs reported their relationships becoming stronger over time as their confidence grew and two reported relationships of collaborating as professionals and having professional conversations. One reported fewer meetings in the second year. Two other PCTs reported their relationship as 'not particularly useful' and in a 'rut'.

PCT: I feel more confident sharing my experiences and knowledge as time has gone by...sharing and collaborating as professionals.

PCT: I feel that I am at a sort of rut now, I keep asking myself 'Where to next?' and our meetings have become more just talking about 'what's on top'.

\section{How are the Practising Teacher Criteria incorporated into your interactions?}

All mentors and PCTs mentioned being familiar with the PTC. They were seen as an explicit part of their mentoring during meetings, observations and goals being linked to them. 
Mentor: I know them 'off by heart'. PTC focus is explicitly recorded for each term's two formal observations as the lesson's purpose, goal and focus.

PCT: My mentor often refers to the PTC. I have paper work to see exactly what is expected and my observations are based around the criteria.

\section{How has the blue handbook 'Guidelines for Induction and Mentoring and Mentor Teachers 2011' been incorporated into your induction programme?}

All mentors were aware of the Guidelines and had used them in some capacity, for example developing new school guidelines or just referring to procedures. On the other hand PCTs were not as familiar with them. One PCT made the suggestion that a handbook for PCTs would make it easier to understand the PCT role and expectations.

Mentor: We used this book extensively when reviewing our PCT mentoring systems at the beginning of the year.

Mentor: In the course we attended we looked at the guidelines and I found them to be easy to understand but I don't tend to refer back to them very often anymore.

PCT: I believe that I have a copy but do not refer back to it myself because I am so busy getting my head around teaching in general.

PCT: I know my mentor is aware of it however I am not sure whether it is something that is frequently referred to. It would be beneficial that a handbook for beginners was also available-this would make it easier to speak to my mentor about my role.

\section{How might the induction and mentoring programme in this school be improved?}

When asked about the induction and mentoring programme in their own schools four out of six PCTs were complimentary about their mentoring programme.

PCT: My school has a great mentoring programme. I feel that my school supports and guides me where necessary and helps me to be the best teacher that I can be.

However there was some frustration expressed in the following examples.

PCT: Better training for first time mentors so that all are on the same page and understand what their role is. I feel this is hugely important because as a beginner 
teacher I need someone who can mentor me, rather than someone who is unsure of their place. However, experienced mentors and new mentors do not formally meet about good mentoring.

PCT: I would have liked management to check in to see how the mentoring programme is working for me.

Some issues were raised for improving the programme.

Mentor: I feel that I would've been better prepared having taken a course or talked with experienced mentor teachers prior to the beginning of the year when I started with my PCT. I felt quite lost and wasn't really sure what to do.

Mentor: We are 'time poor', so alter expectations, regarding priorities, tasks, and time available.

Mentor: We have just recently reviewed our programme and updated documentation. We will likely review the changes at the end of the year.

\section{Do you consider yourself to be mentoring in line with the 'Guidelines for Induction and Mentoring and Mentor Teachers 2011' and in an 'educative' manner?}

The final question asked mentors to self-identify as mentoring in the educative manner. All six mentors said 'yes' they were mentoring in an educative manner.

These data started to build a picture of how mentoring was happening in the schools and alerted me to some issues that could be followed up on in subsequent interviews. For example it started to signal a difference in perception between some mentors and PCTs and concern around the lack of training was identified by both mentors and PCTs. Mentors and PCTs were aware of the elements involved in educative mentoring and these varied in the mentors and PCTs perceptions as to their presence. The next section continues to build this picture of educative mentoring by discussing each of the three relationships. 


\subsection{Relationship One}

\section{Mary (mentor) and Maggie (PCT) Kiwiland School}

The largest school in this case study, Kiwiland School, had four PCTs. A Deputy Principal (DP) was allocated the task of over-seeing the roles and responsibilities of the PCTs and their mentors. Guiding folders were issued to outline the process and provided documents to be used. These included master sheets for recording the focus of PCT meetings and use of PCT release/learning time, a goal sheet summarising the targeted students and their action plan, a reflective journal, and professional development log for recording any professional learning undertaken. There were also master sheets available for mentors to record class observations and feedback to PCTs. Mentors and PCTs met together each term with the DP to clarify any issues. Mary (mentor) found the larger staff gave her the opportunity to chat with other mentors.

Mentor: I have the advantage here it's a big staff, lots of colleagues and a number of us are mentor teachers at the same time. That's a form of in-house support and chitchat.

The DP met weekly with PCTs in pairs to oversee the programme. There was support from the DP for mentors as required but there were no formal interactions within the school or with mentors in other schools. Mary (mentor) would like the support to include meeting with other mentors in a more formal context.

Mentor: It would actually promote the role. It would give it professional validity, profile it, high-light it. I would get very good conversations out of it. Probably genuine, honest conversations, and sharing of scenarios. I would get a sense of comradery and motivation.

\subsubsection{Background to the mentoring relationship}

Mary (Mentor) and Maggie (PCT) were in the first year of this mentoring relationship. Their classes were in different buildings, they taught at different levels and they were in separate teams within the school. This meant that outside their weekly meetings and scheduled observations twice a term, they did not have easy access to each other. Both agreed that the formal part of the process was followed and meetings and observations 
worked well. Educative mentoring was espoused as happening and had the potential to be enacted but was not always happening within this relationship at this time.

Mentor: We will come together once a week and this is our time to do that and in that time we will discuss ...so there is a sense of purpose to it.

PCT: Inside our meetings, fine. We talk about things.

There were differing views emerging around the relationship. The mentor purposely wanted a formal and professional relationship in which to accomplish her mentoring.

Mentor: I decided it wouldn't be a relationship based on friendship. It's a professional relationship and it runs smoothly on those terms.

However the PCT had noticed this and was puzzled that the relationship seemed to stop outside these formal and professional interactions.

PCT: Outside meetings, we don't have a relationship.

It seemed that the PCT did want more than a professional relationship. However being a larger school she had other avenues within the school to solve issues and answer questions which could not wait until the next meeting.

PCT: I would often go and see someone in my own team if I had questions that I wanted answers for.

She felt well supported by others in her team and across the school. Her weekly meetings with the DP and another PCT were very supportive.

PCT: Have a meeting with the Deputy Principal every Tuesday. Sometimes all you need is a sounding board. That's incredibly helpful and I like that I have got that. The DP is at the end of the phone if I ever need her or email.

\subsubsection{Mentor's espoused understanding of educative mentoring and perception of the role}

Mary (mentor) had been in a position of tutoring in the past and saw her role as one of guidance and support and supporting Maggie (PCT) in becoming part of the school culture. 
Mentor: I helped to welcome her into the school, so it was built on a basis of warmth and accommodating and approachability. Like at the end of term one, I met her for coffee one afternoon in the holidays.

She offered a model of professionalism, and operated a high trust model. For example she expected that the PCT's planning would be up to date and did not check it.

Mentor: I see it as offering a model of professionalism, so guidance, a model of professionalism, support. Not micromanaging.

Mary had identified herself as mentoring in the educative manner in the initial survey. She was clear about educative mentoring growing teaching and learning practice.

Mentor: What sits behind it is growing practice and pedagogy. It sits around best practice and going beyond the day to day. It's about what are you doing and why are you doing it this way? As in education, to educate the person, to grow them up in terms of knowledge and skills and abilities.

She maintained that mentors needed to possess special skills and knowledge to be effective mentors that build the PCT's self-efficacy to be teachers.

Mentor: Mentors need to have a big personality in a sense that it is generous and a big heart and reassuring and growing good practitioners, the authentic practitioners not a carbon copy of oneself, instilling in young teachers the confidence to be themselves in the classroom, but within the bounds and the framework of understanding best practice and understanding of pedagogy and learning theories and constructs.

Mary believed conversations needed to be around teaching and learning and classroom practice and alluded to the importance of both the PCT and mentor being receptive and good at listening.

Mentor: There is the skill of being an active listener, a listener not a talker, and being receptive to the message and sensing the concern through what is not stated. 
She took the professional role of mentoring very seriously and saw it as a formal role of meeting the school expectations not just one of compliance. Having the conversations and conducting the activities of regular meetings and class observations were important to her.

Mentor: It's not a paper sign off...it keeps you professionally honest. Coming to it from a perspective of professionalism and integrity.

Mary was familiar with the Guidelines for Induction and Mentoring book.

Mentor: I think the guide book the Teacher's Council made has made a really good fist of it.

\subsubsection{PCT's espoused understanding of educative mentoring and perception of the role}

Maggie (PCT) recognized that a mentor and PCT needed to work alongside and acknowledged Mary (mentor) as a skilled teacher who provided critical feedback during observations.

PCT: I think they need to be problem solvers but also to be supportive of your ideas as well as I guess just being there as a sounding board. She is very good at jumping in and giving me advice on the spot as well...it's actually quite good to get that instantaneous feedback. Critical feedback for me is really helpful to reflect on my own practice and sort of match up with how I think I went.

She recognized the mentor's role in the process but also saw the bigger picture of others' involvement and accepted her own responsibility in the process.

PCT: I guess it is educating the person in their own ability to educate. But that education of the PCT comes from so many avenues. It comes from both, the kids, the parents, the staff but also the mentor teachers. So the mentor teacher has a role in that, but it is not just the mentor's role, within that. There are a lot of things that I do as a $\mathrm{PCT}$, I do my own reading.

Maggie emphasised the importance of the support she was given from other PCTs and teachers.

PCT: My team are incredibly supportive and any of the staff here you can go and ask questions of and that kind of thing. It is really good as well extra PCTs here cause we 
go out for lunch every so often and have a ugh moment. The DP is basically functioning as my mentor teacher in terms of the role of being, ok this is where you are at, let's do something about it, kind of thing.

She referred to the Guidelines looking for what she could expect from her mentor.

PCT: One of the things in the mentor teacher book, which I have read now.... it's supposed to be beneficial, beneficial for the PCT.

Maggie was self-motivated to take on professional learning and development.

PCT: I do my own reading, things change and new research is coming out all the time about ways of doing things. I really like going on courses and things like that.

\subsubsection{Mentoring activities}

\section{a) The meeting}

The purpose of the recorded meeting of Mary and Maggie was to look at planning and assessment and how it might be organized. The mentor began by checking that this was what the PCT wanted and expected.

Mentor: This afternoon, let's look at my planning and organization with a view to help you with yours, is that where we are going?

PCT: Perfect.

Mentor: Would you like to look at the actual planning and planning for delivery as opposed to assessment first?

PCT: I don't mind, why don't we do assessment first and then go to planning, since we have got it here.

For the rest of the meeting the mentor spoke about her planning and assessment and shared how her folder was set up. The PCT responded to her mentor sounding as though she wanted to please her with these comments. The following are examples of the affirming remarks made. It also seemed that the motions of showing and acknowledging the contents, were being performed as a task that needed to be completed.

Mentor: Cool, just like you...folder for everybody, clear file as needed, documentation, year level, you know dependent and task based. Just totally the 
same that you have. Also have separate clear files for the core curriculum, labelled reading, writing and maths assessments.

PCT: Yep.

Mentor: Usage of these is quite level dependent like for example I will, when I come to do them, pop their JAM assessment into this one individually.

PCT: Cool.

Mentor: But obviously I have a system of individual filing so it's one or the other.

PCT: Yep, sure.

During the meeting the mentor asked 30 questions, 28 of which were closed questions requiring a one or two word response. Many of the questions confirmed what was being shared.

Mentor: Now let's look at planning. Shall we do that?

PCT: Yeah.

Mentor: Mmm, and this...did I give you a copy of these?

PCT: Yeah, I have got that, it is at the back of the Numpa books so...

The mentor and PCT asked one open question each requiring a more lengthy response or explanation.

Mentor: In your team what was the discussion?

PCT: In that PCT is different so I don't need to do it, but I will talk to B because we are doing PCT folder stuff next Tuesday.

PCT: What are you writing in here?

Mentor: I just give, for example if it talks about, it's all of the indicators based on the learning progressions in the first year of school, so spoken language... I would say, prompted spoken language, captures...so I make reference to those indicators. It's making notes based on these criteria so that could be something that could work with you in the future. 
The mentor spoke for the majority of the time (62\%) the PCT for less (38\%). On this occasion there were no next steps or goals set for the PCT regarding her planning and assessment but she did learn about her mentor's planning. At the end of the meeting the mentor encouraged the PCT to get her folder set up and hoped this meeting had been useful.

Mentor: Was that helpful just physically seeing models of organization now?

PCT: Yeah, for sure makes me have something to work towards.

It was not possible to know what the PCT would do about her planning or how she reflected on what she had learned. The implications for this are discussed in the next chapter.

\section{b) Document analysis}

Document analysis included PCT feedback from a formal classroom observation and a PCT end of term progress report. Both these practices were fully recorded and related to the dimensions of the PTC.

\section{Mary's (mentor) observation feedback from Maggie's (PCT) guided reading lesson}

At the top of this document was written the current goal of criteria 6 of the PTC; conceptualise, plan and implement an appropriate learning programme. Feedback on the goal was written as 'what was effective, and what else would work in this guided reading lesson'. It was stated that 'Mary and Maggie took the opportunity to use this session as a team teaching occasion'. The instructions given to the students were noted but I am unsure if this was from the mentor or PCT. The mentor's interventions were summarised under the heading, what did you see me do today?

Mentor: The PCT saw the mentor involve the children by prompting and being directive. The mentor used questioning techniques regarding morphology (finding the music in words). The PCT enjoyed the mentor's use of praise to build confidence in children's perception of their abilities.

The question, 'Where to next from here?' was written, and recommended:

Mentor: Incorporating new and different strategies into the reading programme based on the PCTs own professional reading, such as Effective Literacy Practice, Teaching Reading Comprehension, and Teaching Reading Comprehension Strategies. 
It was not clear what these different strategies would be, or how, and when they would be implemented, or if they were recorded as a specific individual goal for the PCT to improve her practice. Tick boxes below this summary, were used to show observed good examples of teaching, such as a visible learning intention being used, and whether children were able to carry out the task. This was likely to reassure the PCT that she was on track. It's not clear whether this happened or not.

\section{Mary's (mentor) end of term progress report for Maggie (PCT)}

The end of term progress report made comments against each of the twelve criteria of the PTC. Although the one or two sentences were general in nature, examples of how these were being achieved were given. For example, criterion one; establish and maintain effective professional relationships focused on the well-being and learning of all akonga.

Term Two, 2014: Maggie interacts confidently with students, colleagues and parents. She is establishing relationships within the wider school community, as evident in her role on the School Gala Committee.

Term Three, 2014: Maggie engages positively with students, and is particularly mindful of the dynamics and learning needs of the younger boys in her class.

There seemed to be a dominance in referring to the PTC in both the observation feedback and end of term progress report. These performance goals were the focus in both cases and seemed to be quite separate from the setting and meeting of tailored individual goals of educative mentoring. The implications for educative mentoring are discussed in the next chapter.

\subsubsection{What it all means}

Kiwiland School required mentors to

- Observe and/or demonstrate in the classroom;

- Complete reports and observation documentation; and

- Attend courses and professional development for mentor teachers.

Mary and Maggie met regularly for lesson observations and lesson demonstrations; reports and observation feedback were completed. Mary had mentored other beginning teachers, was familiar with the Guidelines but had not attended any recent courses for mentor 
teachers. She was keen to support any formal interactions with other mentors, although this hadn't taken place. The formal requirements set out by the school of observing and demonstrating lessons and completing reports and observation documents were being met. However recent professional learning was not. The picture built up of the relationship suggested that Maggie (PCT) was puzzled by the formal relationship and perhaps this inhibited her development. She seemed to be open to a more informal relationship including more emotional support. This relationship appeared to be a formal professional relationship with the mentor in charge.

From the interview data it appeared that both Mary and Maggie had some understanding of 'educative' mentoring. Mary (mentor) identified that it was not only guidance, support and reassurance but also about having a conversation with the PCT about 'what' the PCT was doing and 'why'. Maggie (PCT) saw the component of critical reflection as paramount to educative mentoring. However during the meeting she was not given the opportunity to discuss or reflect on her own planning and assessment or to set a new goal for this. The mentor did most of the talking and the majority of the questions were of a closed variety. The setting of goals when examining documents were set around performance relating to the PTC rather than a more specific and personal teaching and learning goal for Maggie (PCT) focussing on the learning needs of the students and Maggie.

Some elements of educative mentoring with a mentor were happening in this relationship (See Table 3, page 20). Since this relationship was a professional relationship with the mentor in charge, and did not go beyond the formal meetings and observations there was little emotional support offered outside these formal interactions. However emotional support and becoming part of the school culture was present within Maggie's (PCT) team, meetings with the DP and other teachers within the school. There was little evidence addressing the students' learning needs during the meeting but this is not to say that this would not happen at other meetings. The mentor was an experienced teacher and this was acknowledged by the PCT during the interview. She was also team leader of another team and modelled a good vision of teaching as discussed with team teaching example during the observation. At this time the mentor took over the lesson and decided that the modelling of some approaches would be beneficial. Meetings and observations were taking place but the formal learning conversation revealed little evidence of inquiry into practice, deconstruction 
or co-construction. The mentor spoke for the majority of the time and asked only one open question. Personal goals were not in evidence during the meeting or in the documents.

In summary, in this relationship firstly, there was a geographical difference between classrooms and, secondly the mentor wanted it to be a formal relationship and, thirdly the PCT felt the need for more emotional support. There appeared to be a mismatch in clarifying the role for the mentor and what was expected, and meeting the needs of the PCT.

\subsection{Relationship 2}

\section{Janine (mentor) and Alex (PCT) Pukeko School}

Pukeko School had 167 pupils and one PCT. There was no school policy for induction and mentoring to guide the mentor or PCT. However the PCT maintained that the mentor was always available and open to talk, which provided her with the support she needed. The mentor had the support of the school management team when required.

PCT: She's got an open door policy it just makes it so easy. In some respects I just don't need much more than that, we can approach anything and everything when it happens.

Janine (mentor) had tutored many student teachers in the past and was presently on the Aspiring Principals Programme (APP). She recognised that some PCTs needed daily meetings or interaction to begin with, and some did not and therefore she was flexible in her approach with each new teacher. Supporting new teachers to 'come up with solutions themselves' rather than 'telling people this is how I do it why don't you do it', was singled out as important. Janine welcomed 'any opportunity to share and meet with other teachers that are in the same role' and although this had never happened in her role as a mentor, she could see that perhaps meeting up with both mentors and PCTs initially as a cluster of nearby schools would be of value.

\subsubsection{Background to the mentoring relationship}

Janine and Alex were in their second year of this mentoring relationship. They worked in classrooms which were next door to each other and their students were a year apart in age so there were many undertakings such as reading, writing and maths assessments, and topic 
planning in common. Both identified the effective part of the relationship as being the regular activities of meetings and observations.

Mentor: Definitely regular meetings, keeping it documented, regular observations so she can work on her practice which she does do and just keeping those lines of communication open.

The PCT appreciated that her mentor was doing her job in a manner that not only supported her development but also made her feel trusted and helped build her confidence. Both mentor and PCT acknowledged that this relationship went beyond being a professional mentoring relationship. The element of friendship became apparent.

PCT: We are friends but I also know that she is my mentor. Given me confidence actually in myself as a teacher. I actually feel like I am now more of a colleague than a student.

Mentor: I get her enthusiasm and energy...and I actually have a friend not just a colleague.

Janine (Mentor) was complementary of Alex's (PCT) skills of 'caring 100\% for each and every one her students as individuals'. She maintained that they had 'really good conversations' and were able to laugh at things and genuinely enjoyed working together.

\subsubsection{Mentor's espoused understanding of educative mentoring and perception of the role}

Janine (Mentor) initially said that she was unsure about what educative mentoring was, but given time to ponder, explained it as being a shared approach with both the mentor and PCT contributing their ideas and engaging in a conversation. She also identified it as a 'coaching type of role'. However she qualified that by saying 'contemporary coaching' which involved getting Alex (PCT) to think about solutions in context, what she wanted to achieve, and where she was going next.

Mentor: Rather than you sit there and I will tell you how it is done, it's you sit there and talk about what you are going to do. 
Janine (mentor) emphasised that being an educative mentor contributed to her own learning and understanding of herself as a professional. She was aware that she was also a learner.

Mentor: I think that looking for strengths within yourself or looking at the things that aren't strengths...that I can improve on in my own practice and my own professionalism.

The opportunity to share and meet with other teachers in the same role would be welcomed by Janine as she had no contact with other mentors. She suggested that meeting at the beginning of the year as a cluster would be beneficial. Although she was mindful of the Guidelines, she preferred a university resource publication she had been given a few years ago which related to mentoring and settling in of new teachers but not necessarily with an educative approach. It provided a checklist of a technical nature which ensured new teachers had been shown where resources were and initiated them into becoming part of a school culture.

Mentor: Really used that book (university resource)...more than the Teacher's Council one because it is specific and it gives you check lists and things like that.

Janine (mentor) saw her role as being available, and dealing with issues as they arose without having to wait until the next meeting. From the interview she explained that she was part of the APP, which was delivered in a framework of 'coaching'. This made her aware of the skills of 'listening, effective questioning, reviewing, and reflecting constantly' as key to her role as mentor.

Mentor: We don't want mini 'mes' everywhere. Alex can be asking me a question about how to deal with a situation and by the time she has finished telling me it she will have solved it herself.

\subsubsection{PCT's espoused understanding of educative mentoring and perception of the role}

Alex (PCT) explained mentoring as a 'huge role' and acknowledged Janine (mentor) as being part of her 'learning journey' to guide her in the process of developing as a teacher. She expected her mentor to give feedback, reassurance and ideas on improving her practice. She believed that the fact she and her mentor shared the goal of 'meeting the needs of her 
students' was of great support. However she was also looking to the end of the process and registration as a teacher. Alex felt safe and secure to try new approaches.

PCT: I've made mistakes as everyone does, but I also feel safe in knowing that I have made them that's okay, let's talk about it and let's move on.

Alex (PCT) saw the role of the mentor as someone who was 'open to listening to other peoples' ideas and being receptive'. This listening had developed into a 'reciprocal two way relationship' where she really felt listened to because her mentor asked questions, and showed a genuine interest which made her feel 'valued'.

While she had a long way to go in her teaching and learning it was important to Alex that she felt like a colleague with her mentor. She was respectful not only of her mentor but also of the existing knowledge in the school and utilised these other colleagues too. She confidently expressed that being a colleague with the added bonus of friendship was valuable.

PCT: Just having a good relationship and having a relationship like I have with Janine which is the approachability and openness and knowing that she's also a friend and not just a colleague.

The next section describes the mentoring activities of the meeting and supportive documentation to give a further glimpse into how this relationship might be educative.

\subsubsection{Mentoring activities}

\section{a) The meeting}

The meetings are more about Alex's (PCT) specifics and talking about things that happened for her with her students or her families or her learning. (Mentor)

The expressed purpose of this recorded meeting was to recap on the previous meeting and discuss events happening in the classroom and school. This included things such as Resource Teacher of Learning and Behaviour (RTLB) referral, a kindergarten visit, student behaviours, school programmes such as Te Reo language and looking ahead to the end of term. The mentor encouraged discussion by asking a question and listening, but also making suggestions which often expanded the topic. For example, there was evidence of a relaxed relationship where the mentor shared her knowledge about an administrative issue for a RTLB 
referral. This was a checking of the process but also demonstrated the relationship to be on an equal footing.

Mentor: You have been in contact with her caregivers about that PCT:

No I haven't at this stage because they are away.

Mentor: But they know that something... you have been meeting with them?

PCT: Yep, so that last meeting I discussed the RTLB referral and said that I would get that all typed up and ready which it is, and get her to look over that before I send it off, so that she is happy with it.

Mentor: Ok, and when are they back?

PCT: Back next week, so hopefully l'll be able to catch up with her straight away on the Monday.

Mentor: So you have already got verbal permission for that RTLB referral, so you don't necessarily need to wait for that to be sent off.

PCT: I think she has to sign the form.

Mentor: No you have got verbal permission so on the form, it says or verbal permission.

PCT: That's me not reading properly then.

They then brain stormed how to support two students. In one case this was how to help a student's learning and how his family could help. The other was in celebration of settling in a new student and identifying a strength in working independently while painting which took the form of a sharing dialogue. The PCT had thought about the students she wanted to talk about and had suggestions to make but was also receptive of suggestions made by her mentor.

PCT: But I discovered something, and I thought it was really cool. We did painting and we painted the lady bugs ...so I got the new kids to paint their lady bugs and he just took to it. I didn't have to give him any instructions. 
Mentor: How did he hold his paint brush?

PCT: Kack-handed, he actually held his paint brush a lot better than what he held a pen.

Mentor: Mmm, bigger paint brush?

PCT: Yeah and also because he held it further back and I think the application is completely different too.

Mentor: Bit more smooth and fluid.

PCT: Also he obviously really enjoyed doing it, something he hooked into, he felt quite engaged with and he actually had quite good success. I'll go and get it.

Mentor: That would be cool and if that's what we need to do to get him to write so for example I've had children in the past, where instead of a book they are writing on big bits of paper and really big felt tips pens.

During the meeting the mentor asked twenty-six questions, seven of which were open questions and challenged the PCT to think about her teaching and learning.

Mentor: What else have you got? Have you got anything else on top that's, how are you feeling now that we are coming to the end of the year, the roles, your responsibilities?

PCT: I actually feel really good about it and I'm really looking forward to next year to maybe developing those even further because l've more of a handle on how things work. It is almost like that whole honeymoon period of that first year where everything is a first and you have to work it all out and I know a little bit more now and I'm a little bit wiser.

Mentor: So are you talking about your responsibilities with te reo and art?

PCT: Yep, te reo and art also just my teaching responsibilities. Some things are actually really starting to click and make sense, they are so damn obvious and I know I say this all the time but I guess the more I do the more obvious things become like my writing and maths this week. My maths was creating groups and taking photos and talking about what we saw. 
The end of the above conversation 'and talking about what we saw' was perhaps a missed opportunity for deeper thinking about why and how this learning was valuable if it was. The PCT spoke for the majority of the time (59\%) and the mentor for less time (41\%). The open questions asked by the mentor encouraged the PCT to solve issues herself. The mentor asked one last question, "Did you have any feedback about your progress report last term?" This gave the PCT an opportunity to reflect on the mentor's report and discuss any issues but the PCT responded, "No." There was a sharing of ideas and listening to each other up until the end of the meeting. The implications for this are discussed in the next chapter.

\section{b.) Document analysis}

Documents included minutes from a meeting, feedback from a formal classroom observation, and a progress report based on observation and discussion.

\section{Janine's (mentor) minutes of a formal meeting}

The meeting minutes were brief and clearly laid out, with bullet points under the headings of: from last meeting; and what's on top?

The important dates and times and event decisions were recorded. Since these were the minutes for the recorded meeting discussed above, I am aware of the lengthy discussions which went on around each event. I know that students learning needs were discussed. The meeting minutes were brief but reflected the topics discussed and were recorded during the meeting. There were no goals recorded or set in the meeting minutes.

\section{Janine's (mentor) observation feedback from Alex's (PCT) maths lesson}

The analysed feedback was from a formal classroom observation maths lesson. The sequence of the lesson was described and summarised by the mentor. Comments were made about the lesson plan, introduction, management and activities used during the observed lesson. The teaching and learning strategies commented on included, using prior knowledge, modelling, questioning and setting expectations of behaviour. Specific feedback was given for routines and roles, for example:

Mentor: Great links to prior knowledge - yesterday 60 minutes in an hour, 60 seconds in a minute. You modelled on the board the jumps to get to 10 . Reminding children of what was expected in their noise levels. Had your WALT clearly displayed for children 
to access. It is fantastic to see the children getting used to routines and roles in the classroom.

The suggestions and general comments were encouraging and proposed the implementation of four strategies.

Mentor: Keep going back to the learning intention. As well as reminding children about expected noise levels keep congratulating children who are working at expected level and tidying up etc. could get the children to 'think in their heads' incorporate both imaging (maths) and not calling out (behaviour). Using a modelling book to record what you are doing as whole class learning is handy for children to access later on when doing independent work.

There was no evidence that the PCT was asked to reflect or deconstruct the lesson or if the suggestions would be implemented. However a general comment at the end of the report praised the PCT for her planning, the observed progress in the students' learning, and taking on board and implementing former suggestions. This led me to think that the new suggestions would be implemented but there was no new goal set.

Mentor: You are doing a great job by being firm and caring and you have moved the children in their content and knowledge-this has been noted by other staff members also. Your planning is up to date and shows progress. It has links to curriculum documents. You have shown that you are willing to take on suggestions and your classroom displays are colourful, interesting and relevant.

\section{Janine's (mentor) end of term progress report for Alex (PCT)}

The progress report was compiled from observations and discussions. Comments were made on seven of the twelve criteria under the RTC headings of professional relationships and professional knowledge. Points for further development were given for four of these criteria and left the PCT with issues to consider. For example planning and assessment:

Mentor: Files and curriculum documents are accessible. Planning has teaching elements incorporated. Anecdotal notes have been added, as are researching of resources for the syndicate and class. 
Mentor: Points for further development: Planning folder-dates need to be updated, a good point of reference for this is to think 'can a reliever pick this up and run with it?' Assessment folder: This is not up to date? Think of a system that best suits you.

The report was a summative report, and took into consideration observations and discussions. It was written in a positive, helpful way which gave direction and concluded with encouraging the PCT to 'carry on with reflections and adding them to your planning'.

\subsubsection{What it all means}

Pukeko School required its mentor to do the job of mentoring based on her own knowledge and skills as there was no policy in place to guide her or the PCT.

Janine (Mentor) and Alex (PCT) met formally with regular meetings and observations, and informally as they were in close proximity, taking advantage of the 'open door policy' of the mentor to discuss students, families and teaching and learning as it came up. Janine (mentor) had no contact with other mentors, but had resources on hand, the Guidelines and an older university publication for mentoring which she preferred and utilised to guide her. The added dimension to the relationship of friendship was mentioned by both the mentor and PCT along with mutual trust and respect.

Janine and Alex both had some understanding of what the 'educative' part of mentoring referred to. Janine (mentor) identified that it was a shared approach involving conversations as a platform to solve any issues. Alex (PCT) welcomed ideas and feedback from her mentor to try new things and build her confidence. The mentor asked a number of open ended questions which gave the PCT the opportunity to talk for the majority of the time and share her classroom experiences relating to her students, families and her own teaching and learning. The supplementary documentation of meeting minutes, classroom observation and progress reports were relevant, and made helpful suggestions for the PCT. However there were no personal goals related to the PCTs classroom practice in evidence.

Elements of educative mentoring were happening in this relationship (See Table 3, page 20). There was emotional support and Alex (PCT) felt like a colleague around her mentor and other staff members and was firmly part of the school culture. The conversations around the students confirms the focus was on the learning needs of the students. Janine (mentor) 
was Assistant Principal (AP) as well as an experienced classroom teacher and was presently part of APP. Alex (PCT) identified that a 'reciprocal two way relationship' had developed where she really felt listened to because her mentor asked questions, and showed a genuine interest which made her feel 'valued'. The reciprocal nature of the relationship demonstrated a shared understanding around the students' learning needs as demonstrated by the dialogue above (page $59 \& 60$ ). Learning conversations were taking place with some evidence of deconstruction, as described above. Reflection was encouraged by open ended questions. Janine (mentor) recognised that all PCTs had different needs. Weekly meetings quickly became fortnightly as Alex (PCT) proved herself to be quite capable of getting things done and taking on board new ideas and trying things out. It is possible that different needs may have needed to be addressed at these meetings. Alex (PCT) reported critical feedback being given in such a 'lovely way that made everything seem really positive even if it is in negatives'. Personal goals were not in evidence during the meeting or in the documents analysed. There were no personal goals set for Alex (PCT) during the meeting or in the documentation from the class observation but there were suggestions for development. The element of friendship was an extra that was mentioned by both mentor and PCT and the importance of this perhaps warrants more investigation and is discussed in chapter five.

\subsection{Relationship 3}

\section{Lisa (mentor) and Hannah (PCT) Tui Primary School}

Tui Primary School was a school with 407 pupils and had three PCTs. A new school document had been drawn up based on the Guidelines and PTC which were to be used in partnership. It was expected that the PTC would contribute to the documentation required to work towards full registration. These were shared with all mentors and PCTs at a meeting early in the year by the DP who had responsibility for overseeing the mentoring programme. Lisa (Mentor) at this school was aware of the clear guidelines but wanted some further check by management.

Mentor: Very clear guidelines. We need to have our management to come and check that we are doing the right things as well. We send copies of our minutes, perhaps a conversation might be good. 
The PCT used the terms, tutor (term used prior to educative mentoring implementation) and mentor interchangeably and utilised the school guidelines to make sure she was meeting the expectations.

PCT: Had a meeting with our DP and there was a new document formed a PCT document...outlining expectations and how many times we should meet and what we should do, expectations for observations and things like that...I refer to it to make sure I am doing what the school expects.

\subsubsection{Background to the mentoring relationship}

Lisa (Mentor) and Hannah (PCT) were near the end of the first year of this mentoring relationship. They taught classes where the students were a year apart in age and their classes were close to each other and within easy reach for informal chats. The mentor identified the relationship as being one of professional colleagues.

Mentor: I admire her strengths, I let her come to me a lot of the time. What do you need? How can I support you? I think it's a good professional collegial team.

The mentor and PCT both identified the informal discussions and that on the spot chats worked well for them. The PCT found the relaxed relationship gave her confidence which helped her cope with classroom observations.

PCT: I don't enjoy that (observation) but I have to get over myself but mostly it is probably an informal relaxed relationship which has worked for me confidence wise.

\subsubsection{Mentor's espoused understanding of educative mentoring and perception of the role}

Lisa (Mentor) explained educative mentoring as being 'reflective' and not just about what she knew but linking her knowledge and skills to pedagogy and professional reading and other people's theories. She then doubted this explanation, by saying 'I could be completely on the wrong track', but did know that it was 'not just sharing my recipes'. Lisa had reservations about whether she was doing the best job and felt something was missing.

Mentor: I don't know quite how to describe it. I do go in there and say: What can I do? How can I help? I feel redundant a lot of the time because I do feel that she is a very competent teacher. 
She saw her role as providing experience and direction for Alex and encouraged her to think for herself. Although Lisa, who was an experienced teacher, worried that she did not have the skills to meet Hannah's needs. This perhaps signals the need for training and professional learning.

Mentor: I get challenged at times as to how I am going to put something across if she does ask a question. I question every day, am I actually supporting Hannah as well as I could be?

There was little support in place when Lisa (mentor) tutored her first beginning teacher. She has attended a number of courses over the years and recently started an online course but did not complete it. Getting together with other mentors a few times a year and 'learning from one another' and creating a network within the cluster of nearby schools would be really useful. She was adamant that it would have to be constructive and being given release during teaching time would show management support for mentoring.

Mentor: As long as they don't become a session where it is just this happened, and this happened it has to be a constructive conversation it can't be just a venting session.

\subsubsection{PCT's espoused understanding of educative mentoring and perception of the role}

Hannah (PCT) identified the important elements of educative mentoring as inquiring into her practice and reflecting on her practice.

PCT: I suppose if it is educative mentoring it's about the teaching and the process and the looking for that whole inquiry type thing, looking at the practice and it's always reflective.

Hannah valued her mentor as an experienced teacher with strong curriculum and pedagogical knowledge. She thought mentors needed to be good communicators and a 'people person'.

PCT: I can go to my tutor teacher with whatever, even if it is a silly question. She has often said to me there is never a silly question. So I feel reassured. It would be terrible to have someone who I wouldn't feel able to go to with anything. If there was a barrier up that would be the worst. 
She acknowledged that she needed positive comments to build her confidence but she wanted more than this.

PCT: She tells me I am doing a good job and the feedback has been positive but sometimes that hasn't been enough, you're doing so well, you're brilliant everything is great.

Hannah (PCT) expressed the need for more discussion and challenge. For example she could be asked to justify her choices of teaching strategies. More questions like 'why have you done it that way?', rather than 'how has the week gone?' would be more helpful to her teaching and learning. Hannah felt it needed to be more about the 'way she was teaching' rather than the 'act of teaching'. This lack of challenge is evident in the recording of the meeting discussed in the next section.

\subsubsection{Mentoring activities}

\section{a.) The meeting}

The purpose of the recorded meeting was to give feedback from the recent reading observation and to discuss events happening in the class and school. The mentor talked about what she saw in the observed reading lesson and the PCT responded with one word or one sentence responses. Hannah (PCT) was not given time to reflect during the meeting, but she may have already done this after the observation. When the mentor said, 'it did seem you were doing a lot of talking', this seemed a good opportunity for Hannah (PCT) to deconstruct by describing and analysing why this was happening at this time, but this did not happen. Instead Lisa (mentor) said she did not need to justify why.

Mentor: What you were doing was absolutely fine and I put that down. I know I was supposed to be looking at this stuff but I was listening to your reading as well. The way that they were allowed to read independently for a wee while to allow you to go and roam. That's a really effective thing. That's very cool. It did seem that you were doing a lot of talking but I am taking a little snap shot, I'm looking at lots of things and I'm turning back and then I'm looking at lots of things so I don't think I'm being judgemental.

PCT: I did. I did do a lot of talking because they didn't kind of get. 
Mentor: And that's your reason and that's fine, don't justify, that's just what I saw and you have a reason for it, that's great. I did put down, do you use post-its?

PCT: No I haven't been.

Mentor: So just when you have got your book, that way you know exactly what...because when you pick up the book oh this is what I want, this is what I want to do. By the time you get to your reading group though that's all gone especially when you have had a hard group just before. So that option, particularly with that older group.

PCT: That makes sense, yep.

There were no new goals arising from the observation, set at this time. The meeting also attended to discussing student's progress and the mentor was complimentary of the PCTs role in that.

Mentor: I didn't put it in here but A she said, 'classroom', she stopped, she looked and she went back and changed it to 'room' which was correct so she is really visually checking and she has come on so far, well done.

PCT: Yes, she has.

Mentor: And she won't need reading recovery, she's twelve.

PCT: That's a thirteen, nearly thirteen.

Mentor: That's fantastic. That's absolutely huge and that's you.

Lisa (mentor) was an active listener when Hannah (PCT) shared an interaction with a parent and how to handle a gifted student. Hannah had the opportunity to deconstruct and explain the situation and present evidence she had observed and how she had approached the situation. The mentor was supportive and also considered next year for this student.

PCT: I had a meeting with H's Mum during the week, she approached me during the meeting just to see how she was doing socially in class. She has been a bit upset at home.

Mentor: Really? About what? 
PCT: Well she couldn't really elaborate but I said she was fine. She is upset and crying at home about school and I said that she is just not like that at all in class, not like that at all. So we had quite a good meeting and chat. And she's happy, she would sit up talking for that day and said, 'my friend D...' And at play time she was playing with $L$ and I watched her on duty and so I told all that to her Mum. She did say to me that $\mathrm{H}$ has come home and said that she gets her spelling words wrong so that $\mathrm{M}$ can catch up.

Mentor: Oh.

PCT: So I said okay. So she is very aware of where the other children are and I think she has made the connection that they are not where she is.

Mentor: So playing own abilities down, yeah?

PCT: Yeah, so I spoke to other teachers about it and I said to her Mum that we will just...make sure that I say to everyone that we do our best and be proud of our best. Like I said to her after the Maths test yesterday, I am so proud of you, you have done such a job, I can tell all your wonderful thinking and I want to see this at group time and you could help the group, make sure you tell me how you are working things out and you can help teach the other kids, and stuff like that so hopefully.

Mentor: Poor darling. So she is going through with children who are academically her peer?

PCT: Yeah, so I have...J, M and in there with $\mathrm{T}$.

Mentor: There may even need to be cross grouping with one of the year 3 classes.

At this meeting the mentor talked for $52 \%$ of the time and the PCT for $48 \%$ of the time. There were 38 questions asked with only two of them being open-ended. The PCT, asked, 'what does that mean I teach them next?' which enquired into her own practice. The PCT had stated that she would welcome the challenge to talk about her own practice and the actual 'act of teaching'. In the meeting she did do so, to a small degree but at her own initiative, not as the result of open ended questioning. At this meeting the mentor asked no challenging questions when there was perhaps the opportunity to ask, 'How else can we address gifted needs and 
why?' There was no co-construction of goals for where to next as a result of the classroom observation.

\section{b.) Document analysis}

The documents volunteered were minutes from two meetings. Unfortunately there were no observation documents provided.

\section{Lisa's (mentor) minutes for two formal meetings}

All items on the agenda were linked to the RTC which related to professional knowledge in practice and professional relationships and values. For example under relationships with students, parents and staff it was recorded that this was linked to RTC 1 (establish and maintain effective professional relationships focused on the learning and wellbeing of all akonga) and criteria 2 (demonstrate commitment to promoting the well-being of all akonga) and the minutes related to what was discussed about a student. The meetings covered curriculum competence, teaching and class management, planning and preparation and general. It was noted that the classroom observation was discussed under professional qualities but no next steps or action plans were included in the minutes. A column in the minutes related to action required by the PCT or mentor. It can be concluded that meetings happened and were recorded.

\subsubsection{What it all means}

Tui Primary School had a policy in place based on the summarised 12 bullet points from the Guidelines (Education Council of Aotearoa New Zealand, 2015a, p. 16). There were templates available for observations, meetings and RTC check list.

Lisa (Mentor) and Hannah (PCT) met formally with regular meetings and observations, and also found informal discussions helpful. Lisa wanted the school management to take more of an interest in what she was doing by giving feedback more often. She could see that a mentor cluster would be helpful by learning from one another but it had to be constructive. They both recognised that there was something missing in this educative mentoring relationship. Lisa (mentor) questioned whether she was doing enough for her PCT and she put this down to Hannah being very competent and not really needing her. Hannah (PCT) explained that all the positive feedback (while good for her confidence) was not enough. She 
wanted more discussion around her choices of teaching strategies and challenging questions like, why have you done it that way?

Some elements of educative mentoring were happening in this relationship (See Table 3, page 20). Informal interactions worked well for this relationship and Hannah (PCT) felt well supported with much positive praise. There was evidence that conversations were around the students and their learning needs as the dialogue above demonstrates (page 67-69). Lisa (mentor) was an experienced teacher who was doing her very best by being supportive and positive and was very good at passing on wisdom but was uncertain about what more she could do and didn't understand what was truly involved with being an educative mentor. She espoused being reflective about teaching and learning and 'not just sharing her recipes'. Hannah (PCT) also identified reflection as a key element along with inquiring into her practice as a major way to do this. Even though reflection was espoused as a key element to educative mentoring, it seems that it was what was missing in this relationship.

During the meeting the mentor asked more than 30 closed questions and she spoke slightly more (52\%) than the PCT. The mentor asked no open-ended questions. It was the PCT who asked the two open-ended questions.

This relationship can be considered as one of colleagues working in an informal relationship with informal discussions working better for the mentor but possibly not the PCT. The PCT was offered support from her mentor. The relationship was functioning quite well but with a missing element, that of the challenge of open-ended questions relating to classroom practice and inquiry.

Personal goals were not in evidence during the meeting or in documents. There was an absence of personal gaols set for Hannah (PCT) during the meeting. The implications of this will be discussed in the next chapter.

\subsection{Chapter summary}

This chapter presented the findings of the data from the online survey and across the three mentor/PCT relationships. The purpose of this chapter was to present the reader with a picture of the mentoring enacted in three schools. The online survey provided background information with which to begin the interviews. The mentors all self-identified as mentoring 
in the educative manner, but in fact educative elements were lacking in all mentoring practices. This was an interesting finding.

Each mentoring relationship was described by firstly explaining the context in which it took place, the school and background to the relationship; secondly by relating the mentor and PCTs espoused understanding of educative mentoring and the perception of the mentor's role; and lastly by explaining the activities of meetings and analysis of documents. A summary of each relationship was presented by considering what it all means. The implications of these findings are discussed in the next chapter. 


\section{CHAPTER FIVE: DISCUSSION}

\subsection{Chapter overview}

This case study was designed to investigate what educative mentoring looked like in the New Zealand primary school and to gauge how well the Guidelines for Induction and Mentoring and Mentors (Education Council of Aotearoa New Zealand, 2015a) have been understood and embedded by mentors into practice since 2011.

Given the evidence from the online survey, interviews, meeting and documentation I have found that the role of the mentor and what mentors understood their role to be was the critical element for establishing a relationship. The findings suggested that both mentors and PCTs were uncertain of what was expected of them. It appeared that there was confusion over the role which impacted on the relationship and both the role and relationship ultimately impacted on the practice.

In fact, moving from giving advice and guidance to one of co-construction suggests different beliefs about how learning happens. Just reading a book and, perhaps, attending a one day course does not ensure that educative mentoring will happen. It also requires an environment where people are asked to delve into their theories of practice (Timperley et al., 2007).

The themes identified through the findings were:

1. Role of the mentor

2. Relationship

3. Practice of mentoring

All three themes are important for deliberate educative mentoring to take place. The role of the mentor must first be understood, otherwise the developing relationship and the practice of mentoring could be quite different from the stated educative approach. The educative approach of mentoring is stated as 'dedicated time to guide, support, give feedback and facilitate evidence-informed reflective learning conversations' (Education Council of Aotearoa New Zealand, 2015a, p. 10). The mentor may have the dedicated time to guide and support and be going through the motions of meetings and observations and learning conversations, but this could be in the form of a relationship in the old sense of 'advice and guidance' of a tutor or being a wise and experienced practitioner. Unless the role of the 
mentor is clarified and understood by both parties, the relationship and practice of deliberate educative mentoring are unlikely to happen. The mentor needs to be supported by training and professional learning to facilitate the practice of educative mentoring.

I suggest that the three themes can be represented as the building of strong foundations, as a triangle demonstrates for the role of the mentor and understanding what is involved by both parties (see figure 2). To optimise results for deliberate educative mentoring the mentor must understand what educative mentoring is, and establish a relationship in order for the practice to occur. A combination of a personal and a professional relationship seems desirable for the practice of mentoring to take place. Once the two themes, the role of the mentor and the relationship are established as solid foundations, the practice of mentoring will be optimal.

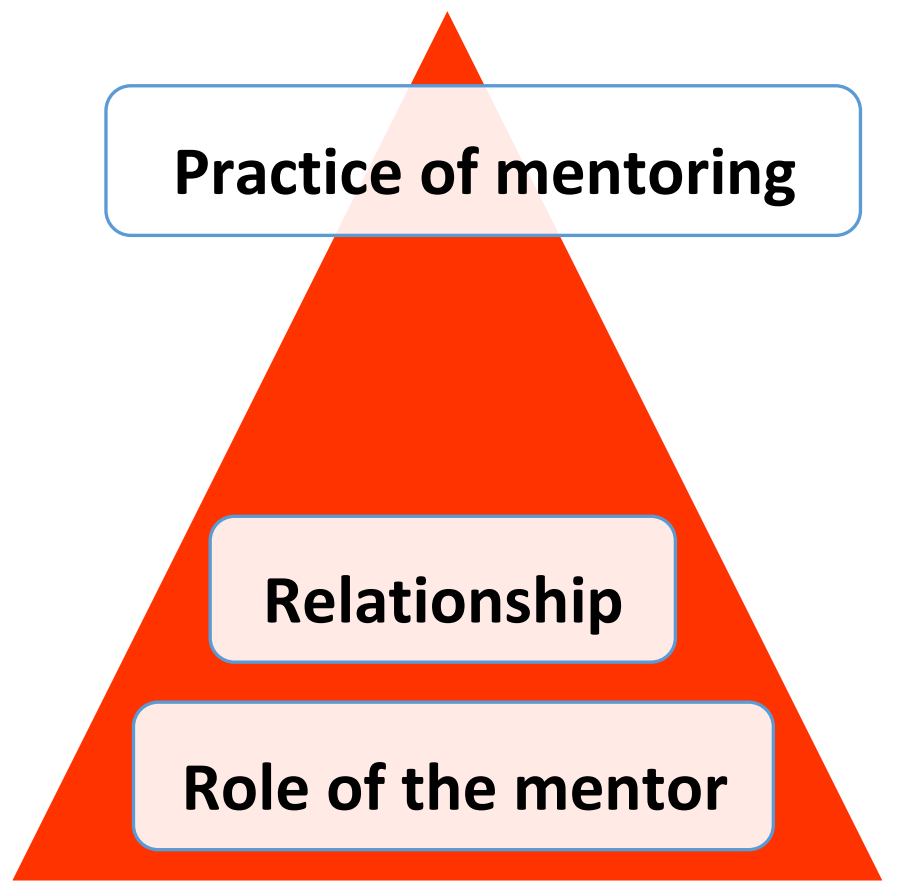

Figure 2. The strong foundations for deliberate educative mentoring

The discussion is organized under the headings of the role of the mentor, the relationship and the practice of mentoring.

In this study the role of the mentor is discussed by considering how deliberate educative mentoring is understood by the mentor and PCT and how the training and professional learning is received for each role. The relationship between the mentor and PCT is then addressed discussing the perceptions of the mentor and PCT in this case study and how the professional and personal relationship contributed to the mentoring. Finally, under 
the practice of mentoring, discussion is included of the activities, of informal discussions, formal meetings and formal observations with the potential to be educative. A recorded meeting used the lenses of speaking time, questioning, deconstruction and co-construction, to gauge the extent to which educative mentoring was present. An analysis of documents is presented with a focus on educative elements. The discussion in this chapter leads to a final chapter where I examine some of the issues needing to be addressed for mentoring to be deliberately educative.

\subsection{The role of the mentor}

The role of the mentor is dependent on how the mentor understands the concept of educative mentoring. There appeared to be confusion from participants about this. In the online survey the mentors and PCTs did agree that some of the elements were being used, however in the interviews although mentors and PCTs did use key words from the Guidelines, I sensed an uncertainty about what educative mentoring really meant. On one hand, mentors espoused having implemented educative mentoring but during the interview they were unable to articulate exactly what this was. Mentors alluded to elements of educative practice being present but the data from the meetings discussed later in the chapter suggest that while these were espoused, they were not often in evidence (Lipton \& Wellman, 2007).

\subsubsection{Understanding the concept of educative mentoring}

All mentors identified as mentoring in the educative manner in the initial survey. They espoused enacting educative practices but the findings suggest that this was not always happening. People often profess to be open to new learning, but their actions suggest a very different set of governing values or theories-in-use (Lipton \& Wellman, 2007). This may be explained by a need to avoid feelings of vulnerability or incompetence, and embarrassment (Kagan, 1990). For example, in relationship three (see page 65) the mentor acknowledged that she was unsure if she was doing enough for her PCT and wanted the school management to take more of an interest by giving feedback. This suggests she was feeling vulnerable and wanting to feel more confident in the role.

When looking at the mentors' and PCTs' understanding of the concept of educative mentoring, there was a perceived difference in the understanding of the process they were involved in. Hobson and Malderez (2013) establish the need to achieve a greater degree of 
consensus on the meaning and purpose of mentoring. A failure to create the appropriate conditions for effective mentoring at the relationship level can prove to be an obstacle to professional learning and well-being of PCTs (Hobson \& Malderez, 2013).

During the interviews mentors saw mentoring as supporting and guiding, but found the word 'educative' more challenging. One mentor stated that educative mentoring was about growing practice and pedagogy and another stated reflection on theories from professional reading, and the third identified the sharing of ideas around teaching and learning which involved conversation rather than telling.

On the other hand, PCTs discussed and used words and ideas that were involved in educative mentoring, for example, inquiring into practice, being reflective, and receiving feedback. When talking about the word 'educative' the PCTs appeared to have more understanding and clarity around the concept. Perhaps PCTs were used to these ideas and the theory that sits behind an educative approach, for example, co-constructing learning, reflection and inquiring into practice were all mentioned. This could be due to more recent exposure to these terms at university during initial teacher education courses.

This difference in understanding suggests a lack of clarification around what would be involved in this process from the start of the mentoring relationship. Mentors had previously been involved in a programme of 'coaching and telling' and were now expected to work 'alongside and co-construct learning'. Time and support are needed to understand a new concept and bring about change. To achieve this transformation to educative mentoring it is necessary to reconsider existing views, challenge the status quo and question the taken-for granteds within the work environment (Brookbank \& McGill, 2006; Mezirow, 1991). This study revealed that there had been limited time and support to practice the skills required by mentors for educative mentoring.

An implication of this difference may need to involve the mentor and PCT in a joint learning session about what the process involved, at the start of the mentoring relationship. It would be valuable for mentors and PCTs to undertake professional learning to clarify the roles and expectations of both the mentor and PCT. In a recent study by Patterson (2013) it was found that mentors, PCTs and principals had different expectations of what was involved in educative mentoring and Patterson recommended that someone be appointed to lead the 
programme. In the present study the two larger schools had implemented a leadership role within senior management for the mentoring of PCTs and met with mentors and PCTs at the beginning of the year to share policy and processes. This meeting was an opportunity to establish expectations, such as regular meetings and observations but perhaps needed to go a step further, to clarify what educative mentoring involved.

As will be discussed in further detail below, what is espoused as educative mentoring is not always being enacted, and while mentors are performing a helpful task with 'advice and guidance' being given, educative practices were not always visible within the meetings. Similarly, another study found mentors to espouse that educative mentoring approaches were happening when surveyed, but evidence of these approaches was rarely visible in the case studies (Cameron et al., 2014). The Guidelines have been in place for more than four years and one day workshops offered. However the mentors did not demonstrate an understanding of what educative mentoring really meant. Without in-depth professional learning opportunities mentors are likely to revert to 'telling' the PCT what to do, rather than ensuring the learning is tailored to the individual teacher (Moir, Barlin, Gless, \& Miles, 2009).

\subsubsection{Mentor training and professional learning}

From the start I was alerted to the issue of mentor training from the online survey. From the six mentors surveyed and then from the three interviews it become apparent that training and professional learning was an issue. In relationship three the mentor felt uncertain about how to help her PCT and the PCT felt that something was missing which could have easily been resolved by training (see page 65). It was not a lack of time or experience or emotional support on the part of the mentor. It does suggest that an experienced, supportive teacher does not automatically make a mentor (Feiman Nemser \& Carver, 2012; Thornton, 2013a). There was a lack of skills and knowledge around engaging the PCT in an effective learning conversation and asking open questions.

Mentors had heard the words 'educative mentoring', seen the guidelines, and had had the opportunity to attended a one day course. However being busy teachers with other positions of responsibility, they had not attended. One mentor had started an online course, but did not have the time to go beyond the first few sessions. 
Mentoring programmes are there to benefit PCTs but good programmes also support the growth for those doing the mentoring (Hanson, 2010). Developing mentors involves learning new and complex skills and understandings that go beyond those needed to be an exemplary teacher, and these skills are rarely intuitive (Achinstein \& Athanases, 2006; FeimanNemser, 2014; Feiman-Nemser \& Carver, 2012; Hanson, 2010). The New Teachers Centre (NTC) provides comprehensive professional development for mentors in a full time programme. The NTC is based in Santa Cruz California and has satellites in other states which develop teachers as leaders (Hanson, 2010; Thornton, 2013b). Their competence in the classroom is converted into confidence as leaders. The skills of building relationships, collaborating, articulating teaching strategies, analysing evidence and supporting teacher growth everyday are practiced (Hanson, 2010, p. 80; Thornton, 2013b). This is supported by Orland-Barak and Hansin (2010) with an emphasis on the right amount of challenge. The deepening of knowledge, the need to question and participate in dialogue are mentor skills to be practiced for exemplary mentors to emerge (Orland-Barak \& Hasin, 2010, p. 435).

Professional learning for mentors is absolutely essential (Feiman-Nemser, 2003; Feiman-Nemser \& Carver, 2012). They contend that teachers rarely have the opportunity to observe colleagues and rarely have the chance to give critical feedback. These are important skills required for mentoring. In a recent interview Feiman-Nemser (2014) explained how good teachers can pull off a seamless performance in the classroom, but the good mentor needs to take that performance apart, break it down, talk about it using deconstruction and co-construction, model it and help someone else learn from it in an integrated principled way. These are some of the skills which need to be embedded for educative mentoring to take place.

More training for mentors in this study will further embed educative mentoring elements. The crucial concern here, is that mentors have not been treated as learners even though the Guidelines explain the importance of mentors being recognized and resourced (Education Council of Aotearoa New Zealand, 2015a, p. 11). Perhaps teachers were expected to have enough skills. As discussed educative mentoring is a new idea and is a shift from being a tutor. Time for mentors to critically reflect about what educative mentoring means along with quality training, and ongoing professional learning is called for. Mentors are caring and supportive people but educative mentoring is a big step for what is involved. The learning 
involved has been underestimated. The mentor must understand their role and want to do it. In this study the mentors and PCTs were working together, but it was not always in an educative manner. A relationship had been established and is discussed next.

\subsection{The relationship}

The degrees of friendship in the relationships in this study ranged from a clearly stated professional relationship, to a mentoring relationship which included a professional relationship alongside a declared friendship, and to a preference for informal discussions and support, with little challenge to practice. All had the potential to include educative elements as well as the elements of emotional support. PCTs were supported to become part of the school culture. Opportunities for regular meetings were provided, observations were occurring and conversations were in evidence (see Table 3, page 20). The 'digging down into practice' for the PCT and providing critical feed back in the form of challenging questions, deconstruction and co-construction were lacking. The presence of both a professional and a personal relationship to some degree seemed desirable.

\subsubsection{The Professional relationship}

In relationship one there were few informal interactions. The mentor preferred a professional relationship and 'decided it wouldn't be a relationship based on friendship.' There was the potential for educative elements to be in evidence in this professional, formal relationship. Unfortunately the PCT found this lack of informal interactions puzzling as discussed in the previous chapter (see page 47). Rowley's (2006) four levels of skill development places this PCT at level two as a disillusioned learner. She has moved from level one and being an enthusiastic beginner who needed technical advice to requiring feedback and support. Feedback from observations happened but she was puzzled by the lack of informal support and friendly interactions outside the formal interactions. Level three involves the teacher as a reluctant learner who needs encouragement. Level four is the independent achiever who needs autonomy to get on with the job of teaching but understands peer dialogue to be essential.

Hargreaves (2005, p. 279) points out that good teaching is charged with 'positive emotion, good teachers aren't just well-oiled machines, they are passionate about ideas'. This makes people vulnerable if they are emotional, therefore mentors recognising that different 
PCTs require varying degrees of support and responding appropriately is important. There is a need for support within the relationship and this is usually two way. But it is the mentor who sets the tone for the mentoring relationship as they are the experienced teacher with the potential knowledge and skills to mentor. Hobson and Malderez (2013) consider the term 'judgementoring' as being judgemental mentoring where mentors operate as assessors and gatekeepers of the process and this may stand in the way of effective mentoring at the relationship level. This suggests a power imbalance. This may have been present in relationship one where there was little informal or friendly banter. The relationship was stated to be a professional one, as decided by the mentor but this did not appear to work for the PCT. It appears that PCTs have different needs, in fact some might need the support that happens with a personal relationship as stated with the Rowley's (2006) four levels of skill development. This personal relationship was not present in relationship one. The consideration of a power imbalance is perhaps an area requiring more thought and investigation.

\subsubsection{The Personal relationship}

The issue of friendship came into relationship two with both mentor and PCT declaring that they were lucky to have a friend as well as a colleague. De Lima (2001) contends that there is a greater likelihood of new and unexpected alternatives emerging from interactions if interactions have not previously involved deep levels of personal commitment. He recommends 'forgetting about friendship' as friends validate rather than challenge ideas and ways of doing things. The promotion of cognitive conflict is needed within educational processes, such as educative mentoring to bring about change (De Lima, 2001). This calls into question the concept of friendship and how helpful relational skills really are to bringing about change. In relationship two, the mentor and PCT were not friends initially but began with a professional relationship in the first year of the mentoring relationship. It appeared that friendship had developed alongside the mentoring relationship. There were some elements of educative mentoring happening in this relationship and the mentor engaged with the PCT as a co-learner. In this case a personal relationship had developed alongside the professional relationship despite De Lima's (2001) warning of forgetting about friendship, this appeared to be a profitable outcome for both mentor and PCT. 
Whether friendship is present or not, being intellectually challenged is key (Mezirow, 1991). In relationship three there was little challenge, and the PCT recognised this as 'wanting more, something missing' and also the mentor 'wanting to do more and be more helpful' but not knowing what that more was. What matters is the type of discourse which occurs when teachers are working together, whether it is an informal or formal discussion, with or without friendship present. By simply discussing and sharing ideas about various instructional methods without critically analysing 'why', means mentors choose to teach in a certain way, and limited learning will result (Mezirow, 1991). It seems that teachers are more inclined to reflect on 'how' they teach rather than on 'why' (Kreber, 2007). However, unless the 'why' is addressed in an educative mentoring relationship, transformational learning will not occur (Mezirow, 1991). This suggests that the mentor requires a level of expertise and the skills to facilitate such a discussion. It's a significant shift for mentors, for example, to understand the importance of the 'why' questions and to use them. In relationship three it was the challenge to practice that was missing for the PCT. The practice of mentoring is discussed in the next section.

\subsection{The practice of mentoring}

In this study mentors and PCTs perceived the following activities as part of the practice of educative mentoring:

1. Informal discussions

2. Formal meetings (including learning conversations)

3. Formal observations (from oral and written feedback)

These activities are examined for educative content and are discussed below.

\subsubsection{Informal discussions}

The online survey gave an early indication that informal interactions were taking place and that PCTs saw these as taking place more often (daily or a few times a day), than mentors acknowledged them to be. Possibly PCTs saw this as establishing a friendship whereas the mentors found the practice of mentoring initially a more professional relationship.

Informal discussions were found to work well in relationship three. This could have been a personal choice or an element of the relationship the mentor found effective. The 
content of these interactions is unknown but according to her it was helpful as access between classrooms was easy and their relationship was relaxed and respectful of one another.

Mentor: I think our informal discussions work better for us, we have our meeting weekly or fortnightly...it is that on the spot discussion that works for us.

However, contemporary research suggests that those with structured and regular programmes appeared to offer benefits over more informal approaches (Cameron et al., 2014). They reported a greater understanding of what quality teaching looked like in practice and a stronger focus on developing teacher expertise than those reporting informal or flexible programmes. Informal and flexible programmes maybe characterised by just in time handy hints' and 'managing the immediate' as described by the advice and support given by a tutor (see page 20). This may be characterised by less involvement in formal interactions where the opportunity for deconstruction and co-construction are provided. In relationship three the dominance of informal interactions may be standing in the way of the PCT experiencing more of a challenge around her choices of teaching strategies. Brookbank and McGill (2006) emphasise that the casual or informal conversation does not provide the necessary safety needed for reflective dialogue leading to transformative learning. The intentional dialogue of deconstruction and co-construction that occurs in the formal interactions of mentoring is necessary (Brookbank \& McGill, 2006). The PCT had every opportunity to build her confidence and competence with many informal and positive interactions but was a 'disillusioned learner' at the skill development level two, needing feedback and support in an intentional way (Rowley, 2006). Emotional support was in evidence but the feedback needed for educative mentoring was identified by both mentor and PCT as needing to be more challenging.

The next section summarises the activities being enacted in mentoring meetings. Close scrutiny is given to the educative characteristics of speaking time, questioning skills, deconstruction and co-construction (Education Council of Aotearoa New Zealand, 2015a, pp. 25-26) when looking to see if the PCT meeting had the potential to be a learning conversation with educative elements.

\subsubsection{Formal meetings - the meeting in action}

Educative mentoring is expected to occur: 
When an experienced colleague provides dedicated time to a PCT to guide, support, give feedback and facilitate evidence-informed reflective learning conversations. (Education Council of Aotearoa New Zealand, 2015a, p. 11)

The online survey gave an early indication that regular weekly meetings were taking place and were between thirty minutes and an hour. The purpose for the meetings in this study varied from, sharing practices, giving feedback from an observation, daily planning, assessment and discussing school events. The PCT meeting was an opportunity for a learning conversation to take place. What I was looking for were elements of educative mentoring, and an analysis of the recorded meetings was used to capture this. It must be acknowledged that a one off scrutiny of a mentoring meeting is inadequate in providing reliable data on which to base conclusions about the presence of educative mentoring. Nevertheless narrowing down the examination to focus on four of the twenty-three characteristics of educative practice as provided by the guidelines (Education Council of Aotearoa New Zealand, 2015a, pp. 25-26) offers a lens for analysis. The lenses of; the PCT is listened to, asking open questions, deconstruction, and co-construction, are intended to capture the mentor 'engaging the PCT in a serious professional conversation'. The concept sitting behind these lenses of deconstruction and co-construction is that the mentor and PCT are building knowledge together and are working as co-learners (Bandura, 2004; Bereiter, 2002; Feiman Nemser \& Carver, 2012). These lenses are defined as:

- PCT is listened to: beliefs are unpacked, mentor speaks less

- Mentor engages with PCT as a co-learner: questions that enquire into and challenge practice are common

- Deconstruction: allows PCT to describe what happened, analyse and discuss the evidence, examine akonga ${ }^{3}$ understandings and outcomes

- Co-construction: design next steps, set new goals and understand the implications for children and learning

(Education Council of Aotearoa New Zealand, 2015a, pp. 25-26)

\footnotetext{
${ }^{3}$ Akonga is a Maori language word for a learner in a range of settings.
} 


\section{What was happening in the meetings?}

By looking closely at what happened during the meeting it can be seen that the exchanges related to emotional support (see Table 3, page 20). There were many examples of support, advice and affirmations given during all the meetings. Although practices of emotional support and guidance and becoming part of the school culture are necessary to build a foundation for a healthy mentoring relationship they reflect only a few elements of educative mentoring (Cameron et al., 2014). These are likely to have already been present in the 'advice and guidance' model when the mentor was operating as a tutor. It is therefore understandable that these are continued.

For example, in relationship one the mentor gave advice around how she set up her planning and assessment folders. The mentor talked the PCT through her folders and the PCT affirmed what the mentor showed as useful with comments such as, "That's ideal, straight forward and organized. Perfect. Cool, sure." A mentor whose dialogue is in the form of a monologue about how things should be done, with which the PCT is obliged to agree (which seems the case here), is unlikely to promote reflective thinking and learning for improvement (Brookbank \& McGill, 2006).

It seemed that the PCT wanted to please the mentor. This type of conversation may reflect power differences and can inhibit learning (Brookbank \& McGill, 2006). The elements that were missing were: challenge for the PCT to explain what she already had in place and why it was not working, there was no sharing evidence by the PCT. The end of the meeting would have been a good time for the PCT to clarify what she would implement to improve her planning and why, instead the meeting concluded with the following dialogue.

Mentor: Was that helpful just physically seeing models of organization now?

PCT: Yeah, for sure makes me have something to work towards.

Mentor: Makes it quite practical. That's us done. There we go.

This would have been a perfect opportunity for a new goal to be set around the PCTs planning, by deciding what she would implement and how, when and why. This will be further discussed under deconstruction. 
In relationship two, the meeting began with a review of the last meeting minutes and checking that things had been followed up on.

Mentor: ...from the last meeting and if there's anything, Sue's hours... all done

PCT: And that's working really well actually.

Mentor: Awesome, so it's RP \& DP. OK. Cool, we don't need to worry about that one

There was guidance and working alongside each other to confirm an RTLB referral. The following dialogue addressed any concerns and lead to checking the form online so both were sure about the process. This might also be seen as the mentor checking on the PCT in this process.

Mentor: You have been meeting with them?

PCT: Yep, so that last meeting I discussed the RTLB referral and said that I would get that all typed up and ready which it is, and get her to look over that before I send it off, so that she is happy with it.

Mentor: So you have already got verbal permission?

The mentor asked some open questions and the PCT was given the opportunity to deconstruct and describe what happened and how she felt about situations. There appeared a lack of real digging into practice and asking the 'why' questions. However there was natural dialogue between the mentor and PCT. The PCT was listened to and things were clarified. The PCT gave examples.

Mentor: What else have you got? Have you got anything else on top that's, how are you feeling now that we are coming to the end of the year, the roles, your responsibilities?

PCT: I actually feel really good about it and I'm really looking forward to next year to maybe developing those even further because l've more of a handle on how things work. It is almost like that whole honeymoon period of that first year where everything is a first and you have to work it all out and I know a little bit more now and I'm a little bit wiser.

Mentor: So are you talking about your responsibilities with te reo and art? 
PCT: Yep, te reo and art also just my teaching responsibilities. Some things are actually really starting to click and make sense, they are so obvious and I know I say this all the time but I guess the more I do the more obvious things become like my writing and maths this week.

In the third relationship the lack of challenge was missing in the meeting. In this meeting the mentor gave feedback from an observation. Feedback was very positive with many affirmations, but there was no opportunity for the PCT to deconstruct or be challenged by the 'why' question, why did you decide to do it that way? What was your thinking?

Mentor: What you were doing was absolutely fine and I put that down. I know I was supposed to be looking at this stuff but I was listening to your reading as well. The way that they were allowed to read independently for a wee while to allow you to go and roam. That's a really effective thing. That's very cool.

Using praise exclusively as feedback is known to be rarely effective and does not enhance learning (Hattie \& Timperley, 2007). The opportunity for the PCT to unpack and discuss beliefs around her purpose for leaving the students to read independently would've given the PCT the opportunity to speak more and deconstruct learning.

It was difficult to find the end of the observation feedback as there was no discussion about where to next or setting a new goal to improve practice. The conversation became about students and how they were getting on, school reports and an interaction with a parent.

\section{Who was doing the talking?}

The mentors in two of the meetings did most of the talking ( $62 \%$ and $52 \%$, see Table 9). In the third meeting the mentor spoke less (41\%) and the PCT had the opportunity to talk more (59\%). Educative mentoring advocates that the PCT is listened to with time to unpack beliefs and the mentor should speak less (Education Council of Aotearoa New Zealand, 2015a, pp. 25-26).

A belief can be defined as a feeling of being sure that someone or something exists or that something is true (Merriman-Webster, 2015). Some teachers, for example, may not have the language to describe their beliefs, or may be reluctant to express what they perceive to be an unpopular belief (Kagan, 1990). While a person may state that "I believe..." this may not 
always be accurate, being influenced by a number of factors. Therefore, the unpacking of beliefs must be inferred by what individuals say and do. The unpacking of beliefs was not found to be prevalent at this time during any of the meetings.

Mentors espoused being good listeners, one said she was a 'listener not talker' but in fact all spent a significant proportion of the time talking and not doing a lot of listening. This is closely linked to asking questions and is discussed next.

\section{Questioning}

Questioning and active listening skills are as fundamental to educative mentoring as they are to teaching and learning in the classroom; easy to list but hard to achieve (Cordingley, 2005). Powerful and effective questions are purported to 'trigger' thinking, ignite inquiry, establish dialogue and evoke creative thinking (Bishop \& Glynn, 1999; Vogt, Brown, \& Issacs, 2003). They are expected to engage learners on a variety of levels of thinking. Mentors who are able to discuss the practices going on in the classroom (deconstruction), and ask the right questions in a non-threatening and analytical way have a valuable skill in being able to participate in the change process (Blackman, 2010). The place for questioning comes after listening to what has been said, without judgement, so that some confidence and trust can be established (Brookbank \& McGill, 2006, p. 184).

In this study, the use of open and closed questions were examined. Closed questions are those that can be answered by 'Yes', 'No', or one word, or a phrase. These questions may close down willingness to speak or speculate, as they save people from having to think and therefore limit opportunities for reflection (Thomas \& Smith, 2004; Whitmore, 2002). These questions have a place but are not considered desirable for educative mentoring.

Open questions are those beginning with 'What', 'Where', 'Why', 'Who', 'How' and 'When', and display natural curiosity in understanding how and why things work and what they mean (Brookbank \& McGill, 2006; Thomas \& Smith, 2004; Vogt et al., 2003). The 'why' questions are likely to be ineffective unless carefully crafted or until relationships are resilient (Vogt et al., 2003). They can easily evoke a defensive response or be perceived as an intensive interrogation and may cause the learner to lose their train of thought (Brookbank \& McGill, 2006; Vogt et al., 2003). On the other hand when the 'why' question comes from genuine curiosity, for example, "I wonder why that has happened?", then there is the potential for 
inquiry and useful insights (Brookbank \& McGill, 2006). Open questions allow PCTs to develop and express their beliefs, ideas or their own strategies for action and should be in the toolbox of educative mentors. It can be concluded that open questions are better for encouraging thinking (Brookbank \& McGill, 2006; Vogt et al., 2003).

The majority of questions in this analysis were closed questions, requiring one or two word answers or merely confirmed what was known. For example "Was that helpful? Can you change it? Are you doing the whole lot?" This establishes the mentor as 'in charge' and 'knowledgeable' and conducts the questioning in order to assess performance (Bishop \& Glynn, 1999). It is not until the mentor asks questions they don't already know the answer to (and realize that they do not have to know the answer), and the PCT is not expected to know the answer, that a shared inquiry is set in motion (Bishop \& Glynn, 1999, p. 144). This type of questioning to develop a shared inquiry is a difficult concept for mentors to become acquainted with and requires professional learning. Teachers are often expected to know all the answers and changing this approach to not knowing all the answers but asking the inquiring, challenging with open questions is digging into the practice of the $\mathrm{PCT}$, and allows educative mentoring to occur (Brookbank \& McGill, 2006).

The lack of open questions asked by mentors was surprising (see Table 9). The fact that the PCT in relationship one asked one open question, "What are you writing in here?", and the PCT in meeting three asked two open questions, "So why do we do that? So what does that mean I teach next?" suggested that they wanted to be more involved in the conversation and needed clarification. Ideally it should be the mentor asking the open ended questions not the PCT. Their mentors did most of the talking and were telling and giving information in the form of a tutor. The second relationship revealed the mentor asking seven open questions. This mentor who asked more open questions also facilitated a conversation where the PCT had the opportunity to speak more about her practice (59\% of the time), which had the potential for educative mentoring to take place.

In summary there was one mentor out of three who asked a reasonable amount of open questions during the meeting, which gave the PCT the chance to talk about practice and the opportunity to speak more than the mentor. The mentor who asked open questions that inquired into practice, also allowed for time to deconstruction and co-construction. The elements of deconstruction and co-construction are discussed next. 
Table 9.

Summary of PCT meeting analysis

\begin{tabular}{lccc} 
& Relationship 1 & Relationship 2 & Relationship 3 \\
\hline Mentor speaking time & $62 \%$ & $41 \%$ & $52 \%$ \\
\hline $\begin{array}{l}\text { PCT speaking time } \\
\text { (n) open questions } \\
/(\text { (n) total } \\
\text { questions }\end{array}$ & $38 \%$ & $59 \%$ & $48 \%$ \\
\hline
\end{tabular}

\section{Deconstruction and reflection}

The purpose of deconstruction is for the PCT to describe what happened in a given situation and be supported by questioning from the mentor, to analyse, and discuss the evidence, with a focus on the students' learning. This gives the opportunity for beliefs to be examined and discussed.

There were some deconstruction examples found in the PCT meetings. However in two out of three of the meetings, instead of the PCT, the mentor deconstructed. For example, in the first meeting the PCT had requested help with her planning and organization of records, so it was expected that the purpose would be to share this practice. The mentor started the meeting by saying, "This afternoon, let's look at my planning and organization with a view to help you with yours, is that where we are going?" This meeting had the potential to be educative but on closer analysis was actually more advising in nature. For educative elements to be present the mentor would have asked what the PCTs present planning looked like and why did she think it needed to be re-organised. There could have been a conversation around the purpose of planning and organization and why this was important and 'digging into' what theory sat behind this. The mentor 'advised' and 'told' the PCT about her own planning and organization and did not ask her to 'dig into' the theory behind this practice. Perhaps she believed that it was best to have things well organized or really believed that having student's assessment and planning at her fingertips was an important step to analysis and setting new goals for students' outcomes. 
In the second relationship, the PCT described and deconstructed some events in the class situation. For example, a discussion around a painting lesson of lady bugs was focused on a new student, and lead to a discussion about whether the student was left or right handed and how he engaged with the activity and the presentation of his work. The PCT also described how she had noticed that another student had trouble with eye tracking and a conversation followed where the PCT described what the situation was, laid out the evidence and came to a conclusion about what was best for the student and how the parents could also help. The mentor listened, asked one open question and moved on to the next item on the agenda. Deconstruction was taking place in this example but there was the potential for taking the next steps of asking more powerful and challenging questions around current practice. For example they could've co-constructed a new goal for this student. Co-construction and goalsetting is discussed in the next section.

In the third relationship, the mentor was giving advice and guidance as feedback from an observation. She began the meeting by saying, "We will go through the observation. What you were doing was absolutely fine and I put that down." This feedback had the potential to be educative if there had been a discussion and deconstruction about what happened in the observation, but as it was the PCT was declared to be 'absolutely fine' and was given positive feedback and affirmations. At one stage the mentor affirmed that the students were able to redirect themselves demonstrating that the teachers expectations were in place which she felt was 'absolutely amazing'. For educative elements to be present the mentor would have asked the PCT to deconstruct the observation by asking, "What did you teach well?" "What did you teach not so well?" "Where to next?" (Hattie \& Timperley, 2007). There could also have been a discussion around the expectations that were in place and how she had implemented this, and why this was important to her classroom practice. During the interview the PCT in this relationship had alluded to the presence of a missing element in the relationship. She acknowledged that the feedback suggested things to do, but admitted it had little to do with the actual act of teaching or the way she was teaching. In answer to the interview question, "What is it that you need at the moment?" She said:

I think what I probably need is more discussion around, the choices that I am making with the teaching strategies and how I am teaching and maybe even challenge like, why have you done it that way...we don't really go into specifics of that at all. It will 
be how has the week gone? What went well? Is there anything that you are worried about? And that is supportive and I will open up and we can I have a discussion that way but it's probably not so much to do with the actual act of teaching, the way I am teaching.

Reflection is not about passing on wisdom or knowledge but is about using open and more challenging questions to deconstruct. This could be easily solved, with a supportive programme about asking questions for the mentor.

The Guidelines (Education Council of Aotearoa New Zealand, 2015a, p. 25) list the importance of 'questions that enquire into and challenge practice are common'. This challenge was missing which also meant a lack of deconstruction. The purpose of deconstruction was for the PCTs to describe what happened, not the mentor. Educative mentoring requires that the PCT speaks and deconstructs for the majority of the time, however the mentors dominated in two meetings, by doing most of the speaking and deconstructing.

\section{Co-construction and goal-setting}

Co-construction involves the mentor and PCT working side by side to set new goals and steps and understand the implications for student's learning taking place. There were few examples of co-constructing between the mentor and PCT, of next steps and setting new goals for the PCT's teaching and learning. Setting goals and reviewing them was not a specific question asked during the interviews but it appeared it did not occur regularly. However during one the interview the PCT was asked, "What specifically are you learning at the moment? Is there some goal that you have set with your mentor?" She answered:

No there isn't really. We have our weekly meetings and we just discuss a lot of things, our observations have a goal. It would be, can you come in and observe a particular teaching strategy or a behaviour management as a whole. Those we set goals for but not really a goal as such.

The meeting for relationship one shared the mentor's procedures and planning and it might be expected that co-constructing where to from here once shared could have taken place. It did not take place. Instead there was no co-construction of where the PCT's wanted to go with reorganizing her planning. It might also be expected that feedback from an 
observation, as with relationship three, would result in where to next for the PCT and the setting of new goals for teaching practice, but instead confirmation was given of an 'absolutely fine' job being done. There was an absence of next steps for the PCT in each relationship.

The meeting for relationship two discussed a pupil (among other things), and the mentor and PCT co-constructed steps taken for addressing a lack of eye tracking in evidence for a new pupil. The PCT had mentioned this to the pupil's Dad who said he had also noticed and the mentor suggested using a tennis ball on a string and training the eyes to track. The PCT had suggested that they do the same at home. The mentor and PCT were working together in putting into place a solution for a child. The conversation could have gone a step further with the mentor probing and challenging the PCT to think about what else could be done to aid eye tracking and how she would know this was improving.

What is really clear about educative mentoring is that it is a joint exercise in thinking and analysing and reflecting and co-constructing the next steps, otherwise it is still an advice and guidance programme.

\section{Elements that were missing}

It can be concluded that two out of three of the meetings did not subscribe to the educative mentoring characteristics of the PCT being listened to, questions that enquired into and challenged practice, deconstruction, and co-construction. This did not fit with what is known as educative mentoring (see Table 3, page 20). The meeting for relationship two subscribed to a greater number of educative mentoring characteristics (see Table 9, page 88).

Firstly, in educative mentoring it is expected that the PCT is listened to and the mentor speaks less. In two relationships the mentors spoke more than the PCTs, hence there was less than half the time for PCTs to be listened to. Mentors seemed to demonstrate the elements of coaching and telling with the advice and support of a tutor (see Table 3, page 20). In the second relationship the PCT was given more than half of the time to speak (see Table 9, page 88).

Secondly, questions to engage PCTs on a variety of levels of thinking were missing. This shortage of open and challenging questions contributed to limited opportunities for PCTs to deconstruct events and co-construct next steps in learning. There was a lack of 'why' 
questions asked and there was no attempt to unpick and reflect on the theory behind the practice.

Thirdly, the element of deconstruction and the opportunity for the PCTs to describe, analyse and discuss evidence was not strong. Two out of three mentors did the deconstructing, rather than the PCT. There was a lack of evidence being used and asked for by the mentors to inquire into the beliefs of the PCTs and the theories that underpinned their beliefs about learning and teaching.

Lastly, the lack of goal setting and where to next for the PCTs practice is of concern. The Guidelines state "goal setting meetings" to be a characteristic of educative mentoring (Education Council of Aotearoa New Zealand, 2015a, p. 25) and this was clearly lacking. The process of setting goals is seen as an important aspect of mentoring content (Blackman, 2010). When realistic goals and expectations are established questions are asked to provide a vehicle for reflective practice (Zachary \& Fischler, 2011). The cycle for educative mentoring inquiry (see Figure 3, page 102) from class observation, to learning conversation including effective questioning and evidence, and setting personal goals is discussed in the next chapter.

\subsubsection{Formal observations}

There were two observation feedback documents examined from two relationships and oral feedback reviewed from the third relationship. In each case the PCTs were given many affirmations and although formats differed, all recorded what happened during the observed lesson sequence. Where goals could be found they related to the PTC.

Observation 1 - written feedback

The goal of the observation was to give feedback on what was effective and what else would work in relation to an observed reading lesson. The goals related to the PTC and in this case, criteria six, 'plan and implement an appropriate learning programme'. The feedback included ticked boxes showing good teaching practice being observed. Where to next, was written as 'incorporate new and different strategies into the reading programme' based on the PCT's professional reading of two suggested texts. I have no way of knowing if a more specific goal for 'where to next' was set, or how this would be achieved or when it would be 
revisited. It is likely that the observation was an exercise in checking that criteria six was achieved.

\section{Observation 2 - written feedback}

The observation of a Maths lesson appeared to have no clear purpose or goal. Feedback was given under headings of teaching and learning strategies, appropriateness of activity, class management, suggestions and general. A suggestion of, 'keep going back to the learning intention' was made. A general comment was complimentary of the PCT, her classroom and the progress being made.

You and the children have developed remarkably over the last term. ...You have shown that you are willing to take on suggestions and you classroom displays are colourful, interesting and relevant. (Mentor)

\section{Observation 3 - oral feedback}

The third observation feedback from the recorded meeting was positive and affirming of what was happening, but included deconstruction from the mentor around what she observed (rather than asking the PCT to deconstruct) and no co-construction of where to next was given as previously discussed (see page $67 \& 68$ ).

Completing the assigned observation seemed to have fulfilled a performance requirement of the PTC, and does have a role in the mentoring process but sits outside the educative mentoring model, because of the lack of personal goals.

\section{Setting of personal goals}

Clarifying and articulating learning goals is indispensable to the success of the mentoring relationship (Education Council of Aotearoa New Zealand, 2015a; Zachary \& Fischler, 2011). Goals can profoundly influence the quantity and the quality of an individual's engagement in learning (Lock \& Latham, 2006). When a person sets goals and attains them this builds a sense of competence and satisfaction which leads to greater interest in learning and to increased intrinsic motivation (Schunk, 1980). The setting of specific high, hard or challenging goals leads to a higher level of task performance than do easy, vague or general goals (Lock \& Latham, 2006), as is expected with educative mentoring. Lock and Latham (2006) further report that feelings of success occur to the extent that people are able to grow and 
meet job challenges by pursuing and attaining goals that are important and meaningful to the individual. While some PCTs come to a mentoring relationship with well-defined goals most come with a general idea about what they want to learn (Zachary \& Fischler, 2011). An important conversation between the mentor and PCT that leads to formulating a SMART goal (specific, measureable, action-orientated, realistic and timely) is critical to ensuring positive results. Zachary and Fischler (2011) recommend turning a starter goal into a SMART goal and this may take more than one meeting. They encourage mentors to explore two kinds of goals with their PCTs 'do goals' and 'be goals'. 'Do goals' are short term, measurable and observable and they focus on knowledge, skills and performance. 'Be goals' on the other hand are often invisible and harder to measure because they involve things such as personal development and character. 'Do goals' can be likened to mastery goals which focus on gaining competence or mastering a new set of skills. These have been found to be more motivating and to develop greater self-efficacy than performance goals which focus on achieving standards, for example PTC (Lock \& Latham, 2006; Schunk, 1980; Zachary \& Fischler, 2011).

Table 3 (see page 20) summarises the practice of educative mentoring as including coconstruction of the new goals and designing new learning steps as a major part of mentoring in an educative manner. The goals tracked in the above examples were to fulfil a school requirement or a performance goal to meet the PTC. The discussion of what the PCT wanted to achieve in their practice in the form of personal goals needed to occur with mentor support, including the skills of questioning, deconstruction and co-construction. This was found to be lacking in the documents and recorded meeting.

An implication for the outcome of lack of personal goals around developing practice, would be to streamline the process around the inquiry cycle (see figure 3, page 102) with particular emphasis on educative mentoring. Educative mentoring is known as a style of mentoring but if it is to be truly educative it cannot totally subscribe to the prescribed Practising Teacher Criteria. The PTC are compliance goals and these are what ultimately lead to registration and must be addressed. However a preoccupation with performance goals rather than personal goals relating to classroom practice is detrimental. This will be further highlighted under recommendations in the next chapter. 


\section{Analysis of documents}

The documents examined were formal observation feedback, as discussed above. The progress reports and meeting minutes are discussed below. All these activities contributed to the mentoring process. All documents established close links with the PTC.

\section{$\square$ Progress reports}

The PCT end of term or progress reports were all written around the dimensions of the PTC. All reports were encouraging and gave positive feedback. For example, in one school a comment was made by the mentor each term for each of the twelve criteria of the PTC, relating to how the PCT was achieving these. For example, criteria one, 'establish and maintain effective professional relationships focused on learning and well-being of all akonga.'

Term 1: PCT interacts confidently with students, colleagues and parents. She is establishing relationships with the wider school community.

Term 2: PCT engages positively with students, and is mindful of the dynamics and learning needs of the younger boys in her class.

This report has a reassuring role for the PCT to let them know they are working towards the PTC, but it is not necessarily educative. This type of report has a role which appears to be a termly summative assessment and possibly fulfils an administrative requirement as an assessment or an appraisal. However this cannot be considered a developmental tool and does not fit with the educative mentoring model.

In a second example, the professional practice report was broken into six sections relating to the PTC of professional relationships and professional knowledge in practice. The report was based on observation and discussion. Once again the report has a reassuring role for the PCT but was not educative. It was positive and affirming and ended with the comment, perhaps a type of goal, 'carry on with reflections and adding them to your planning.'

There did not seem to be documentation to fulfil, "How am I going?", "Where am I going?", "Where am I going next?" (Hattie \& Timperley, 2007). The progress reports relate to "How am I going", which meets the targets of the PTC which have to be present for achieving certification. However while clearly important, they sit outside educative mentoring. 


\section{$\square$ Meeting minutes}

The meeting time was an opportunity for a conversation around classroom practice with the potential to provide educative mentoring for the PCT. The documented meeting minutes presented evidence that the mentor took responsibility for and ensured that they happened on a regular basis. It appeared that the meetings dealt with current issues in the school environment including timetabling, reviewing last meeting, student progress, coming events, and presented solutions. Student's learning and behaviour was discussed. The discussion of an observation was noted as having been discussed but gave no details. An educative focus might have included a new goal for the PCT. Any actions required were recorded. It is difficult to say what type of conversation went on with each recorded point.

As discussed a gap in the mentoring process seems to be the setting of personal goals for the PCT in relation to their classroom practice. There was little evidence in any of the meeting documents, of the setting of personal goals around classroom practice and the revisiting of these. Instead there was a dominance of attaining the PTC in evidence in all documentation which seemed to be quite separate from addressing the process of educative mentoring.

The lack of a clear understanding on the part of mentors, of what is involved in educative mentoring and the acquisition of the skills and knowledge to carry this out, is discussed in the section with some suggestions for moving forward.

\subsection{Chapter summary}

In this chapter the three themes of, the role of the mentor, establishing a relationship, and the practice of mentoring are discussed. For these themes to be come together as the practice of deliberate educative mentoring, the mentor must have a strong foundation of understanding what educative mentoring is, and establish a relationship in order for the practice of mentoring to peak and happen (see Figure 2, page 73).

The first theme, the role of the mentor was highlighted by how the concept of educative mentoring was understood by the mentor and PCT and the training and professional learning received for the role. The second theme, establishing the relationship referred to the perceptions of the mentors and PCTs in this case study and how the 
professional and personal relationship contributed to their mentoring. The third theme of the practice of mentoring discussed the activities, of informal discussions, formal meetings and formal observations with the potential to be educative. A recorded meeting used the lenses of speaking time, questioning, deconstruction and co-construction, to gauge the presence of educative mentoring. The formal observations were discussed using documents and one recording. An analysis of meeting documents, progress reports and observation feedback documents, indicated a lack of goal setting of personal goals with a view to improving teaching practice. There was an emphasis on satisfying the performance goals of the PTC. Mentor training and professional learning is discussed as being vital to teacher quality and in turn the outcomes on student learning (Achinstein \& Athanases, 2006).

The final chapter looks closely at the implications of this discussion and I examine some of the issues needing to be addressed for mentoring to be deliberately educative. The mentors' understanding of the importance of prioritising inquiring into PCT practice, alongside emotional support and becoming part of the school culture, must occur. 


\section{CHAPTER SIX: CONCLUSION}

\subsection{Chapter overview}

This concluding chapter provides an overview of the study and research findings. It begins by summarizing the aims of the study and the findings that addressed the research questions. This is followed by a discussion of implications arising from the themes identified for policy makers, school management, mentors and PCTs involved in the practice of educative mentoring. Next, the limitations of the study are explored, followed by suggestions for future research.

\subsection{Aims of the study}

The purpose of this study was to find what educative mentoring looked like in three New Zealand primary schools. The Guidelines (Education Council of Aotearoa New Zealand, 2015a) signalled a shift from a programme of 'advice and guidance' with a tutor, to a programme of induction and mentoring with a mentor. The literature review in chapter 2 revealed the challenge for mentors to, firstly understand what educative mentoring is and, secondly to learn new skills and knowledge that are involved in the process. This study provided an opportunity to describe how mentors and PCTs engaged in the process of educative mentoring.

The following section reviews how the study addressed the research questions.

\section{Key question:}

What does effective educative mentoring look like in the New Zealand primary school?

The findings described in chapter 4 suggest that the activities of emotional support and becoming part of the school culture which had also been present in the previous 'advice and guidance' programme were in evidence in this study. There was further support from school management and other teachers within the school, if the mentor was not always available (as in relationship one). The educative mentoring activities of regular meetings, observations and learning conversations were taking place but the educative elements of challenging questions, deconstructing and co-constructing were not always present. 


\section{Sub-questions:}

* The word 'educative' is used in relation to the induction and mentoring guidelines, how is this term understood by mentors and PCTs?

Chapters 4 and 5 describe and interpret mentors and PCTs understanding of educative mentoring. There was a difference between mentors and PCTs understanding of educative mentoring. This suggested a lack of clarification about the educative mentoring approach from the start of the mentoring relationship. Mentors stated that they were using elements of educative mentoring but these were not often in evidence. Mentors espoused being good listeners but in fact talked most of the time and asked few open ended questions which hampered the deconstruction and co-construction processes.

How might the educative mentoring process be improved?

The discussion of the findings in chapter 5 suggests that the need for training and ongoing professional learning be prioritised. A tutor's work, of giving 'advice and guidance' (see Table 2, page 20) which included emotional support, becoming part of the school culture, and surviving these induction years, continued to be present. It is the cultivating of inquiry and digging into practice which is at the forefront of educative mentoring that was missing. It was suggested by mentors and PCTs that a sharing of scenarios and coming together as cluster support would be beneficial. Some suggestions for how this might happen are recorded in the recommendations.

What skills and knowledge do mentors still need to embed?

The skills and knowledge of educative mentoring in practice (Education Council of Aotearoa New Zealand, 2015a, pp. 25-26) still need to be embedded. Engaging the PCT in deliberate professional conversations which include challenging open questions, the opportunity for the PCT to deconstruct (describe, analyse and discuss) and co-construct (set new personal goals) were discussed in chapter 5 as skills that mentors need to embed. 


\subsection{Recommendations}

This study has shown that participating mentors do not fully understand educative mentoring. They were going through the motions of regular meetings, formal observations and learning conversations but the following educative elements have been singled out for more focused attention. Professional learning and development of any new skill needs to be ongoing.

\subsubsection{Clarification of the educative mentor role}

Professional learning for mentors is absolutely essential (Feiman-Nemser, 2014). Feiman-Nemser (2014) clarifies the essence of being a good educative mentor as being able to take the performance apart, break it down, talk about it, model it, and help someone else learn it. One-off opportunities may be adequate if the learning involves straight forward transmission of information or increased awareness of new ideas (Timperley et al., 2007) but in the case of educative mentoring, one-off opportunities are not enough. The practice of educative mentoring revealed a variation between mentors. This raises the need for training.

\section{* Additional separate, concise booklets for mentors and PCTs which clarify the} process of educative mentoring. What is involved for each of the stake holders?

The publication of some new material by the Education Council to clarify the roles of mentor and PCT would be helpful.

\section{* Cluster groups for mentors to be mentored}

The building of educative mentoring networks or clusters sounds sensible and easy. An opportunity to share scenarios especially between experienced and new mentors was suggested by mentors during the study.

\subsubsection{Understanding of educative elements}

\section{Asking the challenging questions to focus the learning conversations}

Research emphasises the importance of dialogue between professionals in enriching, supporting and challenging learning (Cordingley, 2005). There were varying degrees of expertise when conducting learning conversations. Mentors had little specific training in 
conducting learning conversations and yet this role is at the foundation of what educative mentoring is about. It is important that mentors are aware that they are listeners who are tasked with asking open ended and powerful questions, inviting the opportunity for PCTs to deconstruct and co-construct.

There were missed opportunities for asking open questions to deconstruct and coconstruct during the learning conversation. Teachers were willing to ask questions but it seemed they did not have a powerful question at their finger-tips. For example, on page 55 the mentor said, 'oh', in response to her PCTs deconstruction of a situation, but if she had said instead, 'what do you think you could do now?' it would embed the mind set of inquiry, deconstruction and co-construction. These are important elements of educative mentoring. Table 10 suggests ready questions to be used for deconstruction and co-construction.

\section{Table 10.}

\section{Ready questions for deconstruction and Co-construction}

\begin{tabular}{|c|c|}
\hline Questions for deconstruction & Questions for co-construction \\
\hline Tell me about.../ Describe to me... & What would you like to talk about first? \\
\hline What went well today? & What are your options/choices? \\
\hline $\begin{array}{l}\text { What did you do not so well? Why/why not? } \\
\text { Can you tell me a little more about how you }\end{array}$ & $\begin{array}{l}\text { What support would be helpful to achieve } \\
\text { the goal? }\end{array}$ \\
\hline $\begin{array}{l}\text { see that? } \\
\text { What had real meaning for you from what you }\end{array}$ & $\begin{array}{l}\text { What is missing here that you would like to } \\
\text { have? }\end{array}$ \\
\hline $\begin{array}{l}\text { observed? What surprised you? What } \\
\text { challenged you? }\end{array}$ & $\begin{array}{l}\text { Look back at your goal. Is this still what you } \\
\text { need/want? }\end{array}$ \\
\hline $\begin{array}{l}\text { What's been your major learning so far? } \\
\text { Why did you choose to do it that way? }\end{array}$ & $\begin{array}{l}\text { How will you know when you have } \\
\text { achieved this goal? }\end{array}$ \\
\hline What new connections are you making? & $\begin{array}{l}\text { Have you thought about...? Would that be } \\
\text { something to consider? }\end{array}$ \\
\hline $\begin{array}{l}\text { How would you describe what you have } \\
\text { learned? }\end{array}$ & Where to next? \\
\hline Why is that learning important to you? & What needs immediate attention here? \\
\hline What do you want to achieve? & \\
\hline
\end{tabular}


6.3.3 Focus on development of the learner according to developmental needs instead of ticking off of the summative PTC.

A preoccupation with the prescribed performance goals of the Practising Teacher Criteria ensure compliance in achieving certification as a teacher. A focus on inquiring and improving practice is at the forefront of educative mentoring (Feiman-Nemser \& Carver, 2012). An inquiry model is offered (see figure 3). I recommend:

First year mentoring relationship focus on personal inquiry and personal short term goal setting (PTC always present) Second year attend to Practising Teacher Criteria alongside personal goals

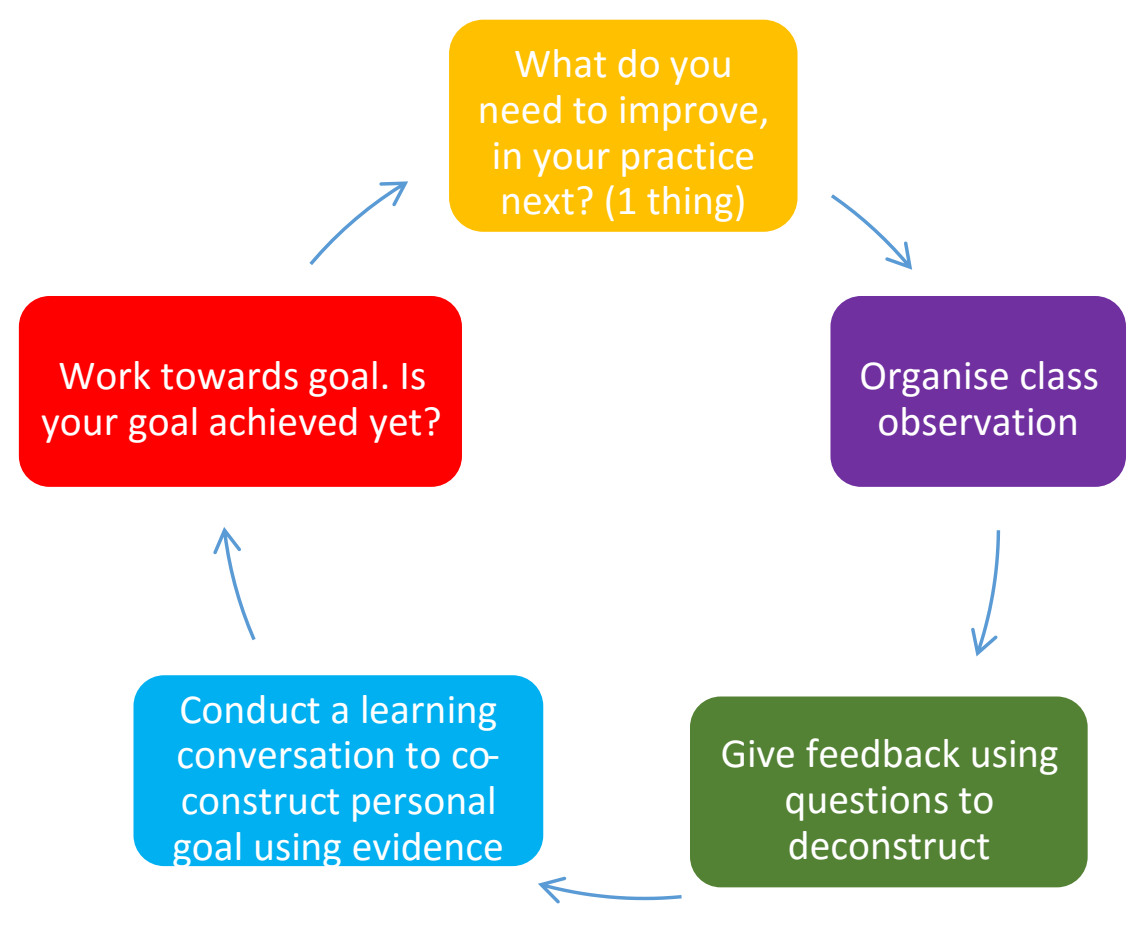

Figure 3. Mentor cycle of educative mentoring inquiry for PCTs - modified from teacher inquiry and knowledge building cycle (Timperley et al., 2007). 


\subsection{Limitations of the research}

There are a number of research limitations that need to be taken into consideration when contemplating the trustworthiness of this study.

Firstly, there is a limited number of participants but the three schools did give a range of contexts and mentors came with range of experience as mentors. Findings may have been different in rural schools or in primary schools in other regions. However findings were still able to alert the sector to possible needs within their own groups.

Secondly, the analysis of documents was from those volunteered by the mentor. This limited my analysis as I would have liked the same amount of documents from each relationship including meeting minutes, observation, progress report and goal sheet.

Thirdly, the questions not asked during the interview. Although I asked about the goals being set I didn't realise these were almost exclusively set around performance goals of the PTC until I examined the documents and thought about the interviews and recorded meetings. I wanted to know more about personal goals. I didn't ask the best questions around goal setting and I would explore this further if I went back again.

\subsection{Opportunities for future research}

During the research certain issues arose that could create possibilities for future research. These include:

- An issue that most mentors and some PCTs mentioned was the lack of training and on-going professional learning for mentors. More research into exactly what avenues there are to support mentor training and professional learning is required.

- An action research approach with mentors. This would involve support with ongoing training by inquiring into mentor's practice and together deconstructing their practice. For example, talking about effective questioning, trying some out and then talking about it after.

- Relational issues in the mentoring. How important is it to be a friend? Is a professional relationship enough? 


\subsection{Chapter summary}

In this chapter I have reviewed the aims of the study and how the questions were addressed. Three recommendations are described. The limitations for research and opportunities for future research are outlined.

Teaching is evolving all the time. The importance of practices and attitudes established in the first few years of teaching affect retention and practice of our future teachers. Educative mentoring shifts the 'tutor' into a being a 'mentor' along a more rigorous and professional pathway of developing new teachers' practice and acknowledging the deliberate business of induction and mentoring for our future teachers. 


\section{REFERENCE LIST}

Achinstein, B., \& Athanases, S. Z. (2006). Mentors in the making. NY: Teachers College Press.

Aitken, H., Ferguson, B., McGrath, F., Piggot-Irvine, E., \& Ritchie, V. (2008). Learning to teach: Success case studies of teacher induction in Aotearoa New Zealand. Wellington: New Zealand Teachers Council.

Annan, B., Lai, M., \& Robinson, V. (2003). Teacher talk to improve teaching practices. Set Research Information for Teachers, 1, 31-35.

Bandura, A. (2000). Exercise of Human Agency through Collective Efficacy. Current Directions in Psychological Science, 9(3), 75-78.

Bandura, A. (2004). Swimming against the mainstream: the early years from chilly tributary to transformative mainstream. Behaviour Research and Theraphy, 42, 613-630.

Bereiter, C. (2002). Education and mind in the knowledge age. London: Lawrence Erlbaum.

Bishop, R., \& Glynn, T. (1999). Culture Counts: Changing Power relations in Education. Palmerston North, New Zealand: Dunmore Press Limited.

Blackman, A. (2010). Coaching as a leadership development tool for teachers. Professional Development in Education, 36(3), 421-441.

Bradbury, L. U. (2010). Educative mentoring: promoting reform-based science teaching through mentoring relationships. Science Education, 94(6), 1049-1071.

Braun, V., \& Clarke, V. (2006). Using thematic analysis in psychology. Qualitative Research in Psychology, 3(2), 77-101. doi: 10.1191/1478088706qp063oa

Brondyk, S., \& Searby, L. (2013). Best practices in mentoring: complexities and possibilities. International Journal of Mentoring and Coaching in Education, 2(3), 189-203. doi: 10.1108/IJMCE-07-2013-0040

Brookbank, A., \& McGill, I. (2006). Facilitating Reflective Learning Through Mentoring \& Coaching. Great Britain: Kogan Page Limited.

Cameron, M. (2007). Learning to teach: A literature review of induction theory and practice. Wellington, New Zealand.

Cameron, M., Berger, J., G., Lovett, S., \& Baker, R. (2007). Early career teachers' opportunities for professional learning: impacts on teaching practice, job satisfaction, motivation, and career decisions. Paper presented at the BERA annual conference, Institute of Education, London. 
Cameron, M., Dingle, R., \& Brooking, K. (2007). Learning to teach: A survey of provisionally registered teachers in New Zealand. New Zealand Teachers Council.

Cameron, M., Whatman, J., Hogden, G., McLeod, L., Bright, N., Nuttal, J., \& Nolan, A. (2014). Evaluation of the Guidelines for induction and mentoring and mentor teachers: Final Report. Wellington: New Zealand Council for Educational Research.

Cordingley, P. (2005). The role of mentoring and coaching in teachers' learning and development. Education Review, 18(2), 68-74.

Cresswell, J. W., Hanson, W. E., Clark Plano, V. L., \& Morales, A. (2007). Qualitative Research Designs: Selection and implementation. The Counselling Psychologist, 35(2), 236-264.

Darling-Hammond, L. (1998). Teacher learning that supports student learning. Educational Leadership, 55(5), 6-18.

De Lima, J. (2001). Forgetting about friendship: Using conflict in teacher communities as a catalyst for school change. Journal of Educational Change, 2, 97-122.

Devos, A. (2010). New teachers, mentoring and the discursive formation of professional identity. Teaching and Teacher Education, 26, 1219-1223.

DeWalt, K., \& DeWalt, B. (2002). Participant observation: A guide for fieldworkers. Walnut Creek, CA:: AltaMira Press.

Education Council of Aotearoa New Zealand. (2015a). Guidelines for induction and mentoring and mentor teachers. Wellington: Learning Media.

Education Council of Aotearoa New Zealand. (2015b). Practising Teacher Criteria.

Eisner. (1998). The enlightened eye: Qualitative inquiry and the enhancement of educational practice. Upper Saddle River, NJ.: Prentice Hall.

Feiman-Nemser, S. (1998). Teachers as teacher educators. European Journal of Teacher Education, 21(1), 63-74.

Feiman-Nemser, S. (2001). Helping novices learn to teach: Lessons from an exemplary support teacher. Journal of Teacher Education, 52(1), 17-32.

Feiman-Nemser, S. (2003). What new teachers need to learn. Association for Supervision and Curriculum Development.

Feiman-Nemser, S. (2014). Educative mentoring. In D. Wansborough (Ed.). Wellington, New Zealand: New Zealand teachers Council. 
Feiman-Nemser, S., \& Carver, C. L. (2012). Creating conditions for serious mentoring: Implications for induction policy. Yearbook of the National Society for the Study of Education, 111(2), 342-364.

Garvey, A., Stokes, P., \& Megginson, P. (2009). Coaching and Mentoring-Theory and Practice. London: Sage.

Haigh, N. (2006). Everyday conversation as a context for professional learning and development. International Journal for Academic Development, 10(1), 3-16. doi: $10.1080 / 13601440500099969$

Hanson, S. G. (2010). What mentors learn. Educational Leadership, May.

Hargreaves, A. (2005). The emotions of teaching and educational change. In A. Hargreaves (Ed.), Extending educational change: International handbook of educational change Hattie, J., \& Timperley, H. (2007). The Power of Feedback. Review of Educational Research, 77(1), 81112.

Hobson, A., Ashby, P., Malderez, A., \& Tomlinson, P. (2009). Mentoring beginning teachers: What we know and what we don't. Teaching and Teacher Education, 25(1), 207-216. doi: http://dx.doi.org/10.1016/j.tate.2008.09.001

Hobson, A., \& Malderez, A. (2013). Judgementoring and the other threats to realizing the potential of school-based mentoring in teacher education. International Journal of Mentoring and Coaching in Education, 2(2), 89-108. doi: 10.1108/IJMCE-03-2013-0019 Ingersoll, R. M., \& Strong, M. (2011). The Impact of Induction and Mentoring Programs for Beginning Teachers: A Critical Review of the Literature. Review of Educational Research, 18(2), 201-233. doi: 10.3102/0034654311403323

Johnson, B., \& Christensen, L. (2010). Educational research: Quantitative, qualitative and mixed approaches. Los Angeles: Sage.

Kagan, D. (1990). Ways of evaluating teacher cognition: inferences concerning the goldilocks principle. Review of Educational Research, 60(419).

Kreber, C. (2007). An analysis of two models of reflection and their implications for educational development. International Journal for Academic Development, 9(1), 2949. doi: $10.1080 / 1360144042000296044$

Langdon, F. (2011). Shifting perception and practice: New Zealand beginning teacher induction and mentoring as a pathway to expertise. Professional Development in Education, 37(2), 241-258. 
Langdon, F., Flint, A., Kromer, G., Ryde, A., \& Karl, D. (2011). Induction and mentoring pilot: Primary. Leading learning in induction and mentoring.

Langdon, F., Lind, P., Shaw, C., \& Pilcher, E. (2010). Realising potential and recognising paradox: The national induction and mentoring programme. New Zealand Annual Review of Education, 19, 78-96.

Lipton, L., \& Wellman, B. (2007). How to talk so teachers will listen. Educational Leadership, 65(1), 30-34.

Lock, E. A., \& Latham, G. P. (2006). New Direction in Goal-Setting Theory. Association for Psychological Science, 15(5), 265-268.

McDonald, L., \& Flint, A. (2011). Effective educative mentoring skills: A collaborative effort. New Zealand Journal of Teachers' Work, 8(1), 33-46.

Merriam, S. B. (2009a). Qualitative Research.

Merriam, S. B. (2009b). Qualitative research: A guide to design and implementation. San Francisco, CA.: Jossey-Bass.

Merriman-Webster. (2015). http://www.merriam-webster.com/dictionary.

Merriman, \& Webster. (2015). Dictionary.

Mezirow, J. (1991). Transformative dimensions of adult learning. San Francisco: Jossey-Bass.

Miles, M. B., \& Huberman, A. M. (1994). Qualitative data analysis: An expanded sourcebook. London: Sage.

Ministry of Education. (2013). How schools are run. 2013, from http://www.minedu.govt.nz/Parents/AllAges/EducationInNZ/SchoolsInNewZealand/ HowSchoolsAreRun.aspx

Ministry of Education, \& New Zealand Teachers Council. (2004). Towards Full Registration: A support Kit for Schools. Wellington, New Zealand: Learning Media Limited.

Moir, E., Barlin, D., Gless, J., \& Miles, J. (2009). New teacher mentoring: Hopes and promise for improving teacher effectiveness. Cambridge, MA.: Harvard Education Press.

Norman, P. J., \& Feiman-Nemser, S. (2005). Mind activity in teaching and mentoring. Teaching and Teacher Education: An International Journal of Research and Studies, 21(6), 679697.

Normore, A., \& Loughry, K. (2006). Avoiding the Pitfalls of a Rookie Year: How a Mentor can Help. Kappa Delta Pi Record, 43(1), 25-29. 
O'Brien, J., \& Christie, F. (2005). Characteristics of support for the new Teacher Induction Scheme in Scotland. Mentoring \& Tutoring: Partnership in learning, 13(2), 189-203.

O'Toole, J., \& Becket, D. (2013). Educational research: Creative thinking and doing (Second Edition ed.). Melbourne, Australia: Oxford University Press.

Orland-Barak, L., \& Hasin, R. (2010). Exemplary mentors' perspectives towards mentoring across mentoring contexts: Lessons from collective case studies. Teaching and Teacher Education, 26, 427-437.

Patterson, S. (2013). Educative mentoring: Challenges and Enablers of Implementation in an Intermediate School Context. (Masters), Victoria University of Wellington, Wellington, New Zealand.

Patton, M. Q. (2002). Qualitative Research \& Evaluation Methods (3 ed.). Thousand Oaks, California: Sage Publications

Piggot-Irvine, E., Aitken, H., Ritchie, J., Ferguson, P. B., \& McGrath, F. (2009). Induction of newly qualified teachers in New Zealand. Asia-Pacific Journal of Teacher Education, 37(2), 175-198. doi: http://dx.doi.org/10/1080/13598660902804030 Punch,

K. (2000). Developing effective research proposals. London: Sage.

Rowley, J. B. (2006). Becoming a high performance mentor. Thousand Oaks, California: Corwin Press.

Saldana, J. (2009). The coding manual for qualitative researchers. London Sage Publications Ltd.

Schunk, D. (1980). Paper presented at the Paper presented at the Annual Convention of the American Psychological Association 88th, Montreal, Quebec, Canada, September 1-5, 1980.

http://www.eric.ed.gov/ERICWebPortal/custom/portlets/recordDetails/detailmini.js p? nfpb=true\& \&ERICExtSearch SearchValue 0=ED192916\&ERICExtSearch Search Type 0=no\&accno=ED192916

Schussler, D., Feiman-Nemser, S., Diez, M. E., \& Murrell, P. (2012). Swimming in deep waters Democracy \& Education, 20(2).

Stake, R. E. (1995). The art of case study research. Thousand Oaks, California.: Sage Publications, Inc. 
Thomas, W., \& Smith, A. (2004). Coaching Solutions (Second ed.). London: Continuum International Publishing Group.

Thornton, K. (2013a). Mentoring beginning teachers - lessons from America. Leading lights, 3, 4-5.

Thornton, K. (2013b). Mentors as educational leaders and change agents. International Journal of Mentoring and Coaching in Education, 3(1), 18-31.

Timperley, H. (2001). Mentoring conversations designed to promote student teacher learning. Asia-Pacific Journal of Teacher Education, 29(2), 111-123.

Timperley, H., Wilson, A., Barrar, H., \& Fung, I. (2007). Teacher Professional Learning and Development: Best Evidence Synthesis Iteration. Wellington, New Zealand: Ministry of Education.

Vogt, E., Brown, J., \& Issacs, D. (2003). The Art of Powerful Questions: Catalyzing Insight, Innovation, and Action. Mill Valley, CA.: Whole Systems Associates.

Wang, J., \& Odell, S. (2002). Mentored learning to teach according to standards-based reform: A critical review. . Review of Educational Research, 72(3), 481-546.

Wang, J., Odell, S., J., \& Schwille, S., A. (2008). Effects of Teacher Induction on Beginning Teachers' Teaching: A Critical Review of the Literature. Journal of Teacher Education, 59, 132-152. doi: 10.1177/0022487107314002

Wansborough, D. (2015). [Induction and mentoring programmes for PCTs prior to 2000].

Whitmore, J. (2002). Coaching for Performance-GROWing People, Performance and Purpose (3rd ed.). London, UK.

Yin, R. K. (2009). Case study research design and methods (Fourth ed. Vol. 5). Thousand Oaks, California: Sage Publications Inc.

Yusko, B., \& Feiman-Nemser, S. (2008). Embracing contraries: Combining assistance and assessment in new teacher induction. Teachers College Record, 110(5), 923-953.

Zachary, L., \& Fischler, L. (2011). Begin with the end in mind: The goal-driven mentoring relationship. Training \& Development, 55(1), 51-53. 


\section{APPENDICES}

Appendix A: Mentor information sheet

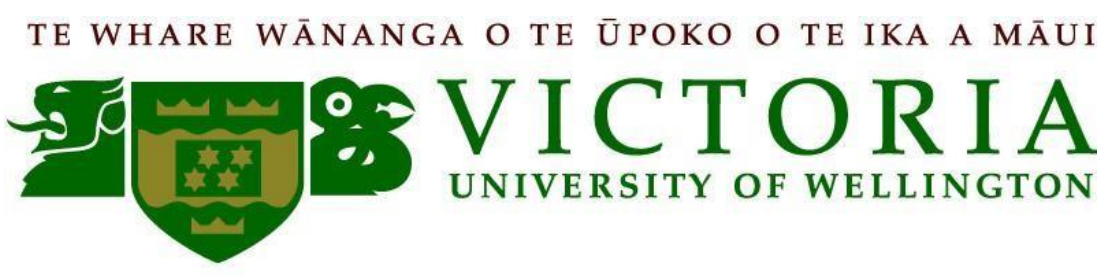

Research project: Mentor Information sheet.

\section{An investigation into educative mentoring for beginning teachers in the New Zealand Primary School}

\section{Researcher}

Kaye Stannard, Victoria University of Wellington.

This sheet gives you some information about this study. Please feel free to ask me any questions or for more information. I am undertaking this research for my Masters thesis. The research is being supervised by Dr Brenda Service, (brenda.service@vuw.ac.nz) and Dr Kate Thornton, (kate.thornton@vuw.ac.nz) School of Education, Victoria University of Wellington.

\section{The purpose of my Masters research.}

This research study will explore how three New Zealand primary schools are currently implementing the educative mentoring guidelines for provisionally registered teachers (PRTs), established by the New Zealand Teachers Council in 2011 (p.24-25). The aim of this in-depth case study is to gain insights into the effectiveness of the mentoring relationship, with the focus on educative mentoring, in an attempt to establish how this contributes to the first years of teaching and outcomes for provisionally registered teachers. This is an opportunity for mentors and PRTs to have their say about "The Guidelines for Induction and Mentoring and Mentor Teachers".

Research question: What does effective educative mentoring practice look like in a New Zealand primary school?

\section{Research process and Participants}

As part of this research I am seeking the participation of mentor teachers and their PRTs. If you choose to participate, participation will consist of:

- Completion of an anonymous online survey (approximately 15-20 mins).

- Being part of a one-to-one interview (30-40 mins at school at time to suit mentor/PRT). 
- Recording a PRT meeting.

- Volunteering of secondary data to be analysed e.g. meeting minutes, reflections, feedback from observations, individual goals and registered teacher criteria data.

A link to the online survey will be emailed to you upon receiving your signed consent form.

One-to-one interviews will be conducted to delve deeper into the conditions required for educative mentoring to take place. A formal mentoring meeting will be recorded which will assist in exploring educative mentoring in practice. Secondary data from personal and official documents will be examined.

This study aims to explore and enrich our understanding of educative mentoring in action and its impact on PRTs teaching and learning.

\section{Confidentiality and access to information}

The information provided is strictly confidential. You will not be identified and pseudonyms will be used. At the completion of the interviews and recorded meeting I will check with you that your comments have been recorded accurately. You will be given the opportunity to change or delete any comments. You may withdraw from the research project up until the completion of data collection (30 Nov 2014).

No other person besides my supervisors, Dr Brenda Service/Dr Kate Thornton and I will see the survey or transcripts of meetings and interviews. It is intended that one or more articles will be submitted for publication in scholarly journals. Surveys and transcripts will be destroyed five years after the completion of the project.

This research has been assessed and approved by Victoria University Faculty of Education Ethics Committee. If you have any ethical concerns about the research please contact Dr Allison Kirkman (allison.kirkman@vuw.ac.nz), ph: 04463 5676, Chair of the Human Ethics Committee, Victoria University of Wellington.

Your consent for this study is highly valued.

Thank you Kaye Stannard

kaye.stannard@vuw.ac.nz

Ph 0273100160 


\section{Appendix B: Mentor consent form}

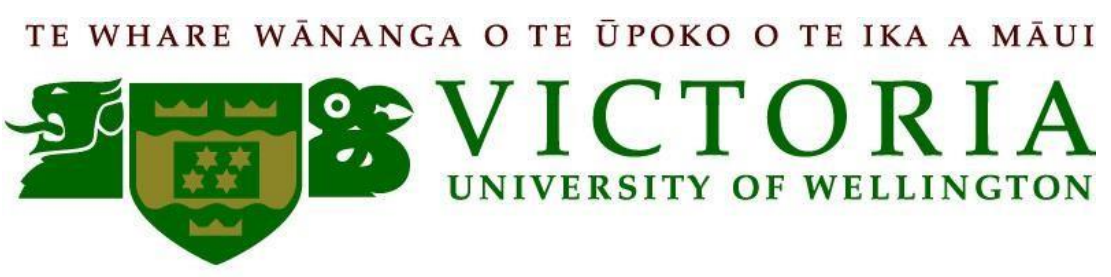

Research project: Mentor consent form

An investigation into educative mentoring for PRTs in the New Zealand Primary School

I agree to taking part in the above research. I have had the project explained to me and I have had the chance to ask any questions.

- I understand that I will be involved in an online survey (15-20 mins), one-on-one interview (30-40 mins), a recording of a formal PRT meeting, and volunteering of secondary data (e.g. goals, meeting minutes, reflections, and/or observation feedback).

- I understand that all data collected will be kept confidential and secure to the researcher and supervisor; the published results will not identify me.

- I understand that I will be provided with a transcript of the interview and PRT meeting for checking before data analysis.

- I understand that I can withdraw from the research project up until the conclusion of the data collection (30 Nov 2014).

I would like a copy of the completed research.

Name

Signature

Date 


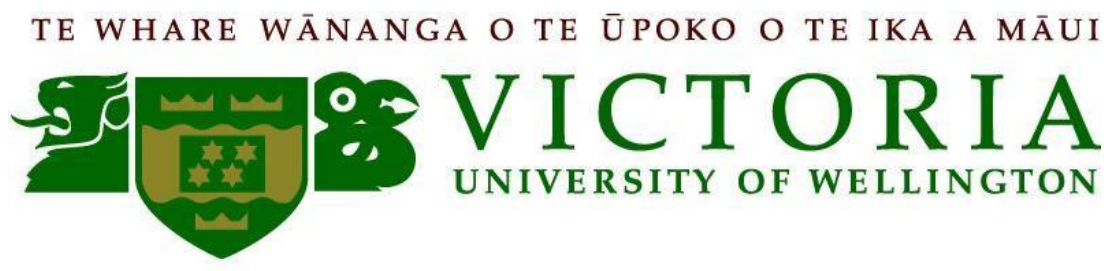

Research project: PRT Information sheet.

\section{An investigation into educative mentoring for beginning teachers in the New Zealand Primary School}

\section{Researcher}

Kaye Stannard, Victoria University of Wellington.

This sheet gives you some information about this study. Please feel free to ask me any questions or for more information. I am undertaking this research for my Masters thesis. The research is being supervised by Dr Brenda Service, (brenda.service@vuw.ac.nz) and Dr Kate Thornton, (kate.thornton@vuw.ac.nz) School of Education, Victoria University of Wellington.

\section{The purpose of my Masters research.}

This research study will explore how three New Zealand primary schools are currently implementing the educative mentoring guidelines for provisionally registered teachers (PRTs), established by the New Zealand Teachers Council in 2011 (p.24-25). The aim of this in-depth case study is to gain insights into the effectiveness of the mentoring relationship, with the focus on educative mentoring, in an attempt to establish how this contributes to the first years of teaching and outcomes for provisionally registered teachers. This is an opportunity for mentors and PRTs to have their say about "The Guidelines for Induction and Mentoring and Mentor Teachers".

Research question: What does effective educative mentoring practice look like in a New Zealand primary school?

\section{Research process and Participants}

As part of this research I am seeking the participation of mentor teachers and their PRTs. If you choose to participate, participation will consist of:

- Completion of an anonymous online survey (approximately 15-20 mins).

- Being part of a one-to-one interview (30-40 mins at school at time to suit mentor/PRT).

- Recording a PRT meeting. 
- Volunteering of secondary data to be analysed e.g. meeting minutes, reflections, feedback from observations, individual goals and registered teacher criteria data.

A link to the online survey will be emailed to you upon receiving your signed consent form.

One-to-one interviews will be conducted to delve deeper into the conditions required for educative mentoring to take place. A formal mentoring meeting will be recorded which will assist in exploring educative mentoring in practice. Secondary data from personal and official documents will be examined.

This study aims to explore and enrich our understanding of educative mentoring in action and its impact on PRTs teaching and learning.

\section{Confidentiality and access to information}

The information provided is strictly confidential. You will not be identified and pseudonyms will be used. At the completion of the interviews and recorded meeting I will check with you that your comments have been recorded accurately. You will be given the opportunity to change or delete any comments. You may withdraw from the research project up until the completion of data collection (30 Nov 2014).

No other person besides my supervisors, Dr Brenda Service/Dr Kate Thornton and I will see the survey or transcripts of meetings and interviews. It is intended that one or more articles will be submitted for publication in scholarly journals. Surveys and transcripts will be destroyed five years after the completion of the project.

This research has been assessed and approved by Victoria University Faculty of Education Ethics Committee. If you have any ethical concerns about the research please contact Dr Allison Kirkman (allison.kirkman@vuw.ac.nz), ph: 04463 5676, Chair of the Human Ethics Committee, Victoria University of Wellington.

Your consent for this study is highly valued.

Thank you Kaye Stannard

kaye.stannard@vuw.ac.nz

Ph 0273100160 


\section{Appendix D: PRT consent form}

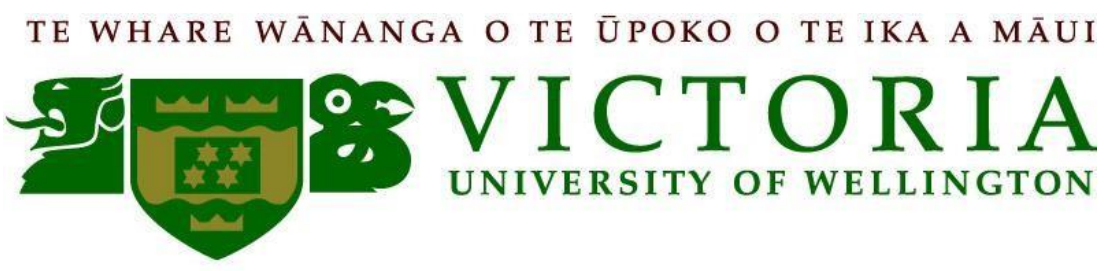

\section{Research project: PRT consent form.}

\section{An investigation into educative mentoring for PRTs in the New Zealand Primary}

\section{School}

I agree to taking part in the above research. I have had the project explained to me and I have had the chance to ask any questions.

- I understand that I will be involved in an online survey (15-20 mins), one-on-one interview (30-40 mins), a recording of a formal PRT meeting, and volunteering of secondary data (e.g. goals, meeting minutes, reflections, and/or observation feedback).

- I understand that all data collected will be kept confidential and secure to the researcher and supervisor; the published results will not identify me.

- I understand that I will be provided with a transcript of the interview and PRT meeting for checking before data analysis.

- I understand that I can withdraw from the research project up until the conclusion of the data collection (30 Nov 2014).

I would like a copy of the completed research. 


\section{Appendix E: Mentor survey questions}

\section{Mentor Survey}

Q1 How many years' experience do you have as a teacher?

Less than 3 years (1)

3-5 years (2)

प $5-10$ years $(3)$

口 $10+$ years $(4)$

Q2 How many years' experience do you have as a mentor teacher?

Less than 2 years (1)

2-5 years (2)

- 5 - 10 years $(3)$

$10+$ years $(4)$

Q3 How often do you meet with your PRT informally at school (e.g. chat)?

$O$ at least once a week (1)

few times a week (2)

$O$ daily (3)

O few times a day (4)

Q4 How often do you meet with your PRT formally at school (e.g. meetings, observations)?

O once a term (1)

O once a month (2)

O fortnightly (3)

O once a week (4)

Q5 What time frame are your formal interactions?

O less than 30 mins (1)

$O$ about 30 mins (2)

O an hour (3)

O more than an hour (4 
Q6 Using a scale of 1-5 where 1 is strongly disagree and 5 is strongly agree please rank how true the following statements are.

\begin{tabular}{|c|c|c|c|c|c|}
\hline & $\begin{array}{c}\text { strongly } \\
\text { disagree (1) }\end{array}$ & Disagree (2) & $\begin{array}{c}\text { Neither } \\
\text { Agree nor } \\
\text { Disagree (3) }\end{array}$ & Agree (4) & $\begin{array}{c}\text { Strongly } \\
\text { Agree (5) }\end{array}$ \\
\hline $\begin{array}{l}\text { My PRT sets } \\
\text { their own } \\
\text { goals. (1) }\end{array}$ & $\mathrm{O}$ & $\mathrm{O}$ & $\mathrm{O}$ & $\mathrm{O}$ & $\mathrm{O}$ \\
\hline $\begin{array}{c}\text { My PRT's } \\
\text { goals are co- } \\
\text { constructed } \\
\text { with me. (2) }\end{array}$ & $\mathrm{O}$ & $\mathrm{O}$ & $\mathrm{O}$ & $\mathrm{O}$ & $\mathrm{O}$ \\
\hline $\begin{array}{l}\text { Meeting and } \\
\text { observation } \\
\text { times are } \\
\text { planned for } \\
\text { and kept to. } \\
\text { (3) }\end{array}$ & $\mathrm{O}$ & O & O & $\mathrm{O}$ & 0 \\
\hline $\begin{array}{c}\text { During } \\
\text { meetings I } \\
\text { spend more } \\
\text { time listening } \\
\text { to my PRT } \\
\text { than talking. } \\
(4)\end{array}$ & 0 & $\mathrm{O}$ & 0 & 0 & 0 \\
\hline $\begin{array}{l}\text { I use effective } \\
\text { questioning to } \\
\text { promote } \\
\text { deeper } \\
\text { thinking to } \\
\text { challenge my } \\
\text { PRT's } \\
\text { pedagogical } \\
\text { beliefs. (5) }\end{array}$ & 0 & O & 0 & 0 & 0 \\
\hline $\begin{array}{l}\text { I use active } \\
\text { listening when } \\
\text { my PRT } \\
\text { speaks. (6) }\end{array}$ & 0 & 0 & $\mathrm{O}$ & O & $\mathrm{O}$ \\
\hline $\begin{array}{l}\text { I encourage } \\
\text { time for } \\
\text { reflection. (7) }\end{array}$ & 0 & O & 0 & 0 & 0 \\
\hline $\begin{array}{l}\text { Inquiry into } \\
\text { learning and } \\
\text { teaching is } \\
\text { standard } \\
\text { practice. (8) }\end{array}$ & 0 & O & 0 & O & $\mathrm{O}$ \\
\hline
\end{tabular}




\begin{tabular}{|c|c|c|c|c|c|}
\hline $\begin{array}{l}\text { We engage in } \\
\text { meaningful } \\
\text { learning } \\
\text { conversations. } \\
\text { (9) }\end{array}$ & 0 & 0 & 0 & 0 & 0 \\
\hline $\begin{array}{l}\text { I use evidence } \\
\text { to back up my } \\
\text { observation } \\
\text { feedback. (10) }\end{array}$ & 0 & 0 & 0 & 0 & 0 \\
\hline $\begin{array}{c}\text { I encourage } \\
\text { my PRT to } \\
\text { make their } \\
\text { own } \\
\text { decisions. } \\
(11)\end{array}$ & 0 & 0 & 0 & 0 & 0 \\
\hline $\begin{array}{c}\text { I have an } \\
\text { 'open door' } \\
\text { policy and my } \\
\text { PRT can } \\
\text { approach me } \\
\text { outside of } \\
\text { scheduled } \\
\text { meeting times. } \\
\text { (12) }\end{array}$ & 0 & 0 & 0 & 0 & 0 \\
\hline $\begin{array}{l}\text { I value the } \\
\text { knowledge my } \\
\text { PRT already } \\
\text { has. (13) }\end{array}$ & 0 & 0 & 0 & 0 & 0 \\
\hline $\begin{array}{c}\text { My PRT } \\
\text { believes I am } \\
\text { an effective } \\
\text { mentor. (14) }\end{array}$ & 0 & 0 & 0 & 0 & 0 \\
\hline $\begin{array}{l}\text { The PRT } \\
\text { programme at } \\
\text { this school is } \\
\text { highly } \\
\text { effective. (15) }\end{array}$ & 0 & 0 & 0 & 0 & 0 \\
\hline
\end{tabular}

Q7 What formal or informal training have you had for the PRT mentor role?

Q8 In what ways (if any) has the way you mentor changed over time?

Q9 How are the RTC (Registered Teacher Criteria) incorporated into your interactions?

Q10 How might the induction and mentoring programme in this school be improved?

Q11 How have you used the blue handbook "Guidelines for Induction and Mentoring and Mentor Teachers 2011" and what parts have you found helpful and why? 
Q12 Do you consider yourself to be mentoring in line with the "Guidelines for Induction and Mentoring and Mentor Teachers 2011" and in an 'educative' manner?

O Yes (1)

No (2) 


\section{Appendix F: PRT Survey questions}

\section{PRT Survey}

Q1 What year PRT are you?

1st year (1)

$\square$ 2nd year (2)

Q2 How often do you meet with your mentor informally at school (e.g. chat)?

$O$ at least once a week (1)

few times a week (2)

O daily (3)

few times a day (4)

Q3 How often do you meet with your mentor formally at school (e.g. meetings, observations)?

O once a term (1)

O once a month (2)

O fortnightly (3)

O once a week (4)

Q5 What time frame are your formal interactions?

O less than 30 mins (1)

$O$ about 30 mins (2)

$O$ an hour (3)

O more than an hour (4) 
Q6 Using a scale of 1-5 where 1 is strongly disagree and 5 is strongly agree please rank how true the following statements are.

\begin{tabular}{|c|c|c|c|c|c|}
\hline & $\begin{array}{c}\text { strongly } \\
\text { disagree (1) }\end{array}$ & Disagree (2) & $\begin{array}{c}\text { Neither Agree } \\
\text { nor Disagree } \\
\text { (3) }\end{array}$ & Agree (4) & $\begin{array}{c}\text { Strongly Agree } \\
\text { (5) }\end{array}$ \\
\hline $\begin{array}{l}\text { I set my own } \\
\text { goals. (1) } \\
\text { Goals are } \\
\text { coconstructed } \\
\text { with my } \\
\text { mentor } \\
\text { teacher. (2) } \\
\text { Meeting and } \\
\text { observation } \\
\text { times are } \\
\text { planned for } \\
\text { and kept to. } \\
\text { (3) } \\
\text { During } \\
\text { meetings my } \\
\text { mentor } \\
\text { spends more } \\
\text { time listening } \\
\text { than talking. } \\
\text { (4) } \\
\text { My mentor } \\
\text { uses effective } \\
\text { questioning } \\
\text { to promote } \\
\text { deeper } \\
\text { thinking and } \\
\text { challenge my } \\
\text { pedagogical } \\
\text { beliefs. (5) }\end{array}$ & O & O & $O$ & $\bigcirc$ & 0 \\
\hline
\end{tabular}



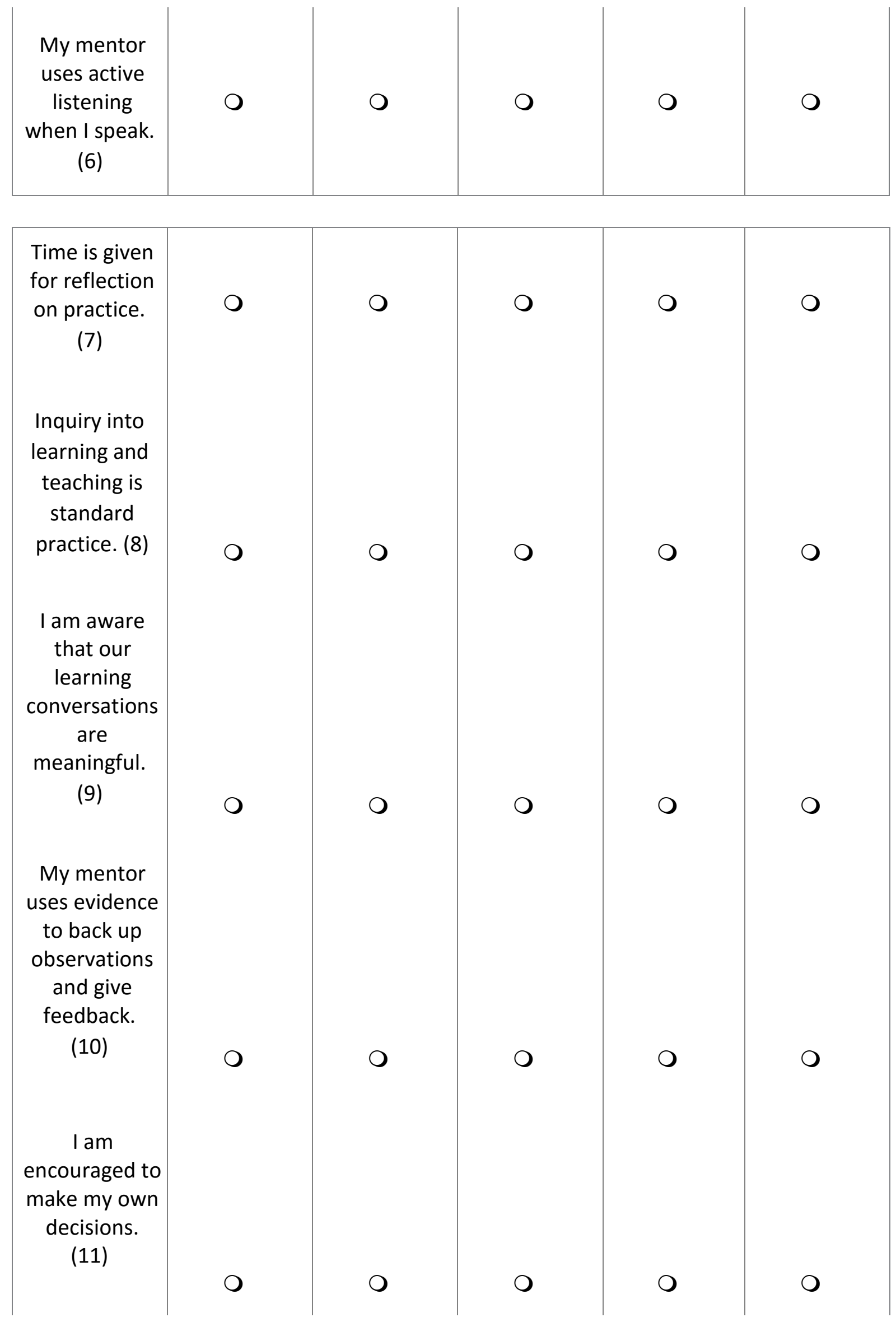


\begin{tabular}{|c|c|c|c|c|c|}
\hline $\begin{array}{l}\text { My mentor } \\
\text { has an 'open } \\
\text { door' policy } \\
\text { and I feel I } \\
\text { can approach } \\
\text { them outside } \\
\text { of scheduled } \\
\text { meeting } \\
\text { times. (12) }\end{array}$ & 0 & 0 & 0 & 0 & 0 \\
\hline $\begin{array}{c}\text { My mentor } \\
\text { teacher } \\
\text { values the } \\
\text { knowledge I } \\
\text { already have. } \\
\text { (13) }\end{array}$ & 0 & 0 & 0 & 0 & 0 \\
\hline $\begin{array}{c}\text { I am given } \\
\text { adequate } \\
\text { support as a } \\
\text { PRT. (14) }\end{array}$ & 0 & 0 & 0 & 0 & 0 \\
\hline $\begin{array}{l}\text { The PRT } \\
\text { programme } \\
\text { at this school } \\
\text { is highly } \\
\text { effective. (15) }\end{array}$ & 0 & 0 & 0 & 0 & 0 \\
\hline
\end{tabular}

Q7 In what ways (if any) has the relationship with your mentor changed over time?

Q8 How are the RTC (Registered Teacher Criteria) incorporated into your interactions?

Q9 How might the induction and mentoring programme in this school be improved?

Q10 How has the blue handbook "Guidelines for Induction and Mentoring and Mentor Teachers 2011" been incorporated in your induction programme? 


\section{Appendix G: Mentor interview outline}

\begin{tabular}{|c|c|c|}
\hline Welcome & \multicolumn{2}{|c|}{$\begin{array}{l}\text { - } \quad \mathrm{Hi} . . . . . . . . . . . . . ., \mathrm{I} \text { appreciate your time. } \\
\text { - There are no right or wrong answers - want to know your opinions. } \\
\text { - The interview should take about } 30 \text { minutes. }\end{array}$} \\
\hline Purpose & \multicolumn{2}{|c|}{$\begin{array}{l}\text { - The purpose of this interview is to hear about your experiences as a mentor } \\
\text { of a PRT and in particular what works, and what does not in this mentor-PRT } \\
\text { relationship. } \\
\text { - I'm completing my thesis on educative mentoring and how this contributes } \\
\text { to the PRTs first two years. This interview will help inform this research. }\end{array}$} \\
\hline Guidelines & \multicolumn{2}{|c|}{$\begin{array}{l}\text { - I'll just remind you that the audio recording will be transcribed and you will } \\
\text { have the opportunity to peruse the transcript and make any changes to } \\
\text { inaccuracies or errors. } \\
\text { - To ensure your anonymity you will be assigned a pseudonym for the } \\
\text { transcript, the data analysis and the final thesis. } \\
\text { - If anyone else is identified in the interview this identity will be kept } \\
\text { confidential to my supervisor and myself. } \\
\text { - The recording will be destroyed after } 5 \text { years of the conclusion of the project. } \\
\text { - Do you have any questions about the process? }\end{array}$} \\
\hline $\begin{array}{l}\text { Warm up/ } \\
\text { build } \\
\text { rapport }\end{array}$ & \multicolumn{2}{|c|}{$\begin{array}{l}\text { Tell me a little about yourself and how this year is going. We'll } \\
\text { move onto the interview now. }\end{array}$} \\
\hline \multirow[t]{4}{*}{ Interview } & Topic questions & Supporting questions \\
\hline & You the mentor & $\begin{array}{l}\text { How do you see your role as a mentor in this } \\
\text { setting? } \\
\text { What skills do you think mentors need you have? } \\
\text { How do you see yourself? }\end{array}$ \\
\hline & $\begin{array}{l}\text { The relationship } \\
\text { enablers/barriers/implications }\end{array}$ & $\begin{array}{l}\text { What skills/attributes do you think PRTs need to } \\
\text { have? } \\
\text { Tell me about the skills/attributes your PRT has? } \\
\text { How would you describe your relationship with } \\
\text { your PRT? (look like? feel like?) } \\
\text { How has the relationship changed over time? } \\
\text { What do you get from this mentoring } \\
\text { relationship? }\end{array}$ \\
\hline & Educative mentoring \& RTC & $\begin{array}{l}\text { The word educative is used in relation to the } \\
\text { Induction \& Mentoring Guidelines. } \\
\text { What does this mean to you? What is your } \\
\text { experience of educative mentoring? } \\
\text { What has worked for you and your PRT? What } \\
\text { specifically is effective? How do you know? Tell } \\
\text { me about your success as an educative } \\
\text { mentor. } \\
\text { How do the RTC impact/work for you? }\end{array}$ \\
\hline
\end{tabular}




\begin{tabular}{|l|l|l|}
\hline & $\begin{array}{l}\text { Professional Learning } \\
\text { What do you do in order to } \\
\text { develop professionally? (as } \\
\text { a mentor) }\end{array}$ & $\begin{array}{l}\text { What support should mentor teachers } \\
\text { receive to carry out the role effectively? What } \\
\text { contact do you have with others mentors? }\end{array}$ \\
\hline & $\begin{array}{l}\text { My Research Question What } \\
\text { does effective educative } \\
\text { mentoring look like in the New } \\
\text { Zealand primary school? }\end{array}$ & $\begin{array}{l}\text { How do you think your PL around mentoring } \\
\text { might be enhanced? }\end{array}$ \\
\hline $\begin{array}{l}\text { Question } \\
\text { strategies }\end{array}$ & $\begin{array}{l}\text { (questions modified from } \\
\text { OrlandBarak, L., Hasin, R. (2010)) } \\
\text { and reflective questions } \\
\text { (Guidelines ...2011, p7) }\end{array}$ & $\begin{array}{l}\text { Use wait time. } \\
\text { Probing } \\
\text { Could you tell me more about your thinking on } \\
\text { that? } \\
\text { Can you think of another example there? } \\
\text { Can you describe that a bit more? } \\
\text { Interpreting \& clarifying You } \\
\text { mean that...? }\end{array}$ \\
\hline $\begin{array}{l}\text { Is it correct that you feel...? } \\
\text { Does the expression...cover what you have just } \\
\text { expressed? }\end{array}$ \\
\hline $\begin{array}{l}\text { End of } \\
\text { interview }\end{array}$ & $\begin{array}{l}\text { Do you have anything you want to add that we have not talked about? Thank } \\
\text { you for your time and contribution. }\end{array}$ \\
\hline
\end{tabular}




\section{Appendix H: PRT interview outline}

\begin{tabular}{|c|c|c|}
\hline Welcome & \multicolumn{2}{|c|}{ 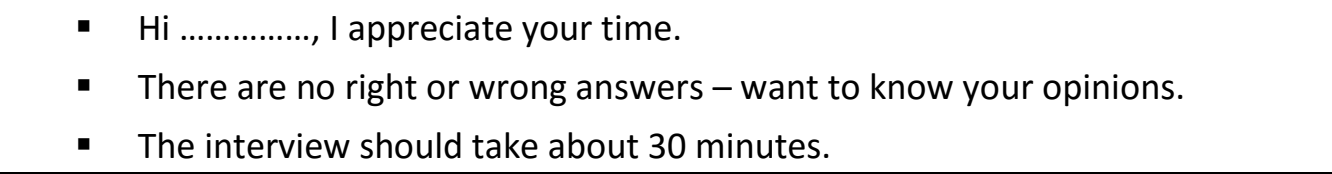 } \\
\hline Purpose & \multicolumn{2}{|c|}{$\begin{array}{l}\text { - The purpose of this interview is to hear about your experiences as a PRT and } \\
\text { in particular what works, and what does not work in your relationship with } \\
\text { your mentor. } \\
\text { - I'm completing my thesis on educative mentoring and what effective } \\
\text { educative mentoring looks like in practice. This interview will help inform } \\
\text { this research. }\end{array}$} \\
\hline Guidelines & \multicolumn{2}{|c|}{$\begin{array}{l}\text { - I'll just remind you that the audio recording will be transcribed and you will } \\
\text { have the opportunity to peruse the transcript and make any changes to } \\
\text { inaccuracies or errors. } \\
\text { - To ensure your anonymity you will be assigned a pseudonym for the } \\
\text { transcript, the data analysis and the final thesis. } \\
\text { - If anyone else is identified in the interview this identity will be kept } \\
\text { confidential to my supervisor and myself. } \\
\text { - The recording will be destroyed after } 5 \text { years of the conclusion of the } \\
\text { project. } \\
\text { - Do you have any questions about the process? }\end{array}$} \\
\hline $\begin{array}{l}\text { Warm up/ } \\
\text { build } \\
\text { rapport }\end{array}$ & \multicolumn{2}{|c|}{$\begin{array}{l}\text { Tell me a little about yourself and how this year is going. We'll } \\
\text { move onto the interview now. }\end{array}$} \\
\hline \multirow[t]{4}{*}{ Interview } & You as a PRT & $\begin{array}{l}\text { Supporting questions } \\
\text { Tell me about the supports in place for you as a } \\
\text { PRT in this setting. } \\
\text { How would you describe your mentors work } \\
\text { with you? } \\
\text { What are you learning? Try to be specific. }\end{array}$ \\
\hline & $\begin{array}{l}\text { The relationship } \\
\text { enablers/barriers/implications }\end{array}$ & $\begin{array}{l}\text { What skills do you think mentors need to have? } \\
\text { Tell me about the skills and knowledge your } \\
\text { mentor has? } \\
\text { How would you describe your relationship with } \\
\text { your mentor? (look like? feel like?) What } \\
\text { in your opinion makes her/him } \\
\text { effective/ineffective? }\end{array}$ \\
\hline & Educative mentoring \& RTC & $\begin{array}{l}\text { The word educative is used in relation to the } \\
\text { Induction \& Mentoring Guidelines. } \\
\text { What does that mean to you? What is your } \\
\text { experience of educative mentoring? } \\
\text { How do the RTC impact/work for you? }\end{array}$ \\
\hline & $\begin{array}{l}\text { Research Question } \\
\text { What does effective educative } \\
\text { mentoring look like in the New } \\
\text { Zealand primary school? }\end{array}$ & $\begin{array}{l}\text { What do you get from an educative mentoring } \\
\text { relationship? (in ref to guidelines) } \\
\text { Is this what you need? What else do you need? }\end{array}$ \\
\hline
\end{tabular}




\begin{tabular}{|l|l|l|}
\hline $\begin{array}{l}\text { Question } \\
\text { strategies }\end{array}$ & & $\begin{array}{l}\text { Use wait time. } \\
\text { Probing } \\
\text { Could you tell me more about your thinking on } \\
\text { that? }\end{array}$ \\
\hline & $\begin{array}{l}\text { Can you think of another example there? } \\
\text { Can you describe that a bit more? } \\
\text { Interpreting \& clarifying You } \\
\text { mean that...? } \\
\text { Is it correct that you feel...? } \\
\text { Does the expression...cover what you have just } \\
\text { expressed? }\end{array}$ \\
\hline $\begin{array}{l}\text { End of } \\
\text { interview }\end{array}$ & $\begin{array}{l}\text { Do you have anything you want to add that we have not talked about? Thank } \\
\text { you for your time and contribution. }\end{array}$ \\
\hline
\end{tabular}

